\title{
The SUMER spectral atlas of solar coronal features ${ }^{\star}$
}

\author{
W. Curdt ${ }^{1}$, E. Landi ${ }^{2,3}$, and U. Feldman ${ }^{2,3}$ \\ 1 Max-Planck-Institut für Sonnensystemforschung, 37191 Katlenburg-Lindau, Germany \\ e-mail: curdt@mps.mpg.de \\ 2 Artep Inc., 2922 Excelsior Springs, Ellicott City, MD 21042, USA \\ ${ }^{3}$ E.O. Hulburt Center for Space Research, Naval Research Laboratory, Washington DC 20375-5320, USA
}

Received 12 May 2004 / Accepted 6 August 2004

\begin{abstract}
We present a spectral atlas of the solar corona in the far-ultraviolet (FUV) and extreme ultraviolet (EUV) wavelength range. The atlas is based on observations obtained between $670 \AA$ and $1609 \AA$ in first order of diffraction and between 465 and $670 \AA$ in second order with the SUMER (Solar Ultraviolet Measurements of Emitted Radiation) spectrograph on $\mathrm{SOHO}$ (Solar and Heliospheric Observatory). This paper complements the SUMER Spectral Atlas of Solar Disk Features, also published in A\&A. The atlas contains off-limb spectra of the corona above a coronal hole, a quiet region, the active corona, and a flare. We provide wavelengths of all detected lines and identification, if available; 311 out of 507 coronal emission lines could be identified or reconfirmed, including several new identifications. Brief descriptions of the data reduction and calibration procedures are given. The spectral radiances are determined with a relative uncertainty of 0.15 to $0.40(1 \sigma)$ and the wavelength scale is accurate to typically $\simeq 30 \mathrm{~m} \AA$. The atlas is also available in a machine readable format.
\end{abstract}

Key words. Sun: UV radiation - Sun: corona - line: identification - atlases

\section{Introduction}

The solar corona cannot be seen when observed in the visible because of the enormous brightness of the solar disk. However, the existence of the corona has been known since prehistoric times from rare eclipse observations, when it becomes visible to the naked eye for several minutes. The nature of the corona remained unexplained, despite the many attempts to determine it, which began around the middle of the 19th century. Spectroscopic observations in the visible had shown that the coronal light is composed of discrete emission lines of which the most prominent are the "red" (6374 $\AA$ ) and the "green" (5303 $\AA$ ) lines. For a long time, all attempts to identify the coronal lines as known laboratory spectral lines failed, in spite of the enormous progress in atomic physics and the systematic research in laboratories all over the world. In desperation some scientists postulated the presence in the solar corona of an element "coronium" lighter than hydrogen to which they attributed the coronal emission.

The first major breakthrough in coronal research occurred in 1939, when Grotrian (1939) suggested that the coronal line emission is due to forbidden transitions in highly ionized atoms. By studying energy levels of Cl-like iron $\left(\mathrm{Fe}^{+9}\right)$ that were derived by Edlén from laboratory-generated spectra, he noticed a coincidence between the difference of levels within the ground configuration and one of the unidentified

* Table 3 and Fig. 3 are only available in electronic form at http://www. edpsciences.org coronal lines. Motivated by Grotrian's suggestion, Edlén succeeded identifying additional lines as transitions within the ground configuration of several other highly ionized atoms (Edlén 1943). Confident in the identifications he concluded that the coronal emission must emerge from million-degree plasmas. The identification of the most prominent coronal emission lines with forbidden transitions of highly ionized species was the starting point of modern coronal physics. It took, however, another decade until the full dimension of Edlén's discovery became apparent.

The bright resonance lines emitted by ions abundant in 1-2 million degree coronal plasmas appear at wavelengths shorter than $500 \AA$. Nevertheless, a substantial number of lines, and in particular those resulting from forbidden transitions within levels of the ground configuration, spin forbidden transitions between the ground configuration and the first excited configuration, or from transitions associated with levels of excited configurations, are expected to fall at wavelengths of $500 \AA \leq \lambda \leq 2000 \AA$. These ranges are not accessible from the ground and could not be observed until the $1950 \mathrm{~s}$, when rockets became available to lift spectroscopic instruments into space.

During the first three decades of the space era spectrometers aboard rockets and satellites recorded solar spectra in the wavelength range from $500 \AA$ to $2000 \AA$ that included numerous emission lines. A substantial number of the newly recorded lines were identified with transitions in highly ionized atoms abundant in the solar upper atmosphere 
(Burton \& Ridgeley 1970; Jordan 1971; Doschek et al. 1976; Feldman \& Doschek 1977; Sandlin et al. 1977, 1986; Feldman \& Doschek 1991). With the launch of the Solar and Heliospheric Observatory (SOHO) that included the Solar Ultraviolet Measurements of Emitted Radiation (SUMER) and the Coronal Diagnostic Spectrometer (CDS), two advanced high-resolution spectrometers, a renewed interest in solar spectroscopy occurred. Based on SUMER recorded spectra Feldman et al. (1997) published the most comprehensive list, to date, of lines in the 500 to $1600 \AA$ wavelength range that were emitted by a quiet coronal streamer. The introduction to that paper provides a detailed overview of the spectroscopic measurements and identifications prior to the launch of SOHO. A list of high temperature $\left(T_{\mathrm{e}} \geq 2 \times 10^{6} \mathrm{~K}\right)$ lines emitted by active region and flare plasmas but not by the quiescent corona also recorded by SUMER were published by Feldman et al. (1998, 2000) and by Curdt et al. (2001a).

Prior to the launch of the $\mathrm{SOHO}$, the most comprehensive list of absolute intensities of solar emission lines emitted by plasmas ranging in temperature between $1 \times 10^{4} \mathrm{~K}$ and $3 \times 10^{6} \mathrm{~K}$ and accessible to normal incidence spectrometers was published by Vernazza \& Reeves (1978). The published list was generated from spectra acquired by the S055 Extreme Ultraviolet spectrometer on the Skylab mission, which had a spectral resolution of $1.6 \AA(F W H M)$ and a spatial resolution of $5^{\prime \prime} \times 5^{\prime \prime}$. The intensities of the brightest lines spanning the 277 to $1335 \AA$ wavelength range were measured from spectra recorded against the solar disk and above the limb and emitted by active region, quiet region and coronal hole plasmas. Due to the fairly low spectral resolution of the instrument many of the moderately intense lines were blended with each other or with nearby brighter lines while most of the fainter ones were lost in the background. Using spectra recorded by the S082 B normal incidence spectrograph on Skylab, Doschek et al. (1976) published absolute intensities of bright lines in the wavelength range from 1150 to $2000 \AA$ which were emitted by quiet region plasmas at temperatures of $T_{\mathrm{e}} \leq 2.5 \times 10^{5} \mathrm{~K}$.

Intensities of lines emitted by stellar upper atmospheres have been observed by the EUV Explorer (EUVE), the International Ultraviolet Explorer (IUE), the Far Ultraviolet Spectroscopic Explorer (FUSE), and the Hubble Space Telescope (HST), Goddard High-Resolution Spectrograph (HST-GHRS) and Space Telescope Imaging Spectrograph (HST-STIS). In a recent communication, Ayres et al. (2003) present a survey of high temperature forbidden lines identified in high-resolution HST-STIS FUV spectra of late-type stars. Redfield et al. (2003) published a similar survey from spectra recorded by FUSE. The solar corona is of special interest for stellar applications, since its emission can be separated from the disk emission (which significantly helps to reveal blending) and it can be spatially resolved and observed with much higher photon statistic than stellar coronae. It also can be considered an exceptional good standard of a cool G2 V star corona.

Curdt et al. (2001b) published a detailed SUMER disk atlas (to be referred to as the disk atlas). Although the disk atlas consists primarily of lines and continua emitted by the chromosphere and transition region plasma, it also contains several coronal emission lines, which are bright enough to be discerned against the intense emission from the cooler regions.

In this paper we present an atlas consisting of spectral profiles and a line list representing the quiescent corona, the corona above coronal holes, and the active and flaring corona, as observed by SUMER above the solar limb. The off-limb atlas contains lines typical of plasmas at temperatures of $T_{\mathrm{e}} \geq 7 \times 10^{5} \mathrm{~K}$ and has to be understood as a companion paper to the disk atlas. The line list contains all observed lines with measured wavelengths, measured radiances, and identification along with atomic transitions when available. For the sake of conciseness, in this paper we will restrict the repetition of details and general information, which has already been presented in the disk atlas, to an absolute minimum.

\section{The SUMER instrument}

SUMER is part of the SOHO mission of ESA and NASA. SOHO was launched in 1995 and injected into a halo orbit around the first Lagrangian point, L1, on 14 February 1996 where, in continuous view of the Sun, it orbits the Sun at a distance of $1.5 \times 10^{6} \mathrm{~km}$ sunward from the Earth.

SUMER is a high-resolution telescope and spectrograph designed to obtain stigmatic slit images with spatial and spectral resolution elements of $1^{\prime \prime}$ and $\simeq 40 \mathrm{~m} \AA$ (in first order) as well as high temporal resolution over the wavelength range from $465 \AA$ to $1610 \AA$. The accessible range depends on which of two detectors is used. While detector " $A$ " can in principle record spectra from $780 \AA$ to $1610 \AA$ in first order of diffraction, the range of detector " $\mathrm{B}$ " reaches from $660 \AA$ to $1500 \AA$. The lower wavelength limit for second order lines results from the steep fall-off of the reflectivity of the silicon carbide optics below $500 \AA$; the shortest-wavelength identified line falls at $465.2 \AA$. The dispersion of the instrument is slightly wavelength dependent. For detector "A", it varies from 45.2 to $41.9 \mathrm{~m} \AA /$ pixel (first order) and 22.6 to $20.9 \mathrm{~m} \AA / \mathrm{pixel}$ (second order) from one end to the other of the SUMER wavelength range; for detector "B", it varies from 44.7 to $41.2 \mathrm{~m} \AA /$ pixel (first order) and from 22.3 to $20.6 \mathrm{~m} \AA /$ pixel (second order). Each detector has 1024 spectral and 360 spatial pixels.

First order lines and second order lines appear superimposed in the spectrum. A few lines could also be observed in third order (Feldman et al. 1997). The central area of the detector is coated with $\mathrm{KBr}$ (potassium bromide). This coating increases the detection quantum efficiency (DQE) mainly in the range from $900 \AA$ to $1500 \AA$. Intensities of lines on both sections of the photocathode can be used to discriminate second order lines from first order lines, since the photocathode responsivity changes differently for lines in different orders.

Off-disk observations of previously unobserved faint intersystem lines are only possible because of the high surface quality of the primary mirror, which results in relatively low scattered light levels, and because of its more efficient lownoise detectors compared to previous instruments that used photographic plates, as discussed by Feldman et al. (1997) and Curdt et al. (1997). Few (if any) spectral lines were recorded by earlier space instruments from regions that extended more 
Table 1. Details of the observing sequence used in the present work.

\begin{tabular}{|c|c|c|c|c|c|c|c|}
\hline Region & Det. & Date & Slit center & Height (Mm) & Height $\left(R_{\odot}\right)$ & Slit & $t_{\text {exp }}(\mathrm{s})$ \\
\hline Coronal Hole & "A" & 13 March 1996 & $\left(0^{\prime \prime},-1180^{\prime \prime}\right)$ & $39-54$ & $1.056-1.077$ & $4^{\prime \prime} \times 300^{\prime \prime}$ & 300 \\
\hline Coronal Hole & "B" & 11 November 1996 & $\left(0^{\prime \prime}, 1149^{\prime \prime}\right)$ & $17-40$ & $1.024-1.057$ & $1^{\prime \prime} \times 300^{\prime \prime}$ & 1200 \\
\hline Quiet Sun & "A" & 13-19 June 2000 & $\left(-600^{\prime \prime},-941^{\prime \prime}\right)$ & $25-44$ & $1.036-1.063$ & $4^{\prime \prime} \times 300^{\prime \prime}$ & 4500 \\
\hline Quiet Sun & "B" & 20 June 1997 & $\left(600^{\prime \prime},-900^{\prime \prime}\right)$ & $14-26$ & $1.020-1.038$ & $1^{\prime \prime} \times 300^{\prime \prime}$ & 1500 \\
\hline Active region & "A" & 4 April 2001 & $\left(954^{\prime \prime}, 500^{\prime \prime}\right)$ & $34-49$ & $1.049-1.070$ & $1^{\prime \prime} \times 300^{\prime \prime}$ & 300 \\
\hline \multirow[t]{2}{*}{ Active region } & "B" & 6 December 2000 & $\left(-1000^{\prime \prime},-320^{\prime \prime}\right)$ & $50-59$ & $1.072-1.084$ & $4^{\prime \prime} \times 300^{\prime \prime}$ & 4200 \\
\hline & & & & $59-70$ & $1.084-1.100$ & $4^{\prime \prime} \times 300^{\prime \prime}$ & 4200 \\
\hline Flare & "A" & 9 May 1999 & $\left(968^{\prime \prime}, 395^{\prime \prime}\right)$ & $21-68$ & $1.030-1.097$ & $4^{\prime \prime} \times 300^{\prime \prime}$ & 300 \\
\hline
\end{tabular}

than $20^{\prime \prime}$ above the limb. In comparison, SUMER has recorded line intensities extending out to 600" (Feldman et al. 1999).

Many more instrumental details can be found in the disk atlas. A comprehensive description of the instrument is given by Wilhelm et al. (1995), and first results and inflight performance characteristics are given by Wilhelm et al. (1997a) and Lemaire et al. (1997).

\section{Observations}

Since the present atlas aims to cover the off-limb solar spectrum emitted by coronal holes, quiet Sun, active regions and flares, many datasets observed at different times and at different locations were necessary. Table 1 provides the basic characteristics of the observations used to create the plots and to derive the radiances given in the line list.

Both detectors have been considered in the present work. Detector "A" was designated the prime source for both first and second order lines, but the 660 to $780 \AA$ section of detector "B" also was used, so that many lines that detector " $A$ " observes as second order lines also could be identified in detector " $\mathrm{B}$ " in first order. This helped to discriminate between first and second order lines in detector " $\mathrm{A}$ ", to observe several first order lines that were too faint or blended to be identified in detector "A", and to slightly improve wavelength measurements.

\subsection{Coronal hole}

The two coronal hole spectra used in the present work were both taken in the early stages of the $\mathrm{SOHO}$ mission above the north and south coronal holes during solar minimum. The field of view was selected in order to minimize any contribution from overarching quiet Sun material.

Both datasets consist of "REFSPEC" spectral scans, encompassing the whole SUMER wavelength range with a long exposure time (300 s and $1200 \mathrm{~s}$ for detectors " $\mathrm{A}$ " and "B", respectively). The use of the 4 " $\times 300^{\prime \prime}$ slit in the detector " $\mathrm{A}$ " dataset and of the 1 " $\times 300$ " slit in the detector "B" dataset ensures that the same level of signal to noise was achieved.
Both the detector "A" and "B" wavelength ranges have been divided into a number of sub-ranges, each shifted from the adjacent one by a fixed amount: detector "A" range was divided in 44 sections with $\simeq 18 \AA$ shift; the detector " $\mathrm{B}$ " wavelength range was observed in 61 sections with $\mathrm{a} \simeq 13 \AA$ shift. The entire wavelength ranges of both detectors have been used for identification purposes.

In both datasets, we have selected for the analysis a fixed number of pixels located in the brightest regions along the slit, corresponding to the heights above the limb (in $R_{\odot}$ and $10^{3} \mathrm{~km}$ ) reported in Table 1.

\subsection{Quiet Sun}

The detector "A" quiet Sun observation is unique in its kind, and it consists of the longest exposure time ever achieved in the UV wavelength range on the Sun. It is described in detail in Parenti et al. (2003). The dataset was obtained observing a quiescent streamer in the southeast quadrant of the Sun. It consists of a modified REFSPEC sequence where the entire detector " $\mathrm{A}$ " wavelength range was divided in 38 sections each shifted by $\simeq 20 \AA$ from the previous one. The basic observing sequence consisted of several consecutive observations of each of the wavelength sections with an exposure time of $300 \mathrm{~s}$ and the wide slit $\left(4^{\prime \prime} \times 300^{\prime \prime}\right)$. This sequence was then repeated five times at three different heights above the solar limb, in order to cover a large distance from the limb. The entire observation lasted approximately a week. In order to maximize the signal-to-noise ratio, and at the same time avoid any transition region material, we have selected the series of observations that was pointed at $\left(-600^{\prime \prime},-941^{\prime \prime}\right)$; in this dataset, each wavelength section was observed three consecutive times during each sequence. Therefore, for each wavelength range we have $5 \times 3=15$ observations of $300 \mathrm{~s}$, for a total observing time of $75 \mathrm{~min}$.

The detector "B" quiet Sun observation was taken in 1997, in a region in the southwest quadrant of the Sun devoid of any activity. The dataset consisted of a REFSPEC sequence with a long exposure time (1500 s), that compensated the use of 
the narrow $1^{\prime \prime} \times 300^{\prime \prime}$ slit. The wavelength range was divided into 61 sections with a shift of $\simeq 13 \AA$; however, only the first 10 sections have been considered in the present work, corresponding to the lowest wavelength range up to $830 \AA$, unavailable to detector " $\mathrm{A}$ " in first order.

In both datasets, we have selected the brightest region along the slit, corresponding to the heights above the limb reported in Table 1 .

\subsection{Active region}

The two active region REFSPECS that we have considered in the present work have been observed during solar maximum close to the solar equator. The detector " $A$ " dataset has been observed over a large active region complex which gave rise to several strong flares during the prolonged SUMER campaign that aimed at monitoring active region behaviour at the limb. However, no flare activity was recorded during the spectral scan considered in the present work. The dataset consists of a standard REFSPEC sequence, composed of 38 sections each shifted by $\simeq 20 \AA$ from the previous one and observed with $300 \mathrm{~s}$ exposure time.

The detector "B" dataset was taken during the December 2000 campaign, over a medium-size active region. The dataset consisted of a modified REFSPEC, where only the 660 to $860 \AA$ range was observed in 10 sections each shifted by $\simeq 13 \AA$. However, each section was consecutively observed 14 times, for a total effective observing time of $70 \mathrm{~min}$, yielding the longest observing time achieved in the $\mathrm{UV}$ on a solar active region.

In the active region observed with detector " $A$ ", we have selected the brightest pixels in the dataset, corresponding to the height above the limb reported in Table 1 . In the detector " $\mathrm{B}$ " active region, cool material was present in the brightest section of the slit. In order not to include any spectral lines emitted by this cool material, and at the same time to select the brightest areas along the slit, the pixels selected for the present study are not the same for all exposures, and they come from two different sections of the slit, whose corresponding height above the limb is reported in Table 1.

\subsection{Flare}

A comprehensive flare spectral atlas in the SUMER wavelength range has been published by Feldman et al. (2000). The dataset analysed in this work was the first complete flare spectrum observed by SUMER. Since then, several flare campaigns have been carried out, but few if any complete flare spectral scans across the SUMER wavelength range have been obtained. Since the aim of the present paper is to present the spectrum of the solar corona above the limb at all solar conditions, for the sake of completeness we have included the dataset already published by Feldman et al. (2000). The description of the observing sequence can be found in Feldman et al. (2000). Basic details of the flare observations are given in Table 1.

\section{Data reduction}

\subsection{Flatfield and geometrical distortion correction}

After decompression, the data set has been flat-field corrected. The flat field exposures closest in time to each of the datasets have been used for the correction. After the flat-field correction, data have been corrected for the geometrical distortion present in SUMER spectra. We have used for both operations the standard SUMER software.

In the case of the quiet Sun detector "A" dataset, observations were taken at different heights but with the same position along the solar E-W direction. Slit positions were chosen so that there was $10^{\prime \prime}$ overlapping between observations at different heights (see Parenti et al. 2003 for more details). Inspection of these overlapping spectra has revealed a residual distortion in the last 1-5 pixels near the bottom edge of the detector. To investigate this effect, we have analysed the centroids of the chromospheric lines: above the limb, these lines are composed of instrument-scattered light and are expected to appear as straight lines along the slit because all solar signatures are smeared. We have analysed the centroid positions along the slit for several positions along the wavelength direction of the detector and have determined an interpolated residual correction function that allows to correct for this effect at any position in the detector, and applied it to the data.

\subsection{Spectral averaging}

To improve the signal-to-noise ratio of the observed spectra, we have averaged the emission of the selected pixels along the slit in each spectral section of each dataset.

However, some more comments are required for the quiet Sun detector "A" and active region detector "B" datasets. The active region detector " $\mathrm{B}$ " dataset was composed of 14 subsequent exposures of each spectral section. To improve the signal-to-noise ratio, we have first averaged all the 14 exposures, and then we have averaged on the selected pixels along the slit. Since the 14 exposures repeated one after the other, without changing the instrument pointing, wavelength range and configuration, the averaging was straightforward.

The quiet Sun detector "A" dataset required additional care. In fact, this dataset is composed of five identical sequences, and within each sequence each spectral section was observed three times before changing to the next spectral section. So, each spectral section has been observed 15 times. The three subsequent exposures within each sequence have been averaged together as for the active region, detector "B", leaving us with 5 averaged exposures for each spectral section. However, since the five subsequent sequences were run at different times, after instrument repointing and changes in the wavelength sections, instrumental effects like the thermoelastic oscillation (cf., Rybàk et al. 1999 for more details) introduced shifts along the wavelength direction between each sequence. In order to avoid artificial line broadening and blending due to these shifts, the five averaged spectra for each section have been first coaligned, and then averaged together. The coalignment shift to each of the five spectra has been obtained by cross-correlation of all the 


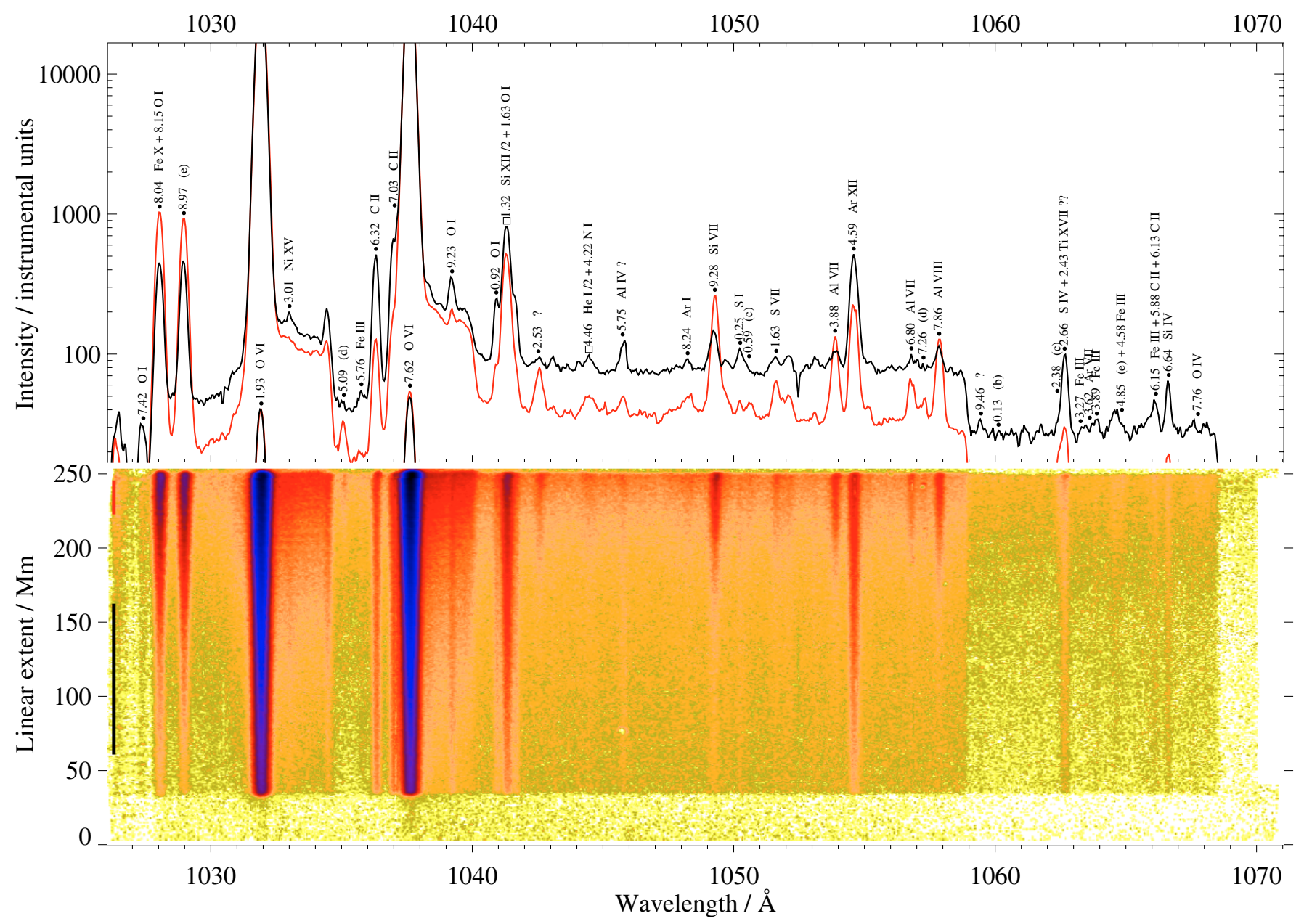

Fig. 1. The SUMER spectral window around $1050 \AA$ after application of basic data reduction steps. 15 frames of 5 min integration time have been added for this deep exposure. The slit is positioned in the South-East quadrant of the field of view. North is up and closer to the limb than the bottom pixels. We have also added the line identification and two profiles, the red one averaged in the near-limb section of the slit, the black one further out.

strongest and unblended spectral lines in each of the spectral scans. An example of such a processed primary data product is shown in Fig. 1, where we display a data array recorded with detector " $\mathrm{A}$ " in the wavelength range around $1050 \AA$ A. Figure 1 also illustrates the subsequent data reduction steps.

\subsection{Gaussian line fitting}

Gaussian spectral line profiles have been fitted to all possible spectral features in all datasets, using a multiGaussian program that permits decomposition of partially blended lines.

In each dataset, more than one measurement of line intensity and wavelength were possible, because each line could be measured in different spectral sections, several lines were observed in both detectors, and short wavelength lines can be observed in first and second order. Final wavelengths were obtained by averaging all the measurements for each line.

\subsection{Wavelength calibration}

To determine the wavelength scale, fitted line centroids and spectral pixels need to be converted to angstrøm. Since there is no absolute wavelength reference available in the spectrometer, a wavelength scale can only be derived using solar chromospheric lines, that in off-disk spectra are seen as instrumentscattered light.

The dispersion changes as a function of wavelength, and so each exposure needs an individual calibration. The wavelength calibration is based on identifying the position of chromospheric lines on the detector: the fact that scattered light is practically free of Doppler shifts due to plasma velocity variations along the slit makes these lines very useful for establishing an absolute wavelength scale. Emission lines from neutrals and singly ionized species, which are fairly strong and unblended in the solar disk spectrum and for which the absolute wavelengths are known with high accuracy, have been used as reference lines.

By fitting a Gaussian line profile and measuring the line centroid in pixels, the pixel-to-wavelength relation in each spectral scan can in principle be performed with a precision of $5 \mathrm{~m} \AA$ and better if sufficient lines are available for this purpose. The pixel-to-wavelength relation has been determined by a correlation of the line centroids for all the reference lines in each $43 \AA$ window with their known literature wavelengths. 
Since the non-linear dispersion is known very accurately from the optical design, this correlation leads to a constant offset for each spectral scan. A by-product of this process has been the elimination of some mis-identifications and the identification of problems with the literature values of the wavelengths of some of the reference lines.

The identification of reference lines is sometimes difficult due to blending and to the presence of prominent lines both in first and second order in the SUMER spectrum. Except for a few close blends, the line centroids could be determined by multi-Gauss fits with estimated uncertainties of the order of 0.2 pixel $(\approx 10 \mathrm{~m} \AA$ in first order) or better. The accuracy of the laboratory wavelengths of atomic lines is often better than $2 \mathrm{~m} \AA$. Most of the laboratory wavelengths used for the wavelength calibration were taken from Kelly (1987).

After the spectra have been wavelength-calibrated, the wavelengths should be accurate to typically $30 \mathrm{~m} \AA$ relative to quiet-Sun chromospheric layers. This value can easily reach $40 \mathrm{~m} \AA$ for faint lines or in cases with blend problems. In contrast to the disk atlas, no net Doppler flows are expected, neither for the measured lines nor for the reference lines, which with few exceptions are purely seen as scattered light from the entire disk. A few exceptions might occur in flare and active-region spectra.

\subsection{Radiometric calibration}

The intensity has been converted from counts into physical units. Given the radiometric calibration of SUMER before and during the mission (Hollandt et al. 1996; Wilhelm et al. 1997b; Schühle et al. 1998, 2000), we give the absolute spectral radiances of all observed coronal features in the wavelength range from $660 \AA$ to $1609 \AA$ in first order of diffraction. The radiance of the profiles is scaled to $\mathrm{mW} \mathrm{sr} \mathrm{s}^{-1} \mathrm{~m}^{-2} \AA^{-1}$, while in the line list spectral pixels have been integrated scaling the line emission to photon $\operatorname{arcsec}^{-2} \mathrm{~cm}^{-2} \mathrm{~s}^{-1}$. The overall uncertainty of the radiometric calibration before the $\mathrm{SOHO}$ accident in 1998 is estimated to $15 \%$ below $1250 \AA$, and increases at longer wavelengths to $30 \%$. After the $\mathrm{SOHO}$ recovery these values have changed to $30 \%$ and $40 \%$, respectively.

We have corrected the spectra for local-gain depression effects of the detector channel plates and dead-time effects of the electronics (Wilhelm et al. 2000). However, the large majority of the lines are sufficiently weak not to be significantly affected by this correction. A few bright spectral lines, e.g. the $977 \AA$ C III, sometimes exceed the detector capabilities and produce a ghost in the right shoulder of such a line. We have taken out sections affected by this instrumental artefact.

The intensities in the present atlas have been chosen among all the measurements available for each line from detector "A", when available. Detector "B" measurements were used in the wavelength range between 660 and $792 \AA$, where no first-order detector " $A$ " spectra are available. Therefore, intensities of lines reported in the same solar feature (i.e. quiet Sun, or coronal hole) may actually be emitted by different regions, so that they cannot be directly compared. Also, the instrument required considerable time to cover the entire spectral range. Since the morphology of the structures observed in the active corona may have changed while the spectral range was scanned, the intensities of lines may become less comparable with increasing difference in wavelength.

Flare intensities are intrinsically variable with time, so we felt that it was meaningless to report measured intensities, since the spectra were not simultaneous and physical conditions of the emitting plasmas were very different from one end to the other of the SUMER range. In the line list, flare intensities are theoretical, calculated per unit emission measure using the CHIANTI database (Dere et al. 1997; Young et al. 2003) at the temperature of maximum abundance for each ion. Observed flare lines which have no emissivity value available in CHIANTI or are unidentified, are marked by " $\mathrm{x}$ " in the line list.

\section{Selection of coronal lines}

Once wavelengths and intensities were measured, it was necessary to discriminate between lines emitted by the local coronal plasma and lines observed as instrumental scattered light from disk chromospheric and transition region features.

This crucial task has been carried out by investigating the distribution of the line intensity along the SUMER slit in each of the datasets. In principle, this method allows to carry out an effective discrimination between the two types of lines because the intensity of lines emitted by local plasma decreases with distance from the limb much faster than the intensity of the instrument-scattered lines. While the latter show a decrease of at maximum a factor between 2 and 4 from one end to the other of the SUMER slit, the intensity of the locally emitted lines can decrease, depending of the ionization stage, by more than an order of magnitude. In the present work, we have measured the "typical" intensity distribution along the slit for coronal and instrumental scattered light from the strongest lines in the SUMER wavelength range. This "typical" intensity distribution has been used as a benchmark to discriminate between coronal and scattered light lines. Examples of "typical" intensity distributions for the coronal hole, detector " $\mathrm{A}$ " dataset are displayed in Fig. 2. Coronal lines are characterized by variations of about two orders of magnitude in the intensity at the two edges of the slit; their distributions are slightly different due to different reaction of each emitting ion to changes in the physical properties of the emitting plasma along the slit. All scattered light lines in Fig. 2 have an identical intensity profile, determined by instrumental effects only and not by the local plasma, and they vary by a factor 2 to 3 . These low-temperature lines are indicated by " $F$ " in the line list.

However, there are two problems to consider. The first problem is given by the fact that while instrument-scattered light is independent of the local conditions of the plasma in the field of view, its intensity depends on the conditions of the solar-disk plasma, so in principle observations carried out at different times and dates can have different intensity profiles of the scattered light. To avoid this problem, we have calculated scattered lines intensity profiles like those displayed in Fig. 2 for each of the datasets we have used. 


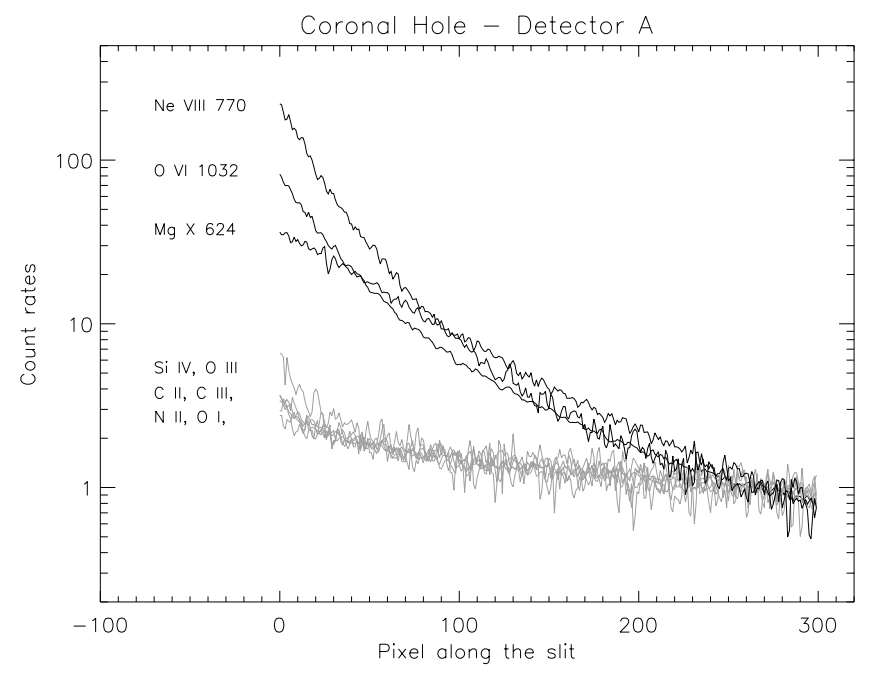

Fig. 2. Intensity distributions of a few strong coronal lines (black line) and several instrument-scattered light lines (grey lines), as a function of the position along the slit. Intensities are in counts.

The second problem is given by weak coronal lines, whose intensity rapidly decreases to levels where it becomes negligible relative to background noise or the instrument-scattered intensity either of its own emission from the disk, or of the emission of a blending chromospheric or transition region line at similar wavelength. The intensity profiles of these lines exhibit "mixed" behaviour: a profile typical of a true coronal line, in pixels close to the brightest pixels along the slit and selected for this atlas; away from them, the profile changes towards an instrument-scattered one. In this case, it is difficult to discriminate between a true coronal or a scattered light emission, especially when a line is so weak that scattered light or noise are big contributors also in the brightest pixels. This problem determines the lower intensity limit at which a coronal line can be safely identified; in the present work, we have rejected all lines whose origin could not be unambiguously identified. These lines are indicated by "I" in the line list.

It is important to note that in each observation the SUMER slit was placed at sufficiently high solar latitudes to allow the SUMER field of view to include plasma at very different heights above the limb. In such a case the coronal line intensities varied from one end to the other of the slit much more than the scattered line intensities. The only exception is the active region, detector " $\mathrm{B}$ " dataset, where the inclination of the slit was such that plasma in the field of view was confined within $0.1 R_{\odot}$ above the limb. In this case, the difference in behaviour between the scattered and the coronal line was more limited and thus a fraction of the observed lines that may have had a coronal origin was rejected due to their ambiguous intensity profiles. Subtraction of the scattered light background is possible for individual lines and individual exposures, if the fall-off curve can be determined. There is, however, no general procedure available to quantify the scattered-light contribution. Therefore we have added the average quiet-Sun radiance profile from the disk atlas for comparison, which may allow an estimate of the scattered-light contribution.
The identification of flare lines was more straightforward, due to their strong confinement to a small portion of the SUMER slit, even if in that observation the SUMER field of view had similar problems to the active region, detector "B" dataset. SUMER has not yet observed a flare spectrum recorded on detector "B".

\section{The SUMER spectral atlas of off-disk features}

\subsection{Physical properties of the emitting plasmas}

The measurement of the physical properties of the emitting plasmas is beyond the scope of the present paper, but a brief review of diagnostics results obtained from spectra emitted by similar regions can be of help to the reader in understanding which physical conditions can be expected.

The quiet Sun, detector "A" spectrum has been thoroughly analysed by Parenti et al. (2003), who have determined the physical parameters (emission measure, electron density and temperature, elemental abundance) of the emitting plasma as a function of time along the whole week encompassing the observations, and as a function of the position along the slit. Parenti et al. (2003) demonstrated that the plasma emitting the spectrum observed by SUMER can be approximated with an isothermal plasma whose characteristics remained constant throughout the week of observation. At the position along the slit considered in the present work, the plasma properties were $T \simeq 1.2 \times 10^{6} \mathrm{~K}, N_{\mathrm{e}} \simeq 2 \times 10^{8} \mathrm{~cm}^{-3}, E M \simeq$ $3 \times 10^{43} \mathrm{~cm}^{-3}$. The element abundances show a normal dependence on the First Ionization Potential (FIP effect), with the low-FIP/high-FIP abundance ratio higher by a factor $\simeq 4$ than in the photosphere (low-FIP elements have a $F I P \leq 10 \mathrm{eV}$, high-FIP elements have $F I P \geq 10 \mathrm{eV}$ ). Since similar results have been found in other works studying the off-disk quiet Sun (i.e. Landi \& Feldman 2003, and references therein), it is reasonable to assume that the electron temperature of the quiet Sun plasma recorded by detector " $\mathrm{B}$ " is very similar, however, being recorded closer to the solar surface the electron density will be higher.

Several studies on off-disk coronal hole plasmas have been carried out with the SUMER experiment, all yielding similar results even though the observations were carried out years apart. In all cases, the emitting plasma was found to be nearly isothermal, although the temperatures were lower than in the quiet Sun and ranged from 5 to $8 \times 10^{5} \mathrm{~K}$ (Wilhelm et al. 1998; Wilhelm 1999). Electron densities have been found to lie in the range from 2 to $10 \times 10^{7} \mathrm{~cm}^{-3}$ (Wilhelm et al. 1998; Wilhelm 1999; Doyle et al. 1999; Doschek et al. 1997, 2001), significantly lower than in the quiet Sun. Interestingly, the spectra recorded above a coronal hole show some similarity to the on-disk sunspot spectrum with enhanced emission in Fe VII, Fe VIII or Mg VIII lines.

Active regions plasmas are not isothermal, due to the presence of multi-temperature magnetic structures along the line of sight. Plasma conditions in different off-disk active regions may be very different, according to the age and size of the region, to the solar cycle phase when the observations are carried, to their activity and even to the position within each region 
Table 2. Ions contributing lines to the atlas.

\begin{tabular}{|c|c|c|c|c|c|c|c|c|c|c|c|c|c|c|c|c|c|c|c|}
\hline Element & V & VI & VII & VIII & IX & X & XI & XII & XIII & XIV & XV & XVI & XVII & XVIII & XIX & $\mathrm{XX}$ & XXI & XXII & XXIII \\
\hline $\mathrm{N}$ & $\mathrm{X}$ & & & & & & & & & & & & & & & & & & \\
\hline O & & X & & & & & & & & & & & & & & & & & \\
\hline \multicolumn{20}{|l|}{ F } \\
\hline $\mathrm{Ne}$ & & $\mathrm{X}$ & $\mathrm{X}$ & $\mathrm{X}$ & & & & & & & & & & & & & & & \\
\hline $\mathrm{Na}$ & & & $\mathrm{X}$ & $\mathrm{X}$ & $\mathrm{X}$ & X & & & & & & & & & & & & & \\
\hline $\mathrm{Mg}$ & & $X$ & $X$ & $X$ & $X$ & $X$ & $X$ & & & & & & & & & & & & \\
\hline $\mathrm{Al}$ & & & $X$ & $\mathrm{X}$ & $X$ & $X$ & $\mathrm{X}$ & & & & & & & & & & & & \\
\hline $\mathrm{Si}$ & & $\mathrm{X}$ & $X$ & $\mathrm{X}$ & $\mathrm{X}$ & $X$ & $\mathrm{X}$ & $\mathrm{X}$ & X & & & & & & & & & & \\
\hline $\mathrm{P}$ & & & & & $\mathrm{X}$ & & & & & & & & & & & & & & \\
\hline S & & $X$ & $X$ & $\mathrm{X}$ & $\mathrm{X}$ & $X$ & $\mathrm{X}$ & $X$ & $\mathrm{X}$ & & & & & & & & & & \\
\hline $\mathrm{Cl}$ & & & $\mathrm{X}$ & & & & $\mathrm{X}$ & $\mathrm{X}$ & & & & & & & & & & & \\
\hline $\mathrm{Ar}$ & & & $X$ & $\mathrm{X}$ & $\mathrm{X}$ & & $\mathrm{X}$ & $\mathrm{X}$ & $X$ & & & & & & & & & & \\
\hline $\mathrm{K}$ & & & & & $\mathrm{X}$ & & $\mathrm{X}$ & $\mathrm{X}$ & $X$ & & & & & & & & & & \\
\hline $\mathrm{Ca}$ & & & $X$ & $X$ & $X$ & $X$ & & $\mathrm{X}$ & $X$ & $X$ & $X$ & & & & & & & & \\
\hline \multicolumn{20}{|l|}{$\mathrm{Sc}$} \\
\hline $\mathrm{Ti}$ & & & & & & & & & & & $\mathrm{X}$ & $X$ & & & & & & & \\
\hline \multicolumn{20}{|l|}{ V } \\
\hline $\mathrm{Cr}$ & & & & & & $X$ & $X$ & & & & & $X$ & $X$ & $\mathrm{X}$ & & $X$ & & & \\
\hline $\mathrm{Mn}$ & & & & & & & & & & & & & $X$ & $\mathrm{X}$ & & $X$ & $X$ & & \\
\hline $\mathrm{Fe}$ & & & $X$ & $\mathrm{X}$ & & $X$ & $X$ & $\mathrm{X}$ & & & & & $\mathrm{X}$ & $\mathrm{X}$ & $X$ & $\mathrm{X}$ & $X$ & $X$ & $X$ \\
\hline Co & & & & & & & & $\mathrm{X}$ & $X$ & & & & & & $X$ & & & & \\
\hline $\mathrm{Ni}$ & & & & & & & & & & $\mathrm{X}$ & $\mathrm{X}$ & & & & $\mathrm{X}$ & & $\mathrm{X}$ & & $\mathrm{X}$ \\
\hline
\end{tabular}

(as demonstrated in Fig. 3 at the separation line at $792 \AA$ ). Therefore the analysis of spectra emitted by active features is more complex than in coronal holes and quiet Sun, and no simple range of density, temperature, emission measure and abundances can be given.

The flare considered in the present work has been extensively studied by Landi et al. (2003), who carried out plasma diagnostics as a function of time for all the duration of the observations. Temperatures in the flare peaked at slightly less than $10 \mathrm{MK}$, and then steadily decreased; the surrounding, nonflaring plasmas remained quiescent at temperatures of $\simeq 4 \mathrm{MK}$. The evolution of the emission measure of the emitting plasma was also determined. The reader is referred to that paper for further details.

\subsection{Line identification}

The identifications presented in the Feldman et al. (1997) paper were used as the starting point for identifying the quiet Sun coronal lines in the present paper. The spectra on which the 1997 identification were based were emitted by quiet Sun streamer plasma at a height of $21000 \mathrm{~km}$ above the equatorial limb. Since during the observations part of the SUMER slit intersected a prominence, the recorded spectra consisted not only of coronal lines $\left(T_{\mathrm{e}} \geq 6 \times 10^{5} \mathrm{~K}\right)$ but also of lines emitted by cooler plasmas. In addition, a number of lines appear which are very bright in disk spectra and were scattered into the spectrometer by surface imperfections of the SUMER front mirror. Although the 1997 spectra contained some 900 lines, 375 were judged to be coronal lines, and only 200 of them were identified. Since the original publication appeared in press 40 additional lines were identified as high excitation transitions in Si VII (Kink et al. 1997, 1999), Fe VII (Ekberg \& Feldman 2003a) and Fe VIII (Ekberg \& Feldman 2003b). In addition few more lines were identified as ground configuration forbidden transitions of K XIII, Cl X, Cl XI and Cl XII (Feldman et al. 2004). The identifications of Dwivedi et al. (1999) in their study of the coronal emission in the spectral ranges from $980 \AA$ to $1020 \AA$ and from $1174 \AA$ to $1214 \AA$ also have been scrutinized for this work.

On May 9, 1999 SUMER succeeded in recording spectra from a M7.6 flare and the active region surrounding it. Using the recorded spectra Curdt et al. (2000) and Feldman et al. (2000) identified some 70 lines associated with the active region and flaring plasmas. The lines in these papers were the basis for the identifications of the high temperature lines $\left(T_{\mathrm{e}} \geq 3 \times 10^{6} \mathrm{~K}\right)$ presented here. The current paper contains 496 isolated lines (plus 11 cases of contributing emission which can not be decomposed) emitted by coronal plasmas at temperatures of $6 \times 10^{5} \leq T_{\mathrm{e}} \leq 2 \times 10^{7} \mathrm{~K} ; 362$ of them were present in the quiet Sun coronal spectra and the rest in the coronal hole, active region or flaring plasma. Of the 507 contributing lines in the spectra 311 lines $(\sim 61 \%)$ are identified, belonging to 
90 different ions from all elements between $\mathrm{N}$ and $\mathrm{Ni}$, with the exception of F, Sc and V (see Table 2). We believe that the vast majority of the unidentified lines belong to transitions within or between levels of excited configurations.

In flaring plasmas the temperatures can surpass $2 \times 10^{7} \mathrm{~K}$ resulting in resonance transitions that appear in the extreme ultraviolet (EUV) and soft X-ray (SXR) spectral regions that for the most part are devoid of lines typical of much cooler plasmas. Many of the transitions within the ground configuration $\left(2 \mathrm{~s}^{2} 2 \mathrm{p}^{k} ; k=1,5\right)$ of highly ionized atoms that are most abundant in flaring plasmas fall in the SUMER range. Additionally transitions of the type $1 \mathrm{~s} 2 \mathrm{~s}{ }^{3} \mathrm{~S}_{1}-1 \mathrm{~s} 2 \mathrm{p}{ }^{3} \mathrm{P}_{0,2}$ in elements with $Z \leq 20$ also fall in this range. Since those lines are intermixed with much lower excitation lines, they provide diagnostic capabilities not possible for measurements in the EUV and SXR ranges. While black-body and recombination continua are normally not present in solar coronal spectra, SUMER often has observed bremsstrahlung during flares as a strong enhancement of the continuum emission emerging from the same confined plasma as the flare lines. Magnetic dipole transitions in highly ionized species, e.g., the Fe XIX $1118 \AA$ line, are a by-product of the physical processes generating emission in the SXR range and can be taken as SXR proxy, thus allowing spectroscopy of such plasmas, particularly Doppler shift measurements, which currently are not possible in the EUV and SXR bands below $100 \AA$.

\subsection{Description of the Atlas}

The spectra in this atlas are displayed as composite profiles of different exposures. Except for small sections around Lyman- $\alpha$ and near the limits of the SUMER spectral range we have selected data recorded on the $\mathrm{KBr}$ photocathode. The bare-MCP sections have been treated separately throughout the radiometric calibration process to compensate for the differences in responsivity, thus enhancing lines recorded in second order of diffraction.

Similar to the disk atlas, spectra are displayed as profiles in different colours. In Fig. 3 the spectra of the corona above a quiet region, an active region, a coronal hole, and in a flare appear as black line, as red line, as blue line, and as green line, respectively. The spectra are presented in portions of $42 \AA$ with $2 \AA$ of overlap. For details of the heights above the limb at which each of the spectra shown in the figure were recorded see Table 1 . Notice that the spectral plots at wavelengths shorter than $792 \AA$ were recorded by detector "B" while those plotted above $792 \AA$ were recorded by detector "A". Different from the line list, where we for practical reasons give the line radiance in units of photon $\operatorname{arcsec}^{-2} \mathrm{~cm}^{-2} \mathrm{~s}^{-1}$, in the plot spectral radiances are given in units of $\mathrm{mW} \mathrm{sr}{ }^{-1} \mathrm{~m}^{-2} \AA^{-1}$ for both orders of diffraction.

Each resolved emission line is indicated by a coded mark, the measured wavelength in angstrom $(\AA)$, and the identification. If available, unidentified lines are characterized by the temperature classification of Feldman et al. (1997). The wavelength values are restricted to three digits, one digit before and two rounded digits after the decimal point. In the plot we have indicated some of the ambiguous lines rejected for the line list. For a better orientation, we also have included the average quiet-Sun profile and the identification of the most important lines from the disk atlas (dotted grey line). The marks are coded according to the temperature classification "chromospheric" (circles), "transition region" (squares), "coronal" (triangles), or "flare" (diamond). Generally, the identifications are placed on top of the profile with the highest emission. Flare line identifications were treated separately and always appear at the flare profile. Open symbols represent lines which are observed in second or third order.

\section{Summary}

The spatially resolved solar spectra studied in this atlas cover the $670 \AA$ to $1609 \AA$ wavelength range. Additional lines were identified in second or third order of diffraction down to $465 \AA$. This atlas, which also is available in machine readable form, combines better spectral and spatial resolution, superior signal to noise ratios as well as wider wavelength coverage than any previously published atlas of a similar kind. It represents our most up-to-date knowledge about the emission of solar coronal features in the SUMER spectral range and includes 507 lines of which $\approx 61 \%$ are identified. It illustrates absolute intensities of the most common solar upper atmosphere coronal structures throughout most of the range with an accuracy of $15 \%$. The lines listed in the atlas belong to the 90 ions listed in Table 2.

The published line intensities - restricted to co-spatial and co-temporal observations - provide a rich resource for probing electron densities, electron temperatures, opacities and elemental abundances of the basic solar upper atmosphere structures. Due to the higher spatial resolution of the SUMER spectrograph the plasma parameters of small solar features also can be investigated. The present atlas represents a powerful tool for the planning of future observations, i.e., to determine adequate integration times, to identify possible blends, and to select proper data extraction windows in upcoming solar experiments. It can also be used as a proxy when investigating stellar spectra. The absolute intensities of lines emitted by the diverse set of ions when combined with the properties of the emitting plasmas can - with the same restrictions mentioned above - be used as a check on the accuracies of atomic physics code calculations.

Acknowledgements. The SUMER project is financially supported by DLR, CNES, NASA and the ESA PRODEX Programme (Swiss contribution). SUMER is part of SOHO, the Solar and Heliospheric Observatory, of ESA and NASA. U.F. acknowledges financial support from NRL/ONR 6.1 basic research programs and NASA grants. The work of E.L. is supported by the NNH04AA12I and W10,232 NASA grants. We appreciate valuable comments of the referee which have helped to improve this communication.

\section{References}

Ayres, T. R., Brown, A., Harper, G. M., et al. 2003, ApJ, 583, 963

Burton, W. M., \& Ridgeley, A. 1970, Sol. Phys., 14, 3

Curdt, W., Feldman, U., Laming, J. M., et al. 1997, A\&AS, 126, 281

Curdt, W., Landi, E., Wilhelm, K., \& Feldman, U. 2000, Phys. Rev. A, 62,022502 
Curdt, W., Landi, E., \& Feldman, U. 2001a, in Recent Insights into the Physics of the Sun and Heliospere, ed. P. Brekke, B. Fleck, \& J. B. Gurman Proc. IAU Symp., Manchester, 2000, PASP, 203, 260

Curdt, W., Brekke, P., Feldman, U., et al. 2001b, A\&A, 375, 591

Dere, K. P., Landi, E., Mason, H. E., et al. 1997, A\&AS, 125, 149

Doyle, J. G., Teriaca, L., \& Banerjee, D. 1999, A\&A, 349, 956

Doschek, G. A., Feldman, U., VanHoosier, M. E., \& Bartoe, J.-D. F. 1976, ApJS, 31, 417

Doschek, G. A., Warren, H. P., Laming, J. M., et al. 1997, ApJ, 482, L109

Doschek, G. A., Feldman, U., Laming, J. M., Schühle, U., \& Wilhelm, K. 2001, ApJ, 546, 559

Dwivedi, B. N., Curdt, W., \& Wilhelm, K. 1999, ApJ, 517, 516

Edlén, B. 1943, Zeitschr. f. Astrophys., 22, 30

Ekberg, J. O., \& Feldman, U. 2003a, ApJ, 595, 517

Ekberg, J. O., \& Feldman, U. 2003b, ApJS, 148, 567

Feldman, U., \& Doschek, G. A. 1977, J. Opt. Soc. Am., 67, 726

Feldman, U., \& Doschek, G. A. 1991, ApJS, 75, 925

Feldman, U., Behring, W. E., Curdt, W., et al. 1997, ApJS, 113, 195

Feldman, U., Curdt, W., Doschek, G. A., et al. 1998, ApJ, 503, 467

Feldman, U., Doschek, G. A., Schühle, U., \& Wilhelm, K. 1999, ApJ, 518,500

Feldman, U., Curdt, W., Landi, E., \& Wilhelm, K. 2000, ApJ, 544, 508

Feldman, U., Landi, E., \& Curdt, W. 2004, ApJ, 607, 1039

Grotrian, W. 1939, Naturwissenschaften, 27, 214

Hollandt, J., Schühle, U., Paustian, W., et al. 1996, Appl. Opt., 35, 5125
Jordan, C. 1971, Sol. Phys., 21, 381

Kelly, R. L. 1987, J. Phys. Chem. Ref. Data, 16, 1

Kink, I., Jupen, C., Engström, L., et al. 1997, ApJ, 487, 956

Kink, I., Engström, L., \& Feldman, U. 1999, ApJ, 512, 496

Landi, E., \& Feldman, U. 2003, ApJ, 592, 607

Landi, E., Feldman, U., Innes, D. E., \& Curdt, W. 2003, ApJ, 582, 506

Lemaire, P., Wilhelm, K., Curdt, W., et al. 1997, Sol. Phys., 170, 105

Parenti, S., Landi, E., \& Bromage, B. J. I. 2003, ApJ, 590, 519

Redfield, S., Ayres, T. R., Linsky, J. L., et al. 2003, ApJ, 585, 993

Rybàk, J., Kučera, A., Schühle, U., \& Wöhl, H. 1999, in Magnetic Fields and Solar Processes, ed. A. Wilson, Proc. 9th EPS meeting, Florence, ESA-SP-448, 361

Sandlin, G. D., Brueckner, G. E., \& Tousey, R. 1977, ApJ, 214, 898

Sandlin, G. D., Bartoe, J.-D. F., Brueckner, G. E., et al. 1986, ApJS, 61,801

Schühle, U., Brekke, P., Curdt, W., et al. 1998, Appl. Opt., 37, 2646

Schühle, U., Curdt, W., Hollandt, J., et al. 2000, Appl. Opt., 39, 418

Vernazza, J. E., \& Reeves, E. M. 1978, ApJS, 37, 485

Young, P. R., Del Zanna, G., Landi, E., et al. 2003, ApJS, 144, 135

Wilhelm, K., Curdt, W., Marsch, E., et al. 1995, Sol. Phys., 162, 189

Wilhelm, K., Lemaire, P., Curdt, W., et al. 1997a, Sol. Phys., 170, 75

Wilhelm, K., Lemaire, P., Feldman, U., et al. 1997b, Appl. Opt., 36, 6416

Wilhelm, K., Marsch, E., Dwivedi, B. N., et al. 1998, ApJ, 500, 1023

Wilhelm, K. 1999, Astroph. \& Sp. Sci., 264, 43

Wilhelm, K., Schühle, U., Curdt, W., et al. 2000, Metrologia, 37(5), 393 
W. Curdt et al.: Coronal EUV atlas, Online Material $p$ I

\section{Online Material}


W. Curdt et al.: Coronal EUV atlas, Online Material $p 2$

Table 3. Line list of the SUMER spectral atlas.

\begin{tabular}{|c|c|c|c|c|c|c|c|c|}
\hline \multirow{2}{*}{$\begin{array}{r}\lambda_{\mathrm{obs}} \\
\AA\end{array}$} & \multirow[t]{2}{*}{ Line } & \multirow{2}{*}{\multicolumn{2}{|c|}{ Transition }} & QS & $\mathrm{CH}$ & $\mathrm{AR}$ & Flare & Notes \\
\hline & & & & \multicolumn{5}{|c|}{ line radiance $L /$ phot $\mathrm{cm}^{-2} \mathrm{~s}^{-1} \operatorname{arcsec}^{-2}$} \\
\hline 465.22 & $\mathrm{Ne}$ VII & $2 \mathrm{~s}^{2}{ }^{1} \mathrm{~S}_{0}$ & $-2 \mathrm{~s} 2 \mathrm{p}{ }^{1} \mathrm{P}_{1}$ & o & o & & & $3^{\text {rd }}$ order \\
\hline 466.24 & Ca IX & $3 \mathrm{~s}^{2}{ }^{1} \mathrm{~S}_{0}$ & $-3 \mathrm{~s} 3 \mathrm{p}{ }^{1} \mathrm{P}_{1}$ & o & & o & & $3^{\text {rd }}$ order \\
\hline 491.39 & S XIII & $2 \mathrm{~s}^{2}{ }^{1} \mathrm{~S}_{0}$ & $-2 \mathrm{~s} 2 \mathrm{p}{ }^{3} \mathrm{P}_{1}$ & o & & 6.2 & & $3^{\text {rd }}$ order \\
\hline 499.40 & Si XII & $1 \mathrm{~s}^{2} 2 \mathrm{~s}^{2} \mathrm{~S}_{1 / 2}$ & $-1 \mathrm{~s}^{2} 2 \mathrm{p}^{2} \mathrm{P}_{3 / 2}$ & 23.3 & & 166.4 & & \\
\hline 520.66 & Si XII & $1 \mathrm{~s}^{2} 2 \mathrm{~s}^{2} \mathrm{~S}_{1 / 2}$ & $-1 \mathrm{~s}^{2} 2 \mathrm{p}^{2} \mathrm{P}_{1 / 2}$ & 13.3 & & 100.9 & & \\
\hline 538.93 & S XII & $2 \mathrm{~s}^{2} 2 \mathrm{p}^{2} \mathrm{P}_{3 / 2}$ & $-2 \mathrm{~s} 2 \mathrm{p}^{2}{ }^{4} \mathrm{P}_{3 / 2}$ & 0.49 & & 0.81 & & \\
\hline 539.44 & Ca VII & $3 \mathrm{~s}^{2} 3 \mathrm{p}^{2}{ }^{3} \mathrm{P}_{0}$ & $-3 \mathrm{~s} 3 \mathrm{p}^{3}{ }^{3} \mathrm{P}_{1}$ & 0.045 & & & & \\
\hline 544.28 & Ca VII & $3 \mathrm{~s}^{2} 3 \mathrm{p}^{2}{ }^{3} \mathrm{P}_{1}$ & $-3 \mathrm{~s} 3 \mathrm{p}^{3}{ }^{3} \mathrm{P}$ & 0.12 & & 0.64 & & \\
\hline 545.23 & Ca XIV & $2 s^{2} 2 p^{3}{ }^{4} S_{3 / 2}$ & $-2 \mathrm{~s}^{2} 2 \mathrm{p}^{3}{ }^{2} \mathrm{P}_{3 / 2}$ & & & 0.43 & 358 & \\
\hline 550.04 & $\mathrm{Al} \mathrm{XI}$ & $1 \mathrm{~s}^{2} 2 \mathrm{~s}^{2} \mathrm{~S}_{1 / 2}$ & $-1 \mathrm{~s}^{2} 2 \mathrm{p}^{2} \mathrm{P}_{3 / 2}$ & 7.9 & & 48.5 & & \\
\hline 551.45 & S VII & $2 s^{2} 2 p^{5} 3 s^{3} P_{1}$ & ${ }_{1}-2 s^{2} 2 p^{5} 3 p^{3} S_{1}$ & 0.12 & 0.18 & 0.35 & & $1^{\text {st }}$ in $\mathrm{QS}$ and $\mathrm{AR}$ \\
\hline 551.45 & Ca VII & $3 \mathrm{~s}^{2} 3 \mathrm{p}^{2}{ }^{3} \mathrm{P}_{2}$ & $-3 \mathrm{~s} 3 \mathrm{p}^{3}{ }^{3} \mathrm{P}_{2}$ & & & & & \\
\hline 552.09 & S XI & $2 \mathrm{~s}^{2} 2 \mathrm{p}^{2}{ }^{3} \mathrm{P}_{1}$ & $-2 \mathrm{~s} 2 \mathrm{p}^{3}{ }^{5} \mathrm{~S}_{2}$ & 0.31 & & 0.54 & & \\
\hline 555.38 & $\mathrm{CaXV}$ & $2 \mathrm{~s}^{2} 2 \mathrm{p}^{2}{ }^{3} \mathrm{P}_{1}$ & $-2 \mathrm{~s}^{2} 2 \mathrm{p}^{2}{ }^{1} \mathrm{~S}_{0}$ & & & & 101 & \\
\hline 557.76 & $\mathrm{CaX}$ & $2 p^{6} 3 s^{2} S_{1 / 2}$ & $-2 p^{6} 3 p^{2} P_{3 / 2}$ & 9.0 & 5.2 & 19.7 & & \\
\hline 558.59 & $\mathrm{Ne} \mathrm{VI}$ & $2 s^{2} 2 p^{2} \mathrm{P}_{1 / 2}$ & $-2 \mathrm{~s} 2 \mathrm{p}^{2}{ }^{2} \mathrm{D}_{3 / 2}$ & & 0.36 & & & \\
\hline 559.96 & $\mathrm{Ne}$ VII & $2 \mathrm{~s} 2 \mathrm{p}{ }^{3} \mathrm{P}_{0}$ & $-2 \mathrm{p}^{2}{ }^{3} \mathrm{P}_{1}$ & 0.069 & $0.25 \#$ & & & \\
\hline 560.40 & $\mathrm{Ne}$ VII & $2 \mathrm{~s} 2 \mathrm{p}^{3} \mathrm{P}_{1}$ & $-2 p^{2}{ }^{3} \mathrm{P}_{1}$ & 0.090 & & 0.85 & & \\
\hline 561.76 & $\mathrm{Ne}$ VII & $2 \mathrm{~s} 2 \mathrm{p}{ }^{3} \mathrm{P}_{2}$ & $-2 \mathrm{p}^{2}{ }^{3} \mathrm{P}_{2}$ & 0.32 & 0.65 & & & \\
\hline 562.80 & $\mathrm{Ne}$ VI & $2 \mathrm{~s}^{2} 2 \mathrm{p}^{2} \mathrm{P}_{3 / 2}$ & $-2 \mathrm{~s} 2 \mathrm{p}^{2}{ }^{2} \mathrm{D}_{5 / 2}$ & & 0.70 & & & $F$ in $\mathrm{QS}$ and $\mathrm{AR}$ \\
\hline 564.00 & Si XI & $2 \mathrm{~s}^{2}{ }^{1} \mathrm{~S}_{0}$ & $-2 s 2 p^{3} P_{2}$ & 1.63 & & 2.6 & & $F$ in $\mathrm{CH}$ \\
\hline 567.83 & Fe Xx & $2 \mathrm{~s}^{2} 2 \mathrm{p}^{3}{ }^{4} \mathrm{~S}_{5 / 2}$ & $-2 \mathrm{~s}^{2} 2 \mathrm{p}^{3}{ }^{2} \mathrm{D}_{3 / 2}$ & & & & 5210 & \\
\hline 568.16 & Al XI & $1 \mathrm{~s}^{2} 2 \mathrm{~s}^{2} \mathrm{~S}_{1 / 2}$ & $-1 s^{2} 2 p^{2} P_{1 / 2}$ & 5.3 & & 23.5 & & $F$ in $\mathrm{CH}$ \\
\hline 569.25 & (e) & & & 0.41 & & 0.59 & & $F$ in $\mathrm{CH}$ \\
\hline 574.01 & $\mathrm{CaX}$ & $2 p^{6} 3 s^{2} S_{1 / 2}$ & $-2 p^{6} 3 p{ }^{2} P_{1 / 2}$ & 6.0 & 3.2 & 12.2 & & \\
\hline 574.88 & S XI & $2 \mathrm{~s}^{2} 2 \mathrm{p}^{2}{ }^{3} \mathrm{P}_{2}$ & $-2 \mathrm{~s} 2 \mathrm{p}^{3}{ }^{5} \mathrm{~S}_{2}$ & 0.66 & & 1.2 & & $F$ in $\mathrm{CH}$ \\
\hline 577.68 & $\mathrm{CaX}$ ? & & & 0.14 & & & & \\
\hline 579.85 & Ca XIV & $2 s^{2} 2 p^{3}{ }^{4} S_{3 / 2}$ & $-2 \mathrm{~s}^{2} 2 \mathrm{p}^{3}{ }^{2} \mathrm{P}_{1 / 2}$ & & & 1.2 & 167 & \\
\hline 580.91 & Si XI & $2 \mathrm{~s}^{2}{ }^{1} \mathrm{~S}_{0}$ & $-2 \mathrm{~s} 2 \mathrm{p}{ }^{3} \mathrm{P}_{1}$ & 15.8 & & 33.9 & & $F, 1^{\text {st }}$ in $\mathrm{CH}$ \\
\hline 581.34 & (c) & & & 0.059 & 0.19 & 0.20 & & \\
\hline 581.60 & (c) & & & 0.21 & 0.21 & 0.44 & & \\
\hline 582.86 & Ca VIII & $3 s^{2} 3 p^{2} \mathrm{P}_{1 / 2}$ & $-3 s 3 p^{2}{ }^{2} D_{3 / 2}$ & & 0.20 & & & $F$ in $\mathrm{QS}$ and $\mathrm{AR}$ \\
\hline 585.75 & Ar VII & $3 \mathrm{~s}^{2}{ }^{2} \mathrm{~S}_{0}$ & $-3 \mathrm{~s} 3 \mathrm{p}{ }^{1} \mathrm{P}_{1}$ & 0.15 & 0.13 & & & \\
\hline 585.77 & Fe XXI & $2 \mathrm{~s}^{2} 2 \mathrm{p}^{2}{ }^{3} \mathrm{P}_{1}$ & $-2 \mathrm{~s}^{2} 2 \mathrm{p}^{2}{ }^{1} \mathrm{D}_{2}$ & & & & 1460 & \\
\hline 586.08 & (e) & & & 0.20 & 0.13 & 0.25 & & \\
\hline 591.63 & & & & & & 0.32 & & \\
\hline 592.23 & Fe XIX & $2 s^{2} 2 p^{4}{ }^{3} P_{2}$ & $-2 s^{2} 2 p^{4}{ }^{1} D_{2}$ & & & 0.85 & 4960 & \\
\hline 592.68 & (f) & & & 6.4 & 0.14 & 7.5 & & \\
\hline 592.80 & & & & & & & 0.52 & \\
\hline 593.08 & (f) & & & 0.66 & & 0.73 & & \\
\hline 596.99 & Ca VIII & $3 s^{2} 3 p^{2} \mathrm{P}_{3 / 2}$ & $-3 \mathrm{~s} 3 \mathrm{p}^{2}{ }^{2} \mathrm{D}_{5 / 2}$ & & 0.35 & & & \\
\hline 604.15 & Si XI & $2 \mathrm{~s} 2 \mathrm{p}{ }^{1} \mathrm{P}_{1}$ & $-2 \mathrm{p}^{2}{ }^{1} \mathrm{D}_{2}$ & 2.5 & & $4.1^{*}$ & & \\
\hline 604.88 & $\mathrm{Cl}$ VII & $2 p^{6} 3 p^{2} P_{3 / 2}$ & $-2 p^{6} 3 d^{2} D_{5 / 2}$ & & & & & \\
\hline 609.80 & $\operatorname{Mg} X$ & $1 \mathrm{~s}^{2} 2 \mathrm{~s}^{2} \mathrm{~S}_{1 / 2}$ & $-1 \mathrm{~s}^{2} 2 \mathrm{p}^{2} \mathrm{P}_{3 / 2}$ & 213.0 & 25.7 & $341.2 *$ & & \\
\hline 611.61 & Si $x$ & $2 \mathrm{~s}^{2} 2 \mathrm{p}^{2} \mathrm{P}_{1 / 2}$ & $-2 \mathrm{~s} 2 \mathrm{p}^{2}{ }^{4} \mathrm{P}_{3 / 2}$ & 0.77 & & $0.76^{*}$ & & $F$ in $\mathrm{CH}$ \\
\hline 613.17 & Al IX & $2 \mathrm{~s} 2 \mathrm{p}^{2}{ }^{2} \mathrm{P}_{3 / 2}$ & $-2 \mathrm{p}^{3}{ }^{2} \mathrm{D}_{5 / 2}$ & 0.34 & & $0.22 *$ & & $F$ in $\mathrm{CH}$ \\
\hline 621.11 & $\mathrm{SiX}$ & $2 s^{2} 2 p^{2} \mathrm{P}_{1 / 2}$ & $-2 \mathrm{~s} 2 \mathrm{p}^{2}{ }^{4} \mathrm{P}_{1 / 2}$ & & & & & cf., $1242.0 \AA$ \\
\hline
\end{tabular}


W. Curdt et al.: Coronal EUV atlas, Online Material $p 3$

Table 3. continued.

\begin{tabular}{|c|c|c|c|c|c|c|c|c|}
\hline \multirow{2}{*}{$\begin{array}{r}\lambda_{\mathrm{obs}} \\
\AA\end{array}$} & \multirow[t]{2}{*}{ Line } & \multirow{2}{*}{\multicolumn{2}{|c|}{ Transition }} & QS & $\mathrm{CH}$ & $\mathrm{AR}$ & Flare & Notes \\
\hline & & & & \multicolumn{5}{|c|}{ line radiance $L /$ phot $\mathrm{cm}^{-2} \mathrm{~s}^{-1} \operatorname{arcsec}^{-2}$} \\
\hline 622.47 & K XIII & $2 s^{2} 2 p^{3}{ }^{4} S_{3 / 2}$ & $-2 \mathrm{~s}^{2} 2 \mathrm{p}^{3}{ }^{2} \mathrm{P}_{1 / 2}$ & & & 1.0 & & \\
\hline 623.33 & $\mathrm{Al} \mathrm{x}$ & $2 \mathrm{~s}^{2}{ }^{1} \mathrm{~S}_{0}$ & $-2 s 2 p^{3} P_{2}$ & 0.44 & & 0.63 & & \\
\hline 624.71 & Si $\mathrm{X}$ & $2 s^{2} 2 p^{2} P_{3 / 2}$ & $-2 \mathrm{~s} 2 \mathrm{p}^{2}{ }^{4} \mathrm{P}_{5 / 2}$ & 8.4 & 0.72 & 9.9 & & \\
\hline 624.97 & $\operatorname{Mg} \mathbf{X}$ & $1 \mathrm{~s}^{2} 2 \mathrm{~s}^{2} \mathrm{~S}_{1 / 2}$ & $-1 s^{2} 2 p^{2} \mathrm{P}_{1 / 2}$ & 118.2 & 16.0 & 345.6 & & \\
\hline 626.41 & (f) & & & 0.68 & & 1.73 & & \\
\hline 627.48 & (d) & & & 0.13 & & 0.12 & & $F$ in $\mathrm{CH}$ \\
\hline 630.50 & Ca VII & $3 \mathrm{~s}^{2} 3 \mathrm{p}^{2}{ }^{3} \mathrm{P}_{1}$ & $-3 \mathrm{~s} 3 \mathrm{p}^{3}{ }^{3} \mathrm{D}_{2}$ & & & 0.80 & & \\
\hline 631.00 & (e) & & & 0.30 & 0.082 & 0.11 & & \\
\hline 631.43 & (d) & & & 0.10 & & & & $F$ in $\mathrm{CH}, \mathrm{AR}$ \\
\hline 632.72 & (e) & & & 0.24 & & 0.71 & & $F$ in $\mathrm{CH}$ \\
\hline 633.54 & & & & 0.072 & & & & \\
\hline 634.74 & & & & 0.085 & & & & \\
\hline 635.62 & & & & 0.080 & & & & \\
\hline 636.34 & K IX & $2 p^{6} 3 s^{2} S_{1 / 2}$ & $-2 p^{6} 3 p^{2} P_{1 / 2}$ & 0.23 & 0.19 & 0.63 & & \\
\hline 637.48 & Ar VII & $3 \mathrm{~s} 3 \mathrm{p}^{3} \mathrm{P}_{1}$ & $-3 \mathrm{p}^{2}{ }^{3} \mathrm{P}_{1}$ & 0.11 & 0.058 & & & \\
\hline 637.75 & $\mathrm{Al} \mathrm{x}$ & $2 \mathrm{~s}^{2}{ }^{1} \mathrm{~S}_{0}$ & $-2 s 2 p{ }^{3} P_{1}$ & 3.0 & 0.18 & 4.9 & & \\
\hline 638.13 & (e) & & & 0.26 & & 0.48 & & $F$ in $\mathrm{CH}$ \\
\hline 638.92 & SiX & $2 s^{2} 2 p^{2} P_{3 / 2}$ & $-2 \mathrm{~s} 2 \mathrm{p}^{2}{ }^{4} \mathrm{P}_{3 / 2}$ & 6.6 & 0.40 & 8.0 & & \\
\hline 639.14 & Ca VII & $3 s^{2} 3 p^{2}{ }^{3} P_{2}$ & $-3 \mathrm{~s} 3 \mathrm{p}^{3}{ }^{3} \mathrm{D}_{3}$ & 0.36 & & 0.64 & & $F$ in $\mathrm{CH}$ \\
\hline 639.89 & (e) & & & 0.18 & & 0.087 & & $F$ in $\mathrm{CH}$ \\
\hline 640.14 & & & & 0.55 & & 0.44 & & \\
\hline 641.18 & & & & 0.018 & & 0.26 & & \\
\hline 641.27 & Ar VII & $3 s 3 p{ }^{3} P_{1}$ & $-3 \mathrm{p}^{2}{ }^{3} \mathrm{P}_{0}$ & 0.054 & & 0.076 & & $F$ in $\mathrm{CH}$ \\
\hline 642.31 & & & & 0.039 & & & & \\
\hline 642.53 & Ar IX & $2 s^{2} 2 p^{5} 3 s^{3} P_{2}$ & $-2 s^{2} 2 p^{5} 3 p{ }^{1} D_{2}$ & 0.026 & 0.035 & 0.040 & & \\
\hline 642.97 & (e) & & & 0.23 & & 0.40 & & $F$ in $\mathrm{CH}$ \\
\hline 644.47 & Ar VII & $3 s 3 p{ }^{3} P_{2}$ & $-3 \mathrm{p}^{2}{ }^{3} \mathrm{P}_{1}$ & 0.23 & & 0.36 & & \\
\hline 648.25 & & & & 0.076 & & 0.26 & & \\
\hline 648.68 & Ca XIII & $2 \mathrm{~s}^{2} 2 \mathrm{p}^{4}{ }^{3} \mathrm{P}_{1}$ & $-2 \mathrm{~s}^{2} 2 \mathrm{p}^{4}{ }^{1} \mathrm{~S}_{0}$ & & & 1.1 & 65.0 & $I$ in $\mathrm{QS}$ \\
\hline 648.70 & S VI & $3 \mathrm{~d}^{2} \mathrm{D}_{5 / 2}$ & $-4 p^{2} P_{3 / 2}$ & & & & & $I$ in $\mathrm{QS}$ \\
\hline 649.09 & Ar XII & $2 s^{2} 2 p^{3}{ }^{4} S_{3 / 2}$ & $-2 \mathrm{~s}^{2} 2 \mathrm{p}^{3}{ }^{2} \mathrm{P}_{3 / 2}$ & & & & 281 & \\
\hline 649.21 & Six & $2 \mathrm{~s}^{2} 2 \mathrm{p}{ }^{2} \mathrm{P}_{3 / 2}$ & $-2 \mathrm{~s} 2 \mathrm{p}^{2}{ }^{4} \mathrm{P}_{1 / 2}$ & 1.9 & 0.15 & 2.8 & & \\
\hline 650.41 & S VI & $2 p^{6} 3 d^{2} D_{3 / 2}$ & $-2 p^{6} 4 p^{2} P_{1 / 2}$ & 0.11 & & & & $I$ in $\mathrm{QS}$ \\
\hline 654.07 & & & & & & & $\mathrm{x}$ & \\
\hline 654.32 & & & & 0.038 & & & & \\
\hline 654.88 & & & & & & & $\mathrm{x}$ & \\
\hline 655.81 & & & & 0.043 & & & & \\
\hline 656.69 & Ar XIII & $2 \mathrm{~s}^{2} 2 \mathrm{p}^{2}{ }^{3} \mathrm{P}_{1}$ & $-2 \mathrm{~s}^{2} 2 \mathrm{p}^{2}{ }^{1} \mathrm{~S}_{0}$ & & & 0.37 & 43.5 & $I$ in $\mathrm{QS}$ \\
\hline 657.33 & & & & & & & $\mathrm{x}$ & \\
\hline 658.27 & & & & 0.15 & & 0.26 & & $F$ in $\mathrm{CH}$ \\
\hline 660.19 & & & & & & 0.64 & $\mathrm{x}$ & $F$ in QS \\
\hline 662.39 & (d) & & & 0.21 & 0.064 & 0.41 & & \\
\hline 662.95 & Cr XVIII & $2 s^{2} 2 p^{3}{ }^{4} S_{3 / 2}$ & $-2 s^{2} 2 p^{3}{ }^{2} D_{5 / 2}$ & & & & 3.8 & \\
\hline 662.95 & Mn XVIII & $2 \mathrm{~s}^{2} 2 \mathrm{p}^{4}{ }^{3} \mathrm{P}_{2}$ & $-2 s^{2} 2 p^{4}{ }^{1} D_{2}$ & & & & 27.3 & \\
\hline 668.52 & S VIII & $2 s^{2} 2 p^{4} 3 p{ }^{4} P_{5 / 2}$ & ${ }_{2}-2 s^{2} 2 p^{4} 3 d^{4} D_{5 / 2}$ & 0.037 & & & & \\
\hline 669.02 & (d) & & & 0.16 & 0.077 & & & \\
\hline 670.02 & $\mathrm{Al} \mathrm{x}$ & $2 \mathrm{~s} 2 \mathrm{p}{ }^{1} \mathrm{P}_{1}$ & $-2 \mathrm{p}^{2}{ }^{1} \mathrm{D}_{2}$ & 0.38 & 0.071 & 0.61 & & \\
\hline
\end{tabular}


W. Curdt et al.: Coronal EUV atlas, Online Material $p 4$

Table 3. continued.

\begin{tabular}{|c|c|c|c|c|c|c|c|c|}
\hline \multirow{2}{*}{$\begin{array}{r}\lambda_{\text {obs }} \\
\AA\end{array}$} & \multirow[t]{2}{*}{ Line } & \multirow{2}{*}{\multicolumn{2}{|c|}{ Transition }} & QS & $\mathrm{CH}$ & $\mathrm{AR}$ & Flare & Notes \\
\hline & & & & \multicolumn{5}{|c|}{ line radiance $L /$ phot $\mathrm{cm}^{-2} \mathrm{~s}^{-1} \operatorname{arcsec}^{-2}$} \\
\hline 670.31 & Ar XII & $2 s^{2} 2 p^{3}{ }^{4} S_{3 / 2}$ & $-2 \mathrm{~s}^{2} 2 \mathrm{p}^{3}{ }^{2} \mathrm{P}_{1 / 2}$ & & & 0.35 & 116 & $I$ in $\mathrm{QS}$ \\
\hline 672.03 & S VIII & $2 s^{2} 2 p^{4} 3 p{ }^{4} P_{5 /}$ & $-2 s^{2} 2 p^{4} 3 d^{4} D_{7 / 2}$ & 0.078 & & & & $F$ in $\mathrm{CH}, I$ in $\mathrm{AR}$ \\
\hline 676.29 & CaIX & $3 \mathrm{~s}^{2}{ }^{1} \mathrm{~S}_{0}$ & $-3 s 3 p^{3} P_{2}$ & 0.069 & 0.11 & & & \\
\hline 676.29 & S VIII & $2 s^{2} 2 p^{4} 3 p{ }^{4} D_{7}$ & ${ }_{2}-2 s^{2} 2 p^{4} 3 d^{4} F_{9 / 2}$ & & & & & \\
\hline 676.51 & Si IX & $2 \mathrm{~s}^{2} 2 \mathrm{p}^{2}{ }^{3} \mathrm{P}_{1}$ & $-2 \mathrm{~s} 2 \mathrm{p}^{3}{ }^{5} \mathrm{~S}_{2}$ & 2.0 & 0.63 & 2.1 & & \\
\hline 676.81 & (e) & & & 1.0 & 0.29 & 1.5 & & \\
\hline 677.72 & & & & & 0.087 & & & \\
\hline 679.27 & Fe XX & $2 \mathrm{~s}^{2} 2 \mathrm{p}^{3}{ }^{2} \mathrm{D}_{5 / 2}$ & $-2 \mathrm{~s}^{2} 2 \mathrm{p}^{3}{ }^{2} \mathrm{P}_{3 / 2}$ & & & & 274 & \\
\hline 679.79 & Mg VIII & $2 \mathrm{~s} 2 \mathrm{p}^{2}{ }^{2} \mathrm{P}_{1 / 2}$ & $-2 \mathrm{p}^{3}{ }^{2} \mathrm{D}_{3 / 2}$ & 0.33 & 0.066 & 0.43 & & \\
\hline 680.39 & Al IX & $2 \mathrm{~s}^{2} 2 \mathrm{p}^{2} \mathrm{P}_{1 / 2}$ & $-2 s 2 p^{2}{ }^{4} P_{3 / 2}$ & 4.3 & 0.33 & 4.4 & & \\
\hline 680.67 & S VII & $2 s^{2} 2 p^{5} 3 p^{3} D_{3}$ & $-2 s^{2} 2 p^{5} 3 d^{3} F_{4}$ & & 0.045 & & & \\
\hline 681.70 & Na IX & $1 s^{2} 2 s^{2} S_{1 / 2}$ & $-1 \mathrm{~s}^{2} 2 \mathrm{p}^{2} \mathrm{P}_{3 / 2}$ & 7.6 & 4.9 & 34.6 & & \\
\hline 682.93 & & & & 0.036 & & & & \\
\hline 683.20 & S VIII & $2 s^{2} 2 p^{4} 3 p{ }^{4} P_{1 /}$ & $-2 s^{2} 2 p^{4} 3 d^{4} D_{3 / 2}$ & 0.056 & & 0.077 & & $I$ in $\mathrm{QS}$ \\
\hline 684.04 & (c) & & & 0.12 & 0.14 & 0.28 & & \\
\hline 686.44 & Fe VIII & $3 \mathrm{p}^{5} 3 \mathrm{~d}^{2}{ }^{2} \mathrm{P}_{3 / 2}$ & $-3 p^{6} 4 p^{2} D_{5 / 2}$ & 0.14 & 0.30 & & & $F$ in AR \\
\hline 686.44 & S VIII & $2 s^{2} 2 p^{4} 3 s^{2} D_{5}$ & $-2 s^{2} 2 p^{4} 3 p^{2} P_{3 / 2}$ & & & & & $F$ in $\mathrm{AR}$ \\
\hline$=686.82$ & S VII & $2 s^{2} 2 p^{5} 3 p^{1} D_{2}$ & $-2 s^{2} 2 p^{5} 3 d^{1} D_{2}$ & 0.055 & & & & \\
\hline 686.82 & S VIII & $2 s^{2} 2 p^{4} 3 p^{2} D_{5}$ & ${ }_{2}-2 s^{2} 2 p^{4} 3 d^{2} F_{7 / 2}$ & & & & & \\
\hline 687.68 & S VII & $2 s^{2} 2 p^{5} 3 p^{3} P_{2}$ & $-2 s^{2} 2 p^{5} 3 d^{1} F_{3}$ & 0.013 & & & & \\
\hline 687.68 & S VIII & $2 s^{2} 2 p^{4} 3 p^{2} D_{3}$ & ${ }_{2}-2 s^{2} 2 p^{4} 3 d^{2} F_{5 / 2}$ & & & & & \\
\hline 688.24 & Al IX & $2 s^{2} 2 p^{2} P_{1 / 2}$ & $-2 \mathrm{~s} 2 \mathrm{p}^{2}{ }^{4} \mathrm{P}_{1 / 2}$ & 0.11 & 0.044 & 0.33 & & \\
\hline 688.68 & Fe VIII & $3 p^{5} 3 d^{2}{ }^{2} P_{3 / 2}$ & $-3 p^{6} 4 d^{2} D_{3 / 2}$ & 0.022 & & & & \\
\hline 689.63 & Mg VIII & $2 \mathrm{~s} 2 \mathrm{p}^{2}{ }^{2} \mathrm{P}_{3 / 2}$ & $-2 \mathrm{p}^{3}{ }^{2} \mathrm{D}_{5 / 2}$ & 0.31 & 0.33 & 0.76 & & \\
\hline$[691.42$ & Ca IX & $3 \mathrm{~s}^{2}{ }^{1} \mathrm{~S}_{0}$ & $-3 s 3 p^{3} P_{1}$ & 0.32 & 0.84 & & & \\
\hline 691.54 & Al IX & $2 \mathrm{~s}^{2} 2 \mathrm{p}^{2} \mathrm{P}_{3 / 2}$ & $-2 \mathrm{~s} 2 \mathrm{p}^{2}{ }^{4} \mathrm{P}_{5 / 2}$ & 0.44 & 0.15 & 0.92 & & \\
\hline$[692.69$ & S VIII & $2 s^{2} 2 p^{4} 3 p^{2} F_{7 /}$ & $-2 s^{2} 2 p^{4} 3 d^{2} G_{9 / 2}$ & 0.027 & & & & \\
\hline 692.69 & Ar IX & $2 s^{2} 2 p^{5} 3 s^{3} P_{2}$ & $-2 s^{2} 2 p^{5} 3 p^{3} D_{2}$ & & & & & \\
\hline 693.33 & & & & 0.079 & 0.085 & & & \\
\hline 693.61 & & & & 0.040 & & & & \\
\hline 693.96 & Mg IX & $1 s^{2} 2 s^{2}{ }^{1} S_{0}$ & $-1 s^{2} 2 s 2 p{ }^{3} P_{2}$ & 0.88 & 0.99 & 3.3 & & \\
\hline 694.13 & Na IX & $1 s^{2} 2 s^{2} S_{1 / 2}$ & $-1 s^{2} 2 p^{2} P_{1 / 2}$ & 3.5 & 2.6 & 18.4 & & \\
\hline 694.69 & Si IX & $2 \mathrm{~s}^{2} 2 \mathrm{p}^{2}{ }^{3} \mathrm{P}_{2}$ & $-2 \mathrm{~s} 2 \mathrm{p}^{3}{ }^{5} \mathrm{~S}_{2}$ & 4.1 & 1.5 & 6.7 & & \\
\hline 695.06 & (c) & & & 0.33 & 0.34 & 0.81 & & \\
\hline$[697.17$ & Fe VIII & $3 p^{6} 4 p^{2} P_{1 / 2}$ & $-3 p^{6} 4 d^{2} D_{3 / 2}$ & 0.24 & 0.62 & & & \\
\hline 697.40 & ArIX & $2 s^{2} 2 p^{5} 3 s^{3} P_{2}$ & $-2 s^{2} 2 p^{5} 3 p^{3} D_{3}$ & 0.051 & & $0.031 \#$ & & \\
\hline 700.24 & Ar VIII & $2 p^{6} 3 s^{2} S_{1 / 2}$ & $-2 p^{6} 3 p^{2} P_{3 / 2}$ & 1.0 & 0.87 & 1.3 & & \\
\hline 701.00 & & & & & & 0.13 & & \\
\hline 703.64 & Al IX & $2 s^{2} 2 p^{2} P_{3 / 2}$ & $-2 \mathrm{~s} 2 \mathrm{p}^{2}{ }^{4} \mathrm{P}_{3 / 2}$ & 0.34 & 0.20 & 0.63 & & \\
\hline 706.04 & Mg IX & $1 s^{2} 2 s^{2}{ }^{1} S_{0}$ & $-1 s^{2} 2 s 2 p{ }^{3} P_{1}$ & 10.2 & 9.2 & 21.5 & & \\
\hline 706.46 & S VI & $2 p^{6} 3 p^{2} P_{1 / 2}$ & $-2 p^{6} 3 d^{2} D_{3 / 2}$ & 0.044 & & & & $F$ in $\mathrm{CH}$ \\
\hline 706.80 & (c) & & & 0.033 & & 0.087 & & \\
\hline 707.65 & (c) & & & 0.058 & & 0.12 & & \\
\hline 708.49 & (c) & & & 0.053 & & & & \\
\hline 708.89 & S IX & $2 s^{2} 2 p^{3} 3 p^{5} P_{2}$ & $-2 s^{2} 2 p^{3} 3 d^{5} D_{3}$ & 0.12 & & 0.15 & & \\
\hline 709.81 & & & & & & 0.12 & & \\
\hline
\end{tabular}


W. Curdt et al.: Coronal EUV atlas, Online Material $p 5$

Table 3. continued.

\begin{tabular}{|c|c|c|c|c|c|c|c|c|}
\hline \multirow{2}{*}{$\begin{array}{r}\lambda_{\mathrm{obs}} \\
\AA \\
\end{array}$} & \multirow[t]{2}{*}{ Line } & \multicolumn{2}{|c|}{ Transition } & QS & $\mathrm{CH}$ & $\mathrm{AR}$ & Flare & Notes \\
\hline & & & & \multicolumn{5}{|c|}{ line radiance $L /$ phot $\mathrm{cm}^{-2} \mathrm{~s}^{-1} \operatorname{arcsec}^{-2}$} \\
\hline 711.39 & & & & $0.038 \#$ & & & & \\
\hline 712.22 & Al IX & $2 s^{2} 2 p^{2} P_{3 / 2}$ & $-2 \mathrm{~s} 2 \mathrm{p}^{2}{ }^{4} \mathrm{P}_{1 / 2}$ & 0.051 & 0.17 & & & \\
\hline 712.22 & S IX & $2 s^{2} 2 p^{3} 3 p^{3} D_{2}$ & $-2 s^{2} 2 p^{3} 3 d^{3} F_{3}$ & & & & & \\
\hline 712.67 & S VI & $2 p^{6} 3 p^{2} \mathrm{P}_{3 / 2}$ & $-2 p^{6} 3 d^{2} D_{5 / 2}$ & & 0.12 & & & $F$ in $\mathrm{QS}, \mathrm{AR}$ \\
\hline 713.49 & & & & & & 0.20 & & \\
\hline 713.82 & Ar VIII & $2 p^{6} 2 p^{6} 3 s^{2} S_{1 /}$ & ${ }^{2}-2 p^{6} 2 p^{6} 3 p^{2} P_{1 / 2}$ & 0.45 & 0.51 & 0.85 & & \\
\hline 714.79 & S IX & $2 s^{2} 2 p^{3} 3 p{ }^{5} P_{3}$ & $-2 s^{2} 2 p^{3} 3 d^{5} D_{4}$ & 0.17 & & 0.19 & & \\
\hline 715.12 & S IX & $2 s^{2} 2 p^{3} 3 p^{3} F_{3}$ & $-2 s^{2} 2 p^{3} 3 d^{3} G_{4}$ & 0.059 & & & & \\
\hline 717.05 & & & & $0.12 \#$ & & & & \\
\hline 717.85 & Ar XI & $2 s^{2} 2 p^{3} 3 s^{5} S_{2}$ & $-2 s^{2} 2 p^{3} 3 p^{5} P_{3}$ & 0.12 & 0.12 & 0.22 & $\mathrm{x}$ & \\
\hline 718.29 & (e) & & & 0.33 & 0.11 & 0.42 & & \\
\hline 719.40 & S IX & $2 s^{2} 2 p^{3} 3 p^{3} F_{4}$ & $-2 s^{2} 2 p^{3} 3 d^{3} G_{5}$ & 0.079 & 0.045 & 0.17 & & \\
\hline 721.26 & Fe VIII & $3 p^{6} 4 p{ }^{4} P_{3 / 2}$ & $-3 p^{6} 4 d^{2} D_{5 / 2}$ & 0.37 & 1.2 & 1.1 & & \\
\hline 721.55 & Fexx & $2 s^{2} 2 p^{3}{ }^{4} S_{3 / 2}$ & $-2 \mathrm{~s}^{2} 2 \mathrm{p}^{3}{ }^{2} \mathrm{D}_{3 / 2}$ & & & & 8140 & \\
\hline 723.75 & Fe VIII & $3 p^{6} 4 p^{2} P_{3 / 2}$ & $-3 p^{6} 4 d^{2} D_{3 / 2}$ & 0.077 & 0.12 & 0.15 & & \\
\hline 724.69 & $\mathrm{ClXI}$ & $2 s^{2} 2 p^{3}{ }^{4} S_{3 / 2}$ & $-2 \mathrm{~s}^{2} 2 \mathrm{p}^{3}{ }^{2} \mathrm{P}_{1 / 2}$ & & & 0.30 & & \\
\hline 725.84 & ArIX & $2 s^{2} 2 p^{5} 3 s^{3} P_{1}$ & $-2 s^{2} 2 p^{5} 3 p^{3} D_{2}$ & $0.077 \#$ & & 0.053 & & \\
\hline 730.41 & ArXI & $2 s^{2} 2 p^{3} 3 s^{5} S_{2}$ & $-2 s^{2} 2 p^{3} 3 p^{5} \mathrm{P}_{2}$ & 0.037 & & 0.14 & & $F$ in $\mathrm{CH}$ \\
\hline 732.20 & & & & & & 0.12 & & \\
\hline 732.68 & (d) & & & 0.098\# & & 0.073 & & \\
\hline 733.83 & (f) & & & 0.063 & & $0.051 \#$ & & \\
\hline 735.11 & & & & & & 0.054\# & & \\
\hline 735.26 & (c) & & & 0.024 & & & & \\
\hline 736.18 & & & & & & 0.11 & & \\
\hline 736.42 & Ar XI & $2 s^{2} 2 p^{3} 3 s^{5} S_{2}$ & $-2 s^{2} 2 p^{3} 3 p^{5} P_{1}$ & 0.081 & & 0.28 & & $F$ in $\mathrm{CH}$ \\
\hline 737.61 & & & & 0.016 & & & & \\
\hline 738.87 & Fe VII & $3 p^{6} 3 d 4 p{ }^{3} P_{2}$ & $-3 p^{6} 3 d 4 d{ }^{3} P_{2}$ & & & $0.15 \#$ & & $F$ in $\mathrm{CH}$ \\
\hline 740.04 & Fe VII & $3 p^{6} 3 d 4 p{ }^{1} F_{3}$ & $-3 p^{6} 3 d 4 d^{1} G_{4}$ & 0.057 & 0.11 & & & \\
\hline 740.74 & Cr XVII & $2 \mathrm{~s}^{2} 2 \mathrm{p}^{4}{ }^{3} \mathrm{P}_{2}$ & $-2 \mathrm{~s}^{2} 2 \mathrm{p}^{4}{ }^{1} \mathrm{D}_{2}$ & & & 0.39 & 20.1 & \\
\hline 741.67 & & & & 0.020 & 0.097 & & & \\
\hline 743.98 & & & & & & 0.13 & & \\
\hline 745.49 & Fe VII & $3 p^{6} 3 d 4 p^{3} F_{2}$ & $-3 p^{6} 3 d 4 d^{3} F_{2}$ & 0.031 & & 0.22 & & \\
\hline 745.80 & Ar XI & $2 \mathrm{~s}^{2} 2 \mathrm{p}^{4}{ }^{3} \mathrm{P}_{1}$ & $-2 \mathrm{~s}^{2} 2 \mathrm{p}^{4}{ }^{1} \mathrm{~S}_{0}$ & 0.047 & & 0.20 & & \\
\hline 749.56 & Mg IX & $1 s^{2} 2 s 2 p^{1} P_{1}$ & $-1 \mathrm{~s}^{2} 2 \mathrm{p}^{2}{ }^{1} \mathrm{D}_{2}$ & 1.6 & 1.6 & 4.4 & & \\
\hline 752.51 & Fe VIII & $3 \mathrm{p}^{5} 3 \mathrm{~d}^{2}{ }^{2} \mathrm{P}_{1 / 2}$ & $-3 p^{6} 4 d^{2} D_{3 / 2}$ & 0.011 & 0.036 & & & \\
\hline 754.98 & Ar VI? & $3 s^{2} 3 p^{2} \mathrm{P}_{3 / 2}$ & $-3 \mathrm{~s} 3 \mathrm{p}^{2}{ }^{2} \mathrm{D}_{3 / 2}$ & 0.020 & & & & \\
\hline 755.40 & (d) & & & 0.025 & & & & \\
\hline 756.72 & Al VIII & $2 \mathrm{~s}^{2} 2 \mathrm{p}^{2}{ }^{3} \mathrm{P}_{1}$ & $-2 \mathrm{~s} 2 \mathrm{p}^{3}{ }^{5} \mathrm{~S}_{2}$ & 0.052 & 0.11 & 0.17 & & \\
\hline 758.59 & Mn XIX & $2 s^{2} 2 p^{3}{ }^{4} S_{3 / 2}$ & $-2 s^{2} 2 p^{3}{ }^{2} D_{3 / 2}$ & & & & 32.8 & \\
\hline 762.65 & Mg VIII & $2 s^{2} 2 p^{2} \mathrm{P}_{1 / 2}$ & $-2 \mathrm{~s} 2 \mathrm{p}^{2}{ }^{4} \mathrm{P}_{3 / 2}$ & 0.099 & 0.33 & 0.35 & & \\
\hline 769.38 & Mg VIII & $2 s^{2} 2 p^{2} P_{1 / 2}$ & $-2 \mathrm{~s} 2 \mathrm{p}^{2}{ }^{4} \mathrm{P}_{1 / 2}$ & 0.24 & 0.97 & 0.97 & & \\
\hline 770.42 & Ne VIII & $1 \mathrm{~s}^{2} 2 \mathrm{~s}^{2} \mathrm{~S}_{1 / 2}$ & $-1 s^{2} 2 p^{2} P_{3 / 2}$ & 39.5 & 41.4 & 177.9 & & \\
\hline 772.29 & Mg VIII & $2 \mathrm{~s}^{2} 2 \mathrm{p}^{2} \mathrm{P}_{3 / 2}$ & $-2 \mathrm{~s} 2 \mathrm{p}^{2}{ }^{4} \mathrm{P}_{5 / 2}$ & 1.3 & 4.1 & 4.8 & & \\
\hline 772.53 & Al VIII & $2 s^{2} 2 p^{2}{ }^{3} \mathrm{P}_{2}$ & $-2 \mathrm{~s} 2 \mathrm{p}^{3}{ }^{5} \mathrm{~S}_{2}$ & 0.11 & 0.45 & 0.72 & & \\
\hline 776.25 & $\mathrm{Sx}$ & $2 s^{2} 2 p^{3}{ }^{4} S_{3 / 2}$ & $-2 \mathrm{~s}^{2} 2 \mathrm{p}^{3}{ }^{2} \mathrm{P}_{3 / 2}$ & 2.3 & 0.14 & 4.1 & & I in $\mathrm{CH}$ \\
\hline
\end{tabular}


W. Curdt et al.: Coronal EUV atlas, Online Material $p 6$

Table 3. continued.

\begin{tabular}{|c|c|c|c|c|c|c|c|c|}
\hline \multirow{2}{*}{$\begin{array}{r}\lambda_{\mathrm{obs}} \\
\AA\end{array}$} & \multirow[t]{2}{*}{ Line } & \multicolumn{2}{|c|}{ Transition } & QS & $\mathrm{CH}$ & AR & Flare & Notes \\
\hline & & & & \multicolumn{5}{|c|}{ line radiance $L /$ phot $\mathrm{cm}^{-2} \mathrm{~s}^{-1} \operatorname{arcsec}^{-2}$} \\
\hline 777.18 & (e) & & & 0.11 & & 0.26 & & \\
\hline 778.38 & & & & 0.11 & & & & \\
\hline 779.45 & Ni XXI & $2 s^{2} 2 p^{4}{ }^{3} P_{2}$ & $-2 \mathrm{~s}^{2} 2 \mathrm{p}^{4}{ }^{3} \mathrm{P}_{1}$ & & & & 152 & \\
\hline 780.34 & $\mathrm{Ne}$ VIII & $1 s^{2} 2 s^{2} S_{1 / 2}$ & $-1 \mathrm{~s}^{2} 2 \mathrm{p}^{2} \mathrm{P}_{1 / 2}$ & 33.1 & 29.7 & 113.9 & & \\
\hline 782.37 & Mg VIII & $2 s^{2} 2 p^{2} P_{3 / 2}$ & $-2 \mathrm{~s} 2 \mathrm{p}^{2}{ }^{4} \mathrm{P}_{3 / 2}$ & 1.2 & 3.9 & 3.3 & & \\
\hline 782.98 & S XI & $2 s^{2} 2 p^{2}{ }^{3} P_{1}$ & $-2 s^{2} 2 p^{2}{ }^{1} S_{0}$ & 1.0 & & 2.4 & & \\
\hline 786.03 & Fe XXI & $2 \mathrm{~s}^{2} 2 \mathrm{p}^{2}{ }^{3} \mathrm{P}_{2}$ & $-2 \mathrm{~s}^{2} 2 \mathrm{p}^{2}{ }^{1} \mathrm{D}_{2}$ & & & & 1040 & \\
\hline 787.43 & $\mathrm{Sx}$ & $2 s^{2} 2 p^{3} S_{3 / 2}$ & $-2 \mathrm{~s}^{2} 2 \mathrm{p}^{3}{ }^{2} \mathrm{P}_{1 / 2}$ & 1.5 & & 2.4 & & \\
\hline 789.44 & Mg VIII & $2 s^{2} 2 p^{2} \mathrm{P}_{3 / 2}$ & $-2 \mathrm{~s} 2 \mathrm{p}^{2}{ }^{4} \mathrm{P}_{1 / 2}$ & 0.27 & 0.95 & 1.2 & & \\
\hline 789.78 & Na VIII & $2 \mathrm{~s}^{2}{ }^{1} \mathrm{~S}_{0}$ & $-2 \mathrm{~s} 2 \mathrm{p}^{3} \mathrm{P}_{1}$ & 0.17 & 0.77 & 1.3 & & \\
\hline 792.79 & Fe VII & $3 p^{6} 3 d 4 p{ }^{3} F_{2}$ & $-3 p^{6} 3 d 4 d^{3} G_{3}$ & & 0.038 & & & \\
\hline 793.18 & Cr XVIII & $2 s^{2} 2 p^{3}{ }^{4} S_{3 / 2}$ & $-2 \mathrm{~s}^{2} 2 \mathrm{p}^{3}{ }^{2} \mathrm{D}_{3 / 2}$ & & & 0.071 & 6.2 & \\
\hline 794.61 & Ni XIX & $2 s^{2} 2 p^{5} 3 s^{3} P_{1}$ & $-2 s^{2} 2 p^{5} 3 s^{3} P_{0}$ & & & 0.13 & 11.5 & \\
\hline 794.94 & & & & & & 0.11 & & \\
\hline 797.90 & (f) & & & 0.72 & 0.065 & 1.0 & & $I$ in $\mathrm{CH}$ \\
\hline 799.10 & Fe VII & $3 p^{6} 3 d 4 p{ }^{3} D_{3}$ & $-3 p^{6} 3 d 4 d^{3} D_{3}$ & & 0.066 & & & \\
\hline 800.64 & $\mathrm{Cl}$ VII & $2 \mathrm{p}^{6} 3 \mathrm{~s}{ }^{2} \mathrm{~S}_{1 / 2}$ & $-2 p^{6} 3 p^{2} P_{3 / 2}$ & & 0.10 & & & \\
\hline 801.69 & Fe VII & $3 p^{6} 3 d 4 p{ }^{3} F_{3}$ & $-3 p^{6} 3 d 4 d^{3} G_{3}$ & & 0.050 & & & \\
\hline$[803.23$ & & & & & 0.060 & & & \\
\hline 803.46 & (e) & & & 1.3 & 0.45 & 2.1 & & \\
\hline [804.16 & S X & $2 \mathrm{~s}^{2} 2 \mathrm{p}^{2} 3 \mathrm{~s}^{4} \mathrm{D}_{7}$ & ${ }_{2}-2 s^{2} 2 p^{2} 3 p{ }^{4} F_{9 / 2}$ & 0.21 & 0.093 & 0.45 & & \\
\hline 804.16 & Fe VII & $3 p^{6} 3 d 4 p^{3} F_{4}$ & $-3 p^{6} 3 d 4 d^{3} G_{4}$ & & & & & \\
\hline 804.42 & (d) & & & 0.18 & 0.25 & 0.48 & & \\
\hline 805.63 & S VIII & $2 s^{2} 2 p^{4} 3 s^{2} D_{5}$ & ${ }_{2}-2 s^{2} 2 p^{4} 3 p^{2} D_{5 / 2}$ & 0.044 & 0.073 & & & \\
\hline 806.92 & (e) & & & 0.036 & & & & $F$ in $\mathrm{CH}, \mathrm{AR}$ \\
\hline$[812.95$ & $\mathrm{Cl}$ VII & $2 p^{6} 3 s^{2} S_{1 / 2}$ & $-2 p^{6} 3 p^{2} P_{1 / 2}$ & 0.033 & 0.064 & & & $F$ in $\mathrm{CH}, \mathrm{AR}$ \\
\hline 812.95 & S VIII & $2 s^{2} 2 p^{4} 3 s^{2} D_{3}$ & ${ }_{2}-2 s^{2} 2 p^{4} 3 p^{2} D_{3 / 2}$ & & & & & $F$ in $\mathrm{CH}, \mathrm{AR}$ \\
\hline 814.52 & Ar IX & $2 s^{2} 2 p^{5} 3 s^{3} P_{2}$ & $-2 s^{2} 2 p^{5} 3 p^{3} S_{1}$ & 0.054 & & & & $F$ in $\mathrm{AR}$ \\
\hline 814.72 & Si XIII & $1 \mathrm{~s} 2 \mathrm{~s}{ }^{3} \mathrm{~S}_{1}$ & $-1 \mathrm{~s} 2 \mathrm{p}^{3} \mathrm{P}_{2}$ & & & & 112 & \\
\hline 815.21 & & & & 0.012 & & & & $F$ in $\mathrm{CH}, \mathrm{AR}$ \\
\hline 818.97 & & & & 0.046 & & & & \\
\hline 820.02 & Co XIX & $2 \mathrm{~s}^{2} 2 \mathrm{p}^{5}{ }^{2} \mathrm{P}_{3 / 2}$ & $-2 \mathrm{~s}^{2} 2 \mathrm{p}^{5}{ }^{2} \mathrm{P}_{1 / 2}$ & & & & 3.8 & \\
\hline 821.22 & Ca IX & $3 \mathrm{~s} 3 \mathrm{p}{ }^{1} \mathrm{P}_{1}$ & $-3 \mathrm{p}^{2}{ }^{1} \mathrm{D}_{2}$ & 0.10 & 0.36 & 0.39 & & \\
\hline 821.71 & Fe $x x$ & $2 \mathrm{~s}^{2} 2 \mathrm{p}^{3}{ }^{2} \mathrm{D}_{3 / 2}$ & $-2 \mathrm{~s}^{2} 2 \mathrm{p}^{3}{ }^{2} \mathrm{P}_{1 / 2}$ & & & & 205 & \\
\hline 830.15 & (d) & & & 0.15 & & & & $F$ in $\mathrm{CH}, I$ in $\mathrm{AR}$ \\
\hline 830.47 & & & & 0.064 & & & & \\
\hline 839.17 & S XI & $2 \mathrm{~s}^{2} 2 \mathrm{p}^{2}{ }^{1} \mathrm{D}_{2}$ & $-2 s 2 p^{3}{ }^{5} S_{2}$ & 0.093 & & & & \\
\hline 839.63 & & & & 0.034 & & & & \\
\hline 843.62 & & & & & & 0.41 & & \\
\hline 844.00 & & & & 0.025 & & 0.72 & & \\
\hline 845.57 & Fe XXII & $2 s^{2} 2 p^{2} \mathrm{P}_{1 / 2}$ & $-2 \mathrm{~s}^{2} 2 \mathrm{p}^{2} \mathrm{P}_{3 / 2}$ & & & & 14000 & \\
\hline 847.66 & S VIII & $2 s^{2} 2 p^{4} 3 s^{4} P_{3 /}$ & ${ }_{2}-2 s^{2} 2 p^{4} 3 p^{4} D_{3 / 2}$ & 0.055 & & & & $F$ in $\mathrm{CH}$ \\
\hline 847.91 & Na VIII & $2 \mathrm{~s} 2 \mathrm{p}{ }^{1} \mathrm{P}_{1}$ & $-2 \mathrm{p}^{2}{ }^{1} \mathrm{D}_{2}$ & 0.053 & 0.16 & & & $F$ in $\mathrm{AR}$ \\
\hline 849.90 & S VIII & $2 s^{2} 2 p^{4} 3 s^{4} P_{5 /}$ & ${ }_{2}-2 s^{2} 2 p^{4} 3 p^{4} D_{7 / 2}$ & 0.18 & 0.13 & & & $F$ in $\mathrm{AR}$ \\
\hline 851.49 & & & & 0.12 & & & & $F$ in $\mathrm{AR}$ \\
\hline 852.85 & & & & 0.044 & & & & $F$ in AR \\
\hline
\end{tabular}


W. Curdt et al.: Coronal EUV atlas, Online Material $p 7$

Table 3. continued.

\begin{tabular}{|c|c|c|c|c|c|c|c|c|}
\hline \multirow{2}{*}{$\begin{array}{r}\lambda_{\mathrm{obs}} \\
\AA\end{array}$} & \multirow[t]{2}{*}{ Line } & \multirow{2}{*}{\multicolumn{2}{|c|}{ Transition }} & \multirow{2}{*}{\multicolumn{4}{|c|}{$\begin{array}{cccc}\text { QS } & \mathrm{CH} & \mathrm{AR} & \text { Flare } \\
\text { line radiance } L / \text { phot }^{-2} \mathrm{~cm}^{-2} \mathrm{~s}^{-1} \operatorname{arcsec}^{-2}\end{array}$}} & \multirow[t]{2}{*}{ Notes } \\
\hline & & & & & & & & \\
\hline 853.51 & PIX & $2 s^{2} 2 p^{3}{ }^{4} S_{3 / 2}$ & $-2 s^{2} 2 p^{32} P_{3 / 2}$ & 0.069 & & & & $F$ in $\mathrm{CH}, \mathrm{AR}$ \\
\hline 854.64 & Mg VII & $2 \mathrm{~s}^{2} 2 \mathrm{p}^{2}{ }^{3} \mathrm{P}_{1}$ & $-2 \mathrm{~s} 2 \mathrm{p}^{3}{ }^{5} \mathrm{~S}_{2}$ & 0.14 & 0.98 & 0.86 & & \\
\hline 855.96 & & & & 0.025 & & & & \\
\hline 856.77 & (f) & & & 1.6 & & 4.1 & & $F$ in $\mathrm{CH}$ \\
\hline 859.96 & S VII & $2 s^{2} 2 p^{5} 3 s^{3} P_{1}$ & $-2 s^{2} 2 p^{5} 3 p^{3} P_{2}$ & 0.034 & & & & $F$ in $\mathrm{AR}$ \\
\hline 860.68 & & & & 0.0086 & & & & \\
\hline 861.09 & PIX & $2 s^{2} 2 p^{3}{ }^{4} S_{3 / 2}$ & $-2 \mathrm{~s}^{2} 2 \mathrm{p}^{3}{ }^{2} \mathrm{P}_{1 / 2}$ & 0.021 & & & & \\
\hline 861.78 & Ti XVI & $2 s^{2} 2 p^{3}{ }^{4} S_{3 / 2}$ & $-2 s^{2} 2 p^{3}{ }^{2} D_{3 / 2}$ & & & & 15.0 & \\
\hline 862.73 & (d) & & & 0.085 & 0.14 & & & $F$ in $\mathrm{AR}$ \\
\hline 864.75 & & & & 0.017 & & & & \\
\hline 867.60 & (g) & & & 0.12 & & & & $F$ in $\mathrm{AR}$ \\
\hline 868.08 & Mg VII & $2 \mathrm{~s}^{2} 2 \mathrm{p}^{2}{ }^{3} \mathrm{P}_{2}$ & $-2 \mathrm{~s} 2 \mathrm{p}^{3}{ }^{5} \mathrm{~S}_{2}$ & 0.25 & 0.20 & 1.9 & & \\
\hline 868.55 & (g) & & & 0.15 & & & & \\
\hline 869.01 & (e) & & & 0.014 & & & & $F$ in AR \\
\hline 871.71 & S IX & $2 \mathrm{~s}^{2} 2 \mathrm{p}^{4}{ }^{3} \mathrm{P}_{1}$ & $-2 s^{2} 2 p^{4}{ }^{1} S_{0}$ & 0.67 & 0.34 & 0.88 & & \\
\hline 871.71 & S VIII & $2 s^{2} 2 p^{4} 3 s^{4} P_{3 / 2}$ & ${ }^{2}-2 s^{2} 2 p^{4} 3 p{ }^{2} D_{5 / 2}$ & & & & & \\
\hline 872.06 & Na VII & $2 s^{2} 2 p^{2} P_{3 / 2}$ & $-2 \mathrm{~s} 2 \mathrm{p}^{2}{ }^{4} \mathrm{P}_{5 / 2}$ & 0.022 & 0.12 & & & $I$ in $\mathrm{AR}$ \\
\hline 873.33 & (d) & & & 0.052 & & & & \\
\hline 874.40 & S VIII & $2 s^{2} 2 p^{4} 3 s^{4} P_{1 / 2}$ & ${ }^{2}-2 s^{2} 2 p^{4} 3 p{ }^{4} D_{3 / 2}$ & 0.068 & & & & \\
\hline 877.08 & S VII & $2 s^{2} 2 p^{5} 3 s^{3} P_{0}$ & $-2 s^{2} 2 p^{5} 3 p{ }^{1} P_{1}$ & 0.049 & & & & \\
\hline$[878.69$ & Si XIII & $1 \mathrm{~s} 2 \mathrm{~s}{ }^{3} \mathrm{~S}_{1}$ & $-1 \mathrm{~s} 2 \mathrm{p}^{3} \mathrm{P}_{0}$ & & & & 22.1 & \\
\hline 878.77 & S IX & $2 s^{2} 2 p^{3} 3 s^{3} D_{3}$ & $-2 s^{2} 2 p^{3} 3 p^{3} F_{4}$ & 0.19 & & & & $F$ in $\mathrm{CH}, \mathrm{AR}$ \\
\hline 879.10 & & & & 0.064 & & & & $F$ in $\mathrm{CH}$ \\
\hline 879.73 & & & & 0.018 & & & & \\
\hline 880.34 & $\mathrm{Na} \mathrm{VII}_{\mathrm{II}}$ & $2 s^{2} 2 p^{2} \mathrm{P}_{3 / 2}$ & $-2 \mathrm{~s} 2 \mathrm{p}^{2}{ }^{4} \mathrm{P}_{3 / 2}$ & & & & & \\
\hline 880.40 & Ca XIV & $2 s^{2} 2 p^{3}{ }^{4} S_{3 / 2}$ & $-2 \mathrm{~s}^{2} 2 \mathrm{p}^{3}{ }^{2} \mathrm{D}_{5 / 2}$ & & & 6.1 & 86.0 & $F$ in $\mathrm{CH}$ \\
\hline 882.45 & & & & 0.037 & & & & \\
\hline 882.68 & S IX & $2 s^{2} 2 p^{3} 3 s^{3} D_{2}$ & $-2 s^{2} 2 p^{3} 3 p^{3} F_{3}$ & 0.52 & & & & $I$ in $\mathrm{AR}$ \\
\hline 882.68 & S IX & $2 s^{2} 2 p^{3} 3 s{ }^{5} S_{2}$ & $-2 s^{2} 2 p^{3} 3 p{ }^{5} \mathrm{P}_{3}$ & & & & & \\
\hline 882.89 & & & & & 0.068 & & & \\
\hline 883.30 & & & & 0.18 & & & & \\
\hline 883.63 & (c) & & & 0.10 & 0.14 & & & $F$ in AR \\
\hline 886.23 & (c) & & & & 0.086 & & & $F$ in $\mathrm{QS}, \mathrm{AR}$ \\
\hline 887.24 & $\mathrm{Ne}$ VII & $2 \mathrm{~s}^{2}{ }^{1} \mathrm{~S}_{0}$ & $-2 \mathrm{~s} 2 \mathrm{p}{ }^{3} \mathrm{P}_{2}$ & & 0.061 & & & \\
\hline 887.74 & S VII & $2 s^{2} 2 p^{5} 3 s^{3} P_{2}$ & $-2 s^{2} 2 p^{5} 3 p^{3} D_{2}$ & 0.041 & & & & $F$ in $\mathrm{CH}, \mathrm{AR}$ \\
\hline 889.13 & S IX & $2 s^{2} 2 p^{3} 3 s^{3} D_{1}$ & $-2 s^{2} 2 p^{3} 3 p^{3} F_{2}$ & 0.026 & & & & $F$ in $\mathrm{CH}$ \\
\hline 890.03 & (c) & & & 0.032 & & & & \\
\hline 892.27 & S IX & $2 s^{2} 2 p^{3} 3 s^{5} S_{2}$ & $-2 s^{2} 2 p^{3} 3 p{ }^{5} P_{2}$ & 0.22 & & & & $F$ in $\mathrm{CH}$ \\
\hline 892.66 & & & & 0.034 & & & & \\
\hline 894.33 & S VII & $2 s^{2} 2 p^{5} 3 s^{3} P_{1}$ & $-2 s^{2} 2 p^{5} 3 p^{3} D_{1}$ & 0.016 & & & & $F$ in $\mathrm{CH}, \mathrm{AR}$ \\
\hline 895.16 & $\mathrm{Ne}$ VII & $2 \mathrm{~s}^{2}{ }^{1} \mathrm{~S}_{0}$ & $-2 s 2 p{ }^{3} P_{1}$ & 3.9 & 1.2 & 2.2 & & \\
\hline 897.35 & S IX & $2 s^{2} 2 p^{3} 3 s^{5} S_{2}$ & $-2 s^{2} 2 p^{3} 3 p^{5} \mathrm{P}_{1}$ & 0.13 & & & & $F$ in $\mathrm{CH}, \mathrm{AR}$ \\
\hline 897.81 & S VII & $2 s^{2} 2 p^{5} 3 s^{3} P_{2}$ & $-2 s^{2} 2 p^{5} 3 p^{3} D_{3}$ & 0.046 & & & & $F$ in $\mathrm{AR}$ \\
\hline 900.77 & (d) & & & 0.068 & & & & $F$ in $\mathrm{CH}, \mathrm{AR}$ \\
\hline 901.88 & & & & 0.069 & & & & \\
\hline 902.99 & S VII & $2 s^{2} 2 p^{5} 3 s^{1} P_{1}$ & $-2 s^{2} 2 p^{5} 3 p{ }^{1} D_{2}$ & 0.13 & & & & \\
\hline
\end{tabular}


W. Curdt et al.: Coronal EUV atlas, Online Material $p 8$

Table 3. continued.

\begin{tabular}{|c|c|c|c|c|c|c|c|}
\hline \multirow{2}{*}{$\begin{array}{r}\lambda_{\mathrm{obs}} \\
\AA \\
\end{array}$} & \multirow[t]{2}{*}{ Line } & \multirow[t]{2}{*}{ Transition } & QS & $\mathrm{CH}$ & $\mathrm{AR}$ & Flare & Notes \\
\hline & & & \multicolumn{5}{|c|}{ line radiance $L /$ phot $\mathrm{cm}^{-2} \mathrm{~s}^{-1} \operatorname{arcsec}^{-2}$} \\
\hline 904.93 & S VII & $2 s^{2} 2 p^{5} 3 p{ }^{5} P_{2}-2 s^{2} 2 p^{5} 3 d^{5} D_{3,2}$ & 0.078 & 0.15 & & & $F$ in AR \\
\hline 905.68 & S VIII & $2 s^{2} 2 p^{4} 3 s^{2} D_{5 / 2}-2 s^{2} 2 p^{4} 3 p^{2} F_{7 / 2}$ & 0.10 & & & & $F$ in $\mathrm{CH}, \mathrm{AR}$ \\
\hline$[908.89$ & S IX & $2 s^{2} 2 p^{3} 3 s^{3} S_{1}-2 s^{2} 2 p^{3} 3 p^{3} P_{2}$ & 0.10 & & & & $F$ in $\mathrm{AR}$ \\
\hline 909.11 & & & 0.030 & & & & \\
\hline 909.41 & Si VII & $2 s^{2} 2 p^{3} 3 p{ }^{5} P_{3}-2 s^{2} 2 p^{3} 3 d^{5} D_{4,5}$ & 0.071 & 0.24 & 0.31 & & \\
\hline 910.86 & Ni XXIII & $2 \mathrm{~s}^{2} 2 \mathrm{p}^{2}{ }^{3} \mathrm{P}_{0} \quad-2 \mathrm{~s}^{2} 2 \mathrm{p}^{2}{ }^{3} \mathrm{P}_{1}$ & & & & 722 & \\
\hline 911.88 & S IX & $2 s^{2} 2 p^{3} 3 s^{3} S_{1} \quad-2 s^{2} 2 p^{3} 3 p{ }^{3} P_{1}$ & 0.090 & & & & $I$ in $\mathrm{AR}$ \\
\hline 914.03 & & & 0.079 & & & & \\
\hline 915.07 & & & 0.038 & & & & \\
\hline 916.70 & S VIII & $2 s^{2} 2 p^{4} 3 s^{3} P_{3 / 2}-2 s^{2} 2 p^{4} 3 p^{2} D_{5 / 2}$ & 0.16 & 0.16 & & & $F$ in QS \\
\hline 918.80 & Si VII & $2 s^{2} 2 p^{3} 3 p^{3} F_{4}-2 s^{2} 2 p^{3} 3 d^{3} G_{5}$ & 0.060 & 0.059 & 0.077 & & \\
\hline$[919.73$ & Tixv & $2 \mathrm{~s}^{2} 2 \mathrm{p}^{4}{ }^{3} \mathrm{P}_{2} \quad-2 \mathrm{~s}^{2} 2 \mathrm{p}^{4}{ }^{1} \mathrm{D}_{2}$ & & & 0.21 & 8.3 & \\
\hline 919.83 & S VIII & $2 s^{2} 2 p^{4} 3 s^{2} D_{3 / 2}-2 s^{2} 2 p^{4} 3 p^{2} F_{5 / 2}$ & 0.066 & 0.034 & & & \\
\hline 920.68 & & & 0.048 & & 0.067 & & \\
\hline 921.56 & (c) & & 0.0084 & & & & \\
\hline 922.27 & (c) & & 0.065 & 0.11 & 0.058 & & \\
\hline 924.93 & & & 0.044 & & & & \\
\hline 926.91 & (f) & & 0.037 & & & & \\
\hline 931.78 & Si VII & $2 s^{2} 2 p^{3} 3 p^{1} F_{3}-2 s^{2} 2 p^{3} 3 d^{1} G_{4}$ & & 0.048 & & & \\
\hline 932.16 & & & 0.040 & & & & \\
\hline 932.95 & & & 0.035 & & & & \\
\hline 933.41 & S VI & $2 p^{6} 3 s^{2} S_{1 / 2} \quad-2 p^{6} 3 p^{2} P_{3 / 2}$ & & 1.0 & 2.0 & & \\
\hline 934.43 & (f) & & 0.040 & & 0.069 & & \\
\hline 934.72 & & & 0.0066 & 0.020 & 0.055 & & \\
\hline 935.28 & & & & & 0.025 & & $I$ in $\mathrm{QS}$ \\
\hline 935.94 & (d) & & 0.012 & 0.0093 & & & \\
\hline 938.70 & $\mathrm{Sx}$ & $2 s^{2} 2 p^{2} 3 s^{4} P_{1 / 2}-2 s^{2} 2 p^{2} 3 p^{4} D_{3 / 2}$ & 0.070 & & 0.16 & & \\
\hline 939.18 & (b) & & & & 0.056 & & $F$ in $\mathrm{CH}, \mathrm{QS}$ \\
\hline 940.13 & (e) & & 0.065 & & 0.10 & & $I$ in $\mathrm{CH}$ \\
\hline 940.87 & $\mathrm{Sx}$ & $2 s^{2} 2 p^{2} 3 s^{4} P_{3 / 2}-2 s^{2} 2 p^{2} 3 p^{4} D_{5 / 2}$ & 0.091 & & 0.095 & & \\
\hline 941.37 & S VII & $2 s^{2} 2 p^{5} 3 s^{3} P_{0} \quad-2 s^{2} 2 p^{5} 3 p^{3} D_{1}$ & 0.0053 & & & & \\
\hline 941.76 & & & 0.0036 & & & & \\
\hline 942.11 & & & & & 0.023 & & \\
\hline 943.63 & CaXIV & $2 s^{2} 2 p^{3}{ }^{4} S_{3 / 2} \quad-2 s^{2} 2 p^{3}{ }^{2} D_{3 / 2}$ & 0.024 & & 7.0 & 478.0 & \\
\hline$[944.35$ & Si VIII & $2 \mathrm{~s}^{2} 2 \mathrm{p}^{3}{ }^{4} \mathrm{~S}_{3 / 2} \quad-2 \mathrm{~s}^{2} 2 \mathrm{p}^{3}{ }^{2} \mathrm{P}_{3 / 2}$ & 4.9 & 7.7 & 11.3 & & \\
\hline 944.57 & S VI & $2 p^{6} 3 s^{2} S_{1 / 2} \quad-2 p^{6} 3 p^{2} P_{1 / 2}$ & & & & & \\
\hline 944.63 & S VIII & $2 s^{2} 2 p^{4} 3 s^{4} P_{5 / 2}-2 s^{2} 2 p^{4} 3 p{ }^{4} P_{3 / 2}$ & & & 0.96 & & \\
\hline 945.90 & K XIII & $2 \mathrm{~s}^{2} 2 \mathrm{p}^{3}{ }^{4} \mathrm{~S}_{3 / 2} \quad-2 \mathrm{~s}^{2} 2 \mathrm{p}^{3}{ }^{2} \mathrm{D}_{5 / 2}$ & & & 0.43 & 2.3 & \\
\hline 946.32 & $\mathrm{Sx}$ & $2 s^{2} 2 p^{2} 3 s^{4} P_{5 / 2}-2 s^{2} 2 p^{2} 3 p^{4} D_{7 / 2}$ & 0.46 & 0.036 & 0.54 & 56.8 & \\
\hline 949.24 & Si VIII & $2 \mathrm{~s}^{2} 2 \mathrm{p}^{3}{ }^{4} \mathrm{~S}_{3 / 2} \quad-2 \mathrm{~s}^{2} 2 \mathrm{p}^{3}{ }^{2} \mathrm{P}_{1 / 2}$ & 1.7 & 3.2 & 5.0 & & \\
\hline 950.16 & Si IX & $2 \mathrm{~s}^{2} 2 \mathrm{p}^{2}{ }^{3} \mathrm{P}_{1} \quad-2 \mathrm{~s}^{2} 2 \mathrm{p}^{2}{ }^{1} \mathrm{~S}_{0}$ & 2.6 & 1.3 & 5.2 & & \\
\hline 951.45 & & & 0.034 & & 0.049 & & \\
\hline 951.88 & S IX & $2 s^{2} 2 p^{3} 3 s^{3} D_{3}-2 s^{2} 2 p^{3} 3 p^{3} D_{3}$ & 0.076 & 0.016 & 0.11 & & \\
\hline 951.92 & P VIII & $2 \mathrm{~s}^{2} 2 \mathrm{p}^{4}{ }^{3} \mathrm{P}_{1} \quad-2 \mathrm{~s}^{2} 2 \mathrm{p}^{4}{ }^{1} \mathrm{~S}_{0}$ & & & & & \\
\hline 953.64 & (d) & & 0.024 & 0.040 & 0.073 & & \\
\hline 955.89 & (d) & & 0.033 & 0.049 & 0.094 & & \\
\hline 956.59 & & & 0.0051 & & 0.028 & & \\
\hline
\end{tabular}


W. Curdt et al.: Coronal EUV atlas, Online Material $p 9$

Table 3. continued.

\begin{tabular}{|c|c|c|c|c|c|c|c|}
\hline \multirow{2}{*}{$\begin{array}{r}\lambda_{\mathrm{obs}} \\
\AA\end{array}$} & \multirow[t]{2}{*}{ Line } & \multirow[t]{2}{*}{ Transition } & QS & $\mathrm{CH}$ & $\mathrm{AR}$ & Flare & Notes \\
\hline & & & \multicolumn{5}{|c|}{ line radiance $L /$ phot $\mathrm{cm}^{-2} \mathrm{~s}^{-1} \operatorname{arcsec}^{-2}$} \\
\hline 957.04 & (b) & & 0.020 & 0.014 & 0.071 & & \\
\hline 958.03 & & & 0.031 & & 0.035 & & \\
\hline 958.34 & S IX & $2 s^{2} 2 p^{3} 3 s^{1} D_{2}-2 s^{2} 2 p^{3} 3 p^{1} F_{3}$ & 0.074 & & 0.083 & & \\
\hline 959.53 & (d) & & 0.11 & 0.078 & 0.14 & & \\
\hline 960.08 & S VII & $2 s^{2} 2 p^{5} 3 s^{1} P_{1} \quad-2 s^{2} 2 p^{5} 3 p{ }^{3} P_{2}$ & & 0.015 & & & \\
\hline 960.62 & $\mathrm{Sx}$ & $2 s^{2} 2 p^{2} 3 s^{4} P_{1 / 2}-2 s^{2} 2 p^{2} 3 p{ }^{4} D_{1 / 2}$ & 0.023 & & 0.042 & & \\
\hline 961.44 & & & 0.0082 & & 0.019 & & \\
\hline 961.80 & S IX & $2 s^{2} 2 p^{3} 3 s^{3} D_{2}-2 s^{2} 2 p^{3} 3 p^{3} D_{2}$ & 0.030 & & 0.029 & & \\
\hline 963.94 & Si VII & $2 s^{2} 2 p^{3} 3 s^{3} F_{4}-2 s^{2} 2 p^{3} 3 p^{3} F_{4}$ & 0.0055 & & & & $I$ in $\mathrm{AR}$ \\
\hline 964.61 & (f) & & 0.050 & & 0.067 & & \\
\hline 965.20 & (d) & & 0.15 & 0.19 & 0.31 & & \\
\hline 965.64 & & & 0.021 & 0.018 & 0.045 & & \\
\hline 967.19 & Si VII & $2 s^{2} 2 p^{3} 3 p^{3} F_{3}-2 s^{2} 2 p^{3} 3 d^{3} F_{3}$ & & 0.0078 & & & \\
\hline 968.44 & Si VII & $2 s^{2} 2 p^{3} 3 s^{1} P_{1}-2 s^{2} 2 p^{3} 3 p^{1} D_{2}$ & 0.025 & 0.021 & 0.033 & & \\
\hline 968.44 & Si VII & $2 s^{2} 2 p^{3} 3 p^{3} F_{2}-2 s^{2} 2 p^{3} 3 d^{3} F_{2}$ & & & & & \\
\hline 968.84 & Ti XVI & $2 \mathrm{~s}^{2} 2 \mathrm{p}^{3}{ }^{2} \mathrm{D}_{3 / 2} \quad-2 \mathrm{~s}^{2} 2 \mathrm{p}^{3}{ }^{2} \mathrm{P}_{3 / 2}$ & & & 0.40 & 2.0 & \\
\hline 970.54 & (c) & & 0.020 & 0.018 & & & \\
\hline 973.33 & $\mathrm{Ne}$ VII & $2 \mathrm{~s} 2 \mathrm{p}^{1} \mathrm{P}_{1} \quad-2 \mathrm{p}^{2}{ }^{1} \mathrm{D}_{2}$ & & 0.26 & & & \\
\hline 974.60 & Si VIII & $2 s^{2} 2 p^{2} 3 p^{2} F_{7 / 2}-2 s^{2} 2 p^{2} 3 d^{2} G_{9 / 2}$ & 0.077 & 0.080 & & & \\
\hline 974.84 & Fe XVIII & $2 \mathrm{~s}^{2} 2 \mathrm{p}^{5}{ }^{2} \mathrm{P}_{3 / 2} \quad-2 \mathrm{~s}^{2} 2 \mathrm{p}^{5}{ }^{2} \mathrm{P}_{1 / 2}$ & & & 15.3 & 8370 & \\
\hline 975.83 & (d) & & 0.052 & 0.035 & 0.079 & & \\
\hline 979.17 & (c) & & 0.061 & & & & \\
\hline 981.75 & (e) & & 0.039 & & & & \\
\hline 982.16 & Si VIII & $2 s^{2} 2 p^{2} 3 p{ }^{4} D_{1 / 2}-2 s^{2} 2 p^{2} 3 d^{4} F_{3 / 2}$ & 0.033 & 0.026 & 0.047 & & \\
\hline 983.56 & Si VIII & $2 s^{2} 2 p^{2} 3 p^{4} D_{3 / 2}-2 s^{2} 2 p^{2} 3 d^{4} F_{5 / 2}$ & 0.069 & 0.038 & 0.095 & & \\
\hline 986.28 & & & 0.083 & & 0.31 & & \\
\hline 986.54 & & & & & 0.071 & & \\
\hline 988.22 & Si VIII & $2 s^{2} 2 p^{2} 3 p^{4} D_{5 / 2}-2 s^{2} 2 p^{2} 3 d^{4} F_{7 / 2}$ & 0.081 & 0.055 & 0.14 & & \\
\hline 992.03 & (e) & & 0.050 & & & & $I$ in $\mathrm{AR}$ \\
\hline 9994.44 & K XIII & $2 s^{2} 2 p^{3}{ }^{4} S_{3 / 2} \quad-2 s^{2} 2 p^{3}{ }^{2} D_{3 / 2}$ & & & & 24.9 & \\
\hline 994.58 & Si VIII & $2 s^{2} 2 p^{2} 3 p^{4} D_{7 / 2}-2 s^{2} 2 p^{2} 3 d^{4} F_{9 / 2}$ & 0.21 & 0.20 & 1.1 & & \\
\hline 996.54 & (c) & & 0.022 & 0.023 & & & \\
\hline 997.44 & $\operatorname{Mg}$ XI & $-1 \mathrm{~s} 2 \mathrm{p}{ }^{3} \mathrm{P}_{2}$ & & & 0.36 & 147 & \\
\hline 997.69 & & & 0.034 & & 0.26 & & \\
\hline 1000.84 & (c) & & 0.042 & 0.095 & 0.099 & & \\
\hline 1005.00 & Si VIII & $2 s^{2} 2 p^{2} 3 p^{4} D_{5 / 2}-2 s^{2} 2 p^{2} 3 d^{4} F_{5 / 2}$ & 0.017 & & & & $I$ in $\mathrm{AR}$ \\
\hline 1005.86 & Mn XXI & $2 \mathrm{~s}^{2} 2 \mathrm{p}^{3}{ }^{2} \mathrm{P}_{3 / 2} \quad-2 \mathrm{~s}^{2} 2 \mathrm{p}^{3}{ }^{2} \mathrm{P}_{1 / 2}$ & & & & 54.8 & \\
\hline 1009.91 & Si VII & $2 s^{2} 2 p^{3} 3 s^{3} P_{2}-2 s^{2} 2 p^{3} 3 p^{3} P_{2}$ & & & & & \\
\hline 1013.05 & (d) & & 0.0055 & & 0.026 & & \\
\hline 1015.79 & (e) & & 0.32 & & 0.44 & & \\
\hline 1016.01 & (e) & & 0.056 & & & & \\
\hline 1018.75 & Ar XII & $-2 \mathrm{~s}^{2} 2 \mathrm{p}^{3}{ }^{2} \mathrm{D}_{5 / 2}$ & 0.11 & & 1.7 & 7.8 & \\
\hline 1018.93 & & & 0.40 & 0.040 & & & \\
\hline 1020.10 & (d) & & 0.030 & & & & \\
\hline 1020.66 & & & 0.0044 & & & & \\
\hline 1023.31 & (e) & & & & & & \\
\hline 1023.50 & (d) & & 0.045 & & 0.035 & & $F$ in $\mathrm{CH}$ \\
\hline
\end{tabular}


W. Curdt et al.: Coronal EUV atlas, Online Material $p 10$

Table 3. continued.

\begin{tabular}{|c|c|c|c|c|c|c|c|c|}
\hline \multirow{2}{*}{$\begin{array}{c}\lambda_{\text {obs }} \\
\AA\end{array}$} & \multirow[t]{2}{*}{ Line } & \multirow{2}{*}{\multicolumn{2}{|c|}{ Transition }} & $\mathrm{QS}$ & $\mathrm{CH}$ & $\mathrm{AR}$ & Flare & Notes \\
\hline & & & & \multicolumn{5}{|c|}{ line radiance $L /$ phot $\mathrm{cm}^{-2} \mathrm{~s}^{-1} \operatorname{arcsec}^{-2}$} \\
\hline 1028.04 & $\mathrm{Fe} X$ & $3 s^{2} 3 p^{4} 3 d^{4} D_{7 /}$ & $2^{-3 s^{2} 3 p^{4} 3 d^{4} F_{7 / 2}}$ & 2.6 & 1.2 & 4.2 & & \\
\hline 1028.97 & (e) & & & 2.2 & 2.2 & 2.9 & & \\
\hline 1031.93 & O VI & $2 s^{2} S_{1 / 2}$ & $-2 \mathrm{p}^{2} \mathrm{P}_{3 / 2}$ & 124 & 74 & 260 & & \\
\hline 1033.01 & $\mathrm{Nixv}$ & $3 \mathrm{~s}^{2} 3 \mathrm{p}^{2}{ }^{3} \mathrm{P}_{1}$ & $-3 \mathrm{~s}^{2} 3 \mathrm{p}^{2}{ }^{1} \mathrm{~S}_{0}$ & 0.046 & & 2.2 & 474 & \\
\hline 1034.40 & Ni XIV & $3 s^{2} 3 p^{3}{ }^{4} S_{3 / 2}$ & $-3 \mathrm{~s}^{2} 3 \mathrm{p}^{3}{ }^{2} \mathrm{P}_{3 / 2}$ & 0.19 & 0.78 & 2.3 & & Possibly a ghost \\
\hline 1035.08 & & & & 0.029 & 0.039 & 0.093 & & \\
\hline 1037.63 & O VI & $2 s{ }^{2} S_{1 / 2}$ & $-2 p^{2} P_{1 / 2}$ & 50.6 & 33.9 & 124 & & \\
\hline 1042.53 & $\mathrm{Fe} X$ & $3 s^{2} 3 p^{4} 3 d^{4} D_{3 /}$ & ${ }_{2}-3 s^{2} 3 p^{4} 3 d^{2} F_{7 / 2}$ & 0.034 & & 0.069 & & \\
\hline 1043.28 & Mg XI & $1 \mathrm{~s} 2 \mathrm{~s}{ }^{3} S_{1}$ & $-1 \mathrm{~s} 2 \mathrm{p}^{3} \mathrm{P}_{0}$ & & & 0.13 & 26.6 & \\
\hline 1049.26 & Si VII & $2 \mathrm{~s}^{2} 2 \mathrm{p}^{4}{ }^{3} \mathrm{P}_{1}$ & $-2 \mathrm{~s}^{2} 2 \mathrm{p}^{4}{ }^{1} \mathrm{~S}_{0}$ & 0.21 & 0.84 & 0.97 & & \\
\hline 1051.63 & S VII & $2 s^{2} 2 p^{5} 3 s^{3} P_{2}$ & $-2 s^{2} 2 p^{5} 3 p^{3} S_{1}$ & 0.027 & 0.086 & & & \\
\hline 1052.09 & & & & 0.0037 & & & & \\
\hline 1053.88 & Al VII & $2 s^{2} 2 p^{3}{ }^{4} S_{3 / 2}$ & $-2 \mathrm{~s}^{2} 2 \mathrm{p}^{3}{ }^{2} \mathrm{P}_{3 / 2}$ & 0.093 & 0.40 & 0.42 & & \\
\hline 1054.59 & Ar XII & $2 \mathrm{~s}^{2} 2 \mathrm{p}^{3}{ }^{4} \mathrm{~S}_{3 / 2}$ & $-2 \mathrm{~s}^{2} 2 \mathrm{p}^{3}{ }^{2} \mathrm{D}_{3 / 2}$ & 0.19 & 0.024 & 2.2 & 146 & \\
\hline 1056.79 & Al VII & $2 s^{2} 2 p^{3}{ }^{4} S_{3 / 2}$ & $-2 \mathrm{~s}^{2} 2 \mathrm{p}^{3}{ }^{2} \mathrm{P}_{1 / 2}$ & 0.032 & 0.18 & 0.21 & & \\
\hline 1057.26 & Si VIII & $2 s^{2} 2 p^{2} 3 s^{2} S_{1 / 2}$ & $-2 s^{2} 2 p^{2} 3 p^{2} P_{3 / 2}$ & 0.015 & & 0.028 & & \\
\hline 1057.86 & Al VIII & $2 \mathrm{~s}^{2} 2 \mathrm{p}^{2}{ }^{3} \mathrm{P}_{1}$ & $-2 \mathrm{~s}^{2} 2 \mathrm{p}^{2}{ }^{1} \mathrm{~S}_{0}$ & 0.088 & 0.21 & 0.27 & & \\
\hline 1062.44 & Fe VIII & $3 p^{6} 4 s^{2} S_{1 / 2}$ & $-3 p^{6} 4 p^{2} P_{3 / 2}$ & 0.018 & & & & $I$ in $\mathrm{CH}$ \\
\hline 1062.44 & & & & & & & $\mathrm{x}$ & \\
\hline 1072.35 & & & & 0.0076 & & & & \\
\hline 1077.17 & & & & & & & $\mathrm{x}$ & \\
\hline 1079.42 & Fe XXIII & $2 s 2 p{ }^{3} P_{2}$ & $-2 \mathrm{~s} 2 \mathrm{p}{ }^{3} \mathrm{P}_{2}$ & & & & 1180 & \\
\hline 1098.48 & $\mathrm{CaXV}$ & $2 \mathrm{~s}^{2} 2 \mathrm{p}^{2}{ }^{3} \mathrm{P}_{1}$ & $-2 s^{2} 2 p^{2}{ }^{1} D_{2}$ & & & 1.4 & 155 & \\
\hline 1101.26 & $\mathrm{ClXI}$ & $2 \mathrm{~s}^{2} 2 \mathrm{p}^{3}{ }^{4} \mathrm{~S}_{3 / 2}$ & $-2 s^{2} 2 p^{3}{ }^{2} D_{5 / 2}$ & 0.042 & & & & \\
\hline 1102.93 & S VII & $2 s^{2} 2 p^{5} 3 s^{3} P_{1}$ & $-2 s^{2} 2 p^{5} 3 p^{3} S_{1}$ & & & 0.043 & & \\
\hline 1111.76 & $\mathrm{NaX}$ & $1 \mathrm{~s} 2 \mathrm{~s}{ }^{3} \mathrm{~S}_{1}$ & $-1 \mathrm{~s} 2 \mathrm{p}^{3} \mathrm{P}_{2}$ & & & 0.14 & 8.6 & \\
\hline 1116.03 & Si VIII & $2 s^{2} 2 p^{2} 3 s^{4} P_{3 / 2}$ & $-2 s^{2} 2 p^{2} 3 p{ }^{4} P_{1 / 2}$ & 0.032 & & 0.10 & & \\
\hline 1118.07 & Fe XIX & $2 s^{2} 2 p^{4}{ }^{3} P_{2}$ & $-2 s^{2} 2 p^{4}{ }^{3} P_{1}$ & & & 0.69 & 4690 & \\
\hline 1119.66 & & & & 0.0097 & & & & \\
\hline 1121.74 & & & & 0.042 & & & & \\
\hline 1124.39 & & & & 0.065 & & 0.28 & & \\
\hline 1126.56 & $\mathrm{ClXI}$ & $2 s^{2} 2 p^{3}{ }^{4} S_{3 / 2}$ & $-2 \mathrm{~s}^{2} 2 \mathrm{p}^{3}{ }^{2} \mathrm{D}_{3 / 2}$ & 0.047 & & & & $F$ in $\mathrm{AR}$ \\
\hline 1130.42 & (e) & & & 0.75 & & 0.87 & & $F$ in $\mathrm{CH}$ \\
\hline 1131.05 & & & & & 0.11 & & & \\
\hline 1132.80 & Si VII & $2 s^{2} 2 p^{3} 3 s^{3} D_{3}$ & $-2 s^{2} 2 p^{3} 3 p^{3} F_{4}$ & 0.12 & 0.23 & 0.21 & & \\
\hline 1133.76 & Ca XIII & $2 \mathrm{~s}^{2} 2 \mathrm{p}^{4}{ }^{3} \mathrm{P}_{2}$ & $-2 s^{2} 2 p^{41} D_{2}$ & 0.25 & 15.0 & 260 & & \\
\hline 1134.10 & Co XIII & $3 s^{2} 3 p^{3}{ }^{4} S_{3 / 2}$ & $-3 s^{2} 3 p^{3}{ }^{2} P_{3 / 2}$ & 0.081 & & & & \\
\hline 1135.02 & & & & & & 0.031 & & \\
\hline 1135.39 & Si VII & $2 s^{2} 2 p^{3} 3 s^{5} S_{2}$ & $-2 s^{2} 2 p^{3} 3 p^{5} P_{3}$ & 0.49 & 0.69 & 0.96 & & \\
\hline 1137.24 & Si VII & $2 s^{2} 2 p^{3} 3 s^{3} D_{2}$ & $-2 s^{2} 2 p^{3} 3 p^{3} F_{3}$ & 0.073 & 0.12 & & & $I$ in AR \\
\hline 1137.99 & & & & 0.023 & & 0.081 & & \\
\hline 1138.48 & (e) & & & 0.089 & & & & \\
\hline 1141.47 & Fe VII & $3 d^{6} 3 d 4 s^{3} D_{3}$ & $-3 d^{6} 3 d 4 p{ }^{3} F_{4}$ & & 0.044 & & & \\
\hline 1142.50 & Si VII & $2 s^{2} 2 p^{3} 3 s^{5} S_{2}$ & $-2 s^{2} 2 p^{3} 3 p{ }^{5} P_{2}$ & 0.19 & 0.44 & & & $I$ in AR \\
\hline 1143.58 & Si VII & $2 s^{2} 2 p^{3} 3 s^{3} P_{2}$ & $-2 s^{2} 2 p^{3} 3 p^{3} D_{3}$ & 0.15 & 0.134 & & & $I$ in AR \\
\hline 1146.57 & Si VII & $2 s^{2} 2 p^{3} 3 s^{5} S_{2}$ & $-2 s^{2} 2 p^{3} 3 p^{5} P_{1}$ & 0.077 & 0.19 & & & $I$ in $\mathrm{AR}$ \\
\hline 1146.88 & (c) & & & 0.13 & 0.20 & & & $I$ in $\mathrm{AR}$ \\
\hline
\end{tabular}


W. Curdt et al.: Coronal EUV atlas, Online Material p 11

Table 3. continued.

\begin{tabular}{|c|c|c|c|c|c|c|c|c|}
\hline \multirow{2}{*}{$\begin{array}{r}\lambda_{\mathrm{obs}} \\
\AA\end{array}$} & \multirow[t]{2}{*}{ Line } & \multirow{2}{*}{\multicolumn{2}{|c|}{ Transition }} & QS & $\mathrm{CH}$ & $\mathrm{AR}$ & Flare & Notes \\
\hline & & & & \multicolumn{5}{|c|}{ line radiance $L /$ phot $\mathrm{cm}^{-2} \mathrm{~s}^{-1} \operatorname{arcsec}^{-2}$} \\
\hline 1148.70 & Si VI & $2 \mathrm{~s}^{2} 2 \mathrm{p}^{4} 3 \mathrm{~s}^{4} \mathrm{P}_{3 /}$ & $2-2 s^{2} 2 p^{4} 3 p^{4} D_{5 / 2}$ & 0.12 & 0.13 & & & \\
\hline 1153.16 & Fe XVII & $2 \mathrm{~s}^{2} 2 \mathrm{p}^{5} 3 \mathrm{~s}^{3} \mathrm{P}_{1}$ & $-2 s^{2} 2 p^{5} 3 s^{3} P_{0}$ & & & 5.2 & 111 & \\
\hline 1157.55 & (d) & & & 0.082 & & & & \\
\hline 1164.82 & & & & & & 0.086 & $\mathrm{x}$ & \\
\hline 1166.17 & Fe VII & $3 d^{6} 3 d 4 s{ }^{3} D_{1}$ & $-3 d^{6} 3 d 4 p{ }^{3} F_{2}$ & & 0.028 & & & \\
\hline$[1167.70$ & Si VII & $2 \mathrm{~s}^{2} 2 \mathrm{p}^{3} 3 \mathrm{~s}^{3} \mathrm{~S}_{1}$ & $-2 s^{2} 2 p^{3} 3 p^{3} P_{2}$ & 0.086 & 0.16 & 0.58 & & \\
\hline 1167.73 & Mn XVII & $2 \mathrm{~s}^{2} 2 \mathrm{p}^{5}{ }^{2} \mathrm{P}_{3 / 2}$ & $-2 \mathrm{~s}^{2} 2 \mathrm{p}^{5}{ }^{2} \mathrm{P}_{1 / 2}$ & & & & 15.8 & \\
\hline 1169.35 & Si VII & $2 \mathrm{~s}^{2} 2 \mathrm{p}^{3} 3 \mathrm{~s}^{3} \mathrm{~S}_{1}$ & $-2 s^{2} 2 p^{3} 3 p^{3} P_{1}$ & 0.046 & 0.079 & & & \\
\hline 1174.64 & Ni XIV & $3 s^{2} 3 p^{3}{ }^{4} S_{3 / 2}$ & $-3 \mathrm{~s}^{2} 3 \mathrm{p}^{3}{ }^{2} \mathrm{P}_{1 / 2}$ & & & 2.6 & $\mathrm{x}$ & \\
\hline 1182.48 & Si VIII & $2 \mathrm{~s}^{2} 2 \mathrm{p}^{2} 3 \mathrm{~s}^{4} \mathrm{P}_{1 /}$ & ${ }_{2}-2 s^{2} 2 p^{2} 3 p{ }^{4} D_{3 / 2}$ & 0.11 & & 0.18 & & $I$ in $\mathrm{CH}$ \\
\hline 1184.04 & Si VIII & $2 \mathrm{~s}^{2} 2 \mathrm{p}^{2} 3 \mathrm{~s}^{4} \mathrm{P}_{3}$ & ${ }^{2}-2 s^{2} 2 p^{2} 3 p^{4} D_{5 / 2}$ & 0.25 & 0.16 & 0.45 & & $I$ in $\mathrm{AR}$ \\
\hline 1187.53 & & & & 0.014 & & & & \\
\hline 1188.10 & & & & & & 0.22 & $\mathrm{x}$ & $1^{\text {st }}$ or $2^{\text {nd }} ?$ \\
\hline 1189.52 & Si VIII & $2 \mathrm{~s}^{2} 2 \mathrm{p}^{2} 3 \mathrm{~s}^{4} \mathrm{P}_{5}$ & ${ }_{2}-2 s^{2} 2 p^{2} 3 p^{4} D_{7 / 2}$ & 0.67 & 0.45 & & & AR short slit \\
\hline 1189.84 & Mg VII & $2 \mathrm{~s}^{2} 2 \mathrm{p}^{2}{ }^{3} \mathrm{P}_{1}$ & $-2 s^{2} 2 p^{2}{ }^{1} S_{0}$ & 0.28 & 1.4 & & & AR short slit \\
\hline 1190.09 & Mg VI & $2 \mathrm{~s}^{2} 2 \mathrm{p}^{3}{ }^{4} \mathrm{~S}_{3 / 2}$ & $-2 \mathrm{~s}^{2} 2 \mathrm{p}^{3}{ }^{2} \mathrm{P}_{3 / 2}$ & 0.13 & 0.90 & & & \\
\hline 1191.64 & Mg VI & $2 \mathrm{~s}^{2} 2 \mathrm{p}^{3}{ }^{4} \mathrm{~S}_{3 / 2}$ & $-2 \mathrm{~s}^{2} 2 \mathrm{p}^{3}{ }^{2} \mathrm{P}_{1 / 2}$ & 0.063 & 0.38 & & & \\
\hline 1192.98 & (f) & & & & & & $\mathrm{x}$ & \\
\hline 1196.21 & $S x$ & $2 s^{2} 2 p^{3}{ }^{4} S_{3 / 2}$ & $-2 s^{2} 2 p^{32} D_{5 / 2}$ & 4.2 & 0.26 & 2.2 & & \\
\hline 1200.67 & & & & 0.056 & & & & \\
\hline 1201.23 & & & & & & 1.8 & $\mathrm{x}$ & \\
\hline 1205.73 & $\operatorname{CrXx}$ & $2 s^{2} 2 p^{2} \mathrm{P}_{1 / 2}$ & $-2 s^{2} 2 p^{2} P_{3 / 2}$ & & & & 118 & \\
\hline 1212.97 & $\mathrm{Sx}$ & $2 s^{2} 2 p^{3}{ }^{4} S_{3 / 2}$ & $-2 \mathrm{~s}^{2} 2 \mathrm{p}^{3}{ }^{2} \mathrm{D}_{3 / 2}$ & 9.6 & 0.38 & 15.5 & $\star$ & \\
\hline 1224.97 & & & & 0.28 & & 0.11 & $\star$ & \\
\hline 1227.46 & & & & & & & & $1^{\text {st }}$ or $2^{\text {nd }} ?$ \\
\hline 1227.65 & (e) & & & 0.032 & & & & $1^{\text {st }}$ or $2^{\text {nd }} ?$ \\
\hline 1230.31 & & & & 0.039 & & & & $1^{\text {st }}$ or $2^{\text {nd }} ?$ \\
\hline 1231.46 & Si IX & $2 \mathrm{~s}^{2} 2 \mathrm{p} 3 \mathrm{~s}^{3} \mathrm{P}_{1}$ & $-2 s^{2} 2 p 3 p{ }^{3} D_{2}$ & 0.57 & & 0.69 & & $F$ in $\mathrm{CH}$ \\
\hline 1232.09 & (d) & & & 0.11 & & 0.51 & & $1^{\text {st }}$ or $2^{\text {nd }} ?$ \\
\hline 1232.65 & Si VIII & $2 \mathrm{~s}^{2} 2 \mathrm{p}^{2} 3 \mathrm{~s}^{4} \mathrm{P}_{5}$ & ${ }_{2}-2 s^{2} 2 p^{2} 3 p^{4} D_{5 / 2}$ & 0.36 & & 0.73 & & $1^{\text {st }}$ or $2^{\text {nd }} ?$ \\
\hline 1232.98 & (e) & & & 0.13 & & & & \\
\hline 1233.30 & & & & & & 1.8 & & \\
\hline 1233.65 & & & & & & 0.27 & & $1^{\text {st }}$ or $2^{\text {nd }} ?$ \\
\hline 1233.94 & & & & & & 1.9 & & $1^{\text {st }}$ or $2^{\text {nd }} ?$ \\
\hline 1234.11 & & & & 0.064 & & & & $1^{\text {st }}$ or $2^{\text {nd }} ?$ \\
\hline 1234.60 & (f) & & & 0.15 & & 0.47 & & $1^{\text {st }}$ or $2^{\text {nd }} ?$ \\
\hline 1236.00 & Si VII & $2 s^{2} 2 p^{3} 3 s^{1} D_{2}$ & $-2 s^{2} 2 p^{3} 3 p^{1} F_{3}$ & 0.061 & 0.11 & & & \\
\hline 1236.15 & & & & & & 0.11 & & $1^{\text {st }}$ or $2^{\text {nd }} ?$ \\
\hline 1236.38 & & & & 0.010 & & & & \\
\hline 1237.05 & & & & 0.050 & & & & $1^{\text {st }}$ or $2^{\text {nd }} ?$ \\
\hline 1237.99 & & & & 0.042 & & 0.73 & & \\
\hline 1238.82 & $\mathrm{NV}$ & $2 \mathrm{~s}^{2} \mathrm{~S}_{1 / 2}$ & $-2 p^{2} \mathrm{P}_{3 / 2}$ & 7.6 & 3.5 & & & \\
\hline 1242.00 & Fe XII & $3 s^{2} 3 p^{3}{ }^{4} S_{3 / 2}$ & $-3 s^{2} 3 p^{3}{ }^{2} P_{3 / 2}$ & 30.9 & 0.81 & 47.8 & & \\
\hline 1242.81 & $\mathrm{Nv}$ & $2 \mathrm{~s}^{2} \mathrm{~S}_{1 / 2}$ & $-2 \mathrm{p}^{2} \mathrm{P}_{1 / 2}$ & 3.9 & 1.9 & & & \\
\hline 1244.94 & K XIII /2 & & & & & 0.080 & & cf., $622.47 \AA$ \\
\hline 1245.18 & (s) & & & & & & & \\
\hline 1248.08 & Ne IX & $1 \mathrm{~s} 2 \mathrm{~s}^{3} \mathrm{~S}_{1}$ & $-1 \mathrm{~s} 2 \mathrm{p}{ }^{3} \mathrm{P}_{2}$ & & & 2.7 & 141 & $F$ in $\mathrm{CH}, \mathrm{QS}$ \\
\hline
\end{tabular}


Table 3. continued.

\begin{tabular}{|c|c|c|c|c|c|c|c|c|}
\hline \multirow{2}{*}{$\begin{array}{r}\lambda_{\mathrm{obs}} \\
\AA\end{array}$} & \multirow[t]{2}{*}{ Line } & \multicolumn{2}{|c|}{ Transition } & \multirow{2}{*}{\multicolumn{5}{|c|}{$\begin{array}{lccc}\text { QS } & \text { CH } & \text { AR } & \text { Flare } \\
\text { line radiance } L / \text { phot } \mathrm{cm}^{-2} \mathrm{~s}^{-1} \operatorname{arcsec}^{-2}\end{array}$}} \\
\hline & & & & & & & & \\
\hline 1253.39 & (e) & & & 0.37 & & & & $I$ in $\mathrm{AR}$ \\
\hline 1256.49 & K XII & $2 \mathrm{~s}^{2} 2 \mathrm{p}^{4}{ }^{3} \mathrm{P}_{2}$ & $-2 s^{2} 2 p^{4}{ }^{1} D_{2}$ & 0.38 & & 1.4 & 19.6 & \\
\hline 1258.06 & Co XIII & $3 s^{2} 3 p^{3} S_{3 / 2}$ & $-3 s^{2} 3 p^{3}{ }^{2} \mathrm{P}_{1 / 2}$ & & & 0.16 & & $1^{\text {st }}$ or $2^{\text {nd }} ?$ \\
\hline 1271.61 & (f) & & & 0.19 & & 0.79 & & $F$ in $\mathrm{CH}$ \\
\hline 1277.22 & Ni XIII & $3 s^{2} 3 p^{4}{ }^{3} P_{1}$ & $-3 s^{2} 3 p^{4}{ }^{1} S_{0}$ & 0.47 & & 1.7 & 133 & $F$ in $\mathrm{CH}$ \\
\hline$[1277.79$ & Ne IX & $1 \mathrm{~s} 2 \mathrm{~s}{ }^{3} \mathrm{~S}_{1}$ & $-1 \mathrm{~s} 2 \mathrm{p}^{3} \mathrm{P}_{0}$ & & & 5.4 & 25.6 & \\
\hline 1277.84 & $\mathrm{Six} / 2$ & & & & & & & cf., $638.92 \AA$ \\
\hline 1291.61 & Ca XIV & $2 s^{2} 2 p^{3}{ }^{2} D_{3 / 2}$ & $-2 \mathrm{~s}^{2} 2 \mathrm{p}^{3}{ }^{2} \mathrm{P}_{3 / 2}$ & & & 1.6 & 69.9 & \\
\hline 1307.52 & P IX & $2 s^{2} 2 p^{3}{ }^{4} S_{3 / 2}$ & $-2 \mathrm{~s}^{2} 2 \mathrm{p}^{3}{ }^{2} \mathrm{D}_{5 / 2}$ & 0.026 & & & & $F$ in $\mathrm{AR}$ \\
\hline 1311.91 & & & & & & 0.015 & & $1^{\text {st }}$ or $2^{\text {nd }} ?$ \\
\hline 1317.62 & PIX & $2 s^{2} 2 p^{3} S_{3 / 2}$ & $-2 \mathrm{~s}^{2} 2 \mathrm{p}^{3}{ }^{2} \mathrm{D}_{3 / 2}$ & 0.17 & & & & $F$ in $\mathrm{AR}$ \\
\hline 1320.79 & & & & & & 0.077 & & $1^{\text {st }}$ or $2^{\text {nd }} ?$ \\
\hline 1322.20 & Mn XII & $3 s^{2} 3 p^{2}{ }^{3} P_{1}$ & $-3 s^{2} 3 p^{2}{ }^{1} S_{0}$ & 0.22 & & 0.24 & & \\
\hline 1322.58 & & & & 0.16 & & & & $1^{\text {st }}$ or $2^{\text {nd }} ?$ \\
\hline 1328.79 & Fe XIX & $2 s^{2} 2 p^{4}{ }^{3} P_{2}$ & $-2 s^{2} 2 p^{4}{ }^{3} P_{0}$ & & & & 7.7 & \\
\hline 1330.53 & Ar XIII & $2 \mathrm{~s}^{2} 2 \mathrm{p}^{2}{ }^{3} \mathrm{P}_{1}$ & $-2 \mathrm{~s}^{2} 2 \mathrm{p}^{2}{ }^{1} \mathrm{D}_{2}$ & & & 0.97 & 43.8 & \\
\hline 1331.50 & (f) & & & 0.28 & & 0.46 & & \\
\hline 1349.37 & Fe XII & $3 s^{2} 3 p^{3} S_{3 / 2}$ & $-3 s^{2} 3 p^{3}{ }^{2} \mathrm{P}_{1 / 2}$ & 18.1 & 0.41 & 28.5 & & \\
\hline 1354.06 & Fe XXI & $2 \mathrm{~s}^{2} 2 \mathrm{p}^{2}{ }^{3} \mathrm{P}_{0}$ & $-2 \mathrm{~s}^{2} 2 \mathrm{p}^{2}{ }^{3} \mathrm{P}_{1}$ & & & & 14100 & \\
\hline 1354.89 & Mn XVIII & $2 \mathrm{~s}^{2} 2 \mathrm{p}^{4}{ }^{3} \mathrm{P}_{2}$ & $-2 \mathrm{~s}^{2} 2 \mathrm{p}^{4}{ }^{3} \mathrm{P}_{1}$ & & & 0.57 & 24.0 & \\
\hline 1368.80 & Co XII & $3 s^{2} 3 p^{4}{ }^{3} P_{1}$ & $-3 s^{2} 3 p^{4}{ }^{1} S_{0}$ & 0.25 & & & & \\
\hline 1370.51 & Ni XII? & & & 0.11 & & & & \\
\hline 1375.95 & $\mathrm{CaXv}$ & $2 \mathrm{~s}^{2} 2 \mathrm{p}^{2}{ }^{3} \mathrm{P}_{2}$ & $-2 s^{2} 2 p^{2}{ }^{1} D_{2}$ & 0.12 & & 2.9 & 183 & \\
\hline 1392.10 & Ar XI & $2 \mathrm{~s}^{2} 2 \mathrm{p}^{4}{ }^{3} \mathrm{P}_{2}$ & $-2 s^{2} 2 p^{4}{ }^{1} D_{2}$ & 0.53 & & 1.8 & 223 & \\
\hline 1408.65 & (f) & & & 0.41 & & 0.65 & & \\
\hline 1409.44 & (e) & & & 1.0 & & 1.6 & & \\
\hline 1410.60 & CrXVI & $2 s^{2} 2 p^{5}{ }^{2} P_{3 / 2}$ & $-2 s^{2} 2 p^{5}{ }^{2} P_{1 / 2}$ & & & 2.1 & 29.0 & $1^{\text {st }}$ or $2^{\text {nd }} ?$ \\
\hline 1411.12 & & & & 2.1 & & 3.9 & & \\
\hline 1428.75 & (f) & & & 4.5 & 0.48 & 6.1 & & \\
\hline 1432.23 & Ca XIV & $2 \mathrm{~s}^{2} 2 \mathrm{p}^{3}{ }^{2} \mathrm{D}_{5 / 2}$ & $-2 s^{2} 2 p^{3}{ }^{2} P_{3 / 2}$ & & & & 27.6 & \\
\hline 1439.99 & Cr XI & $3 s^{2} 3 p^{2}{ }^{3} P_{1}$ & $-3 \mathrm{~s}^{2} 3 \mathrm{p}^{2}{ }^{1} \mathrm{~S}_{0}$ & 0.18 & & 0.28 & & \\
\hline 1440.51 & Si VIII & $2 s^{2} 2 p^{3} S_{3 / 2}$ & $-2 \mathrm{~s}^{2} 2 \mathrm{p}^{3}{ }^{2} \mathrm{D}_{5 / 2}$ & 0.91 & 1.5 & 1.1 & & \\
\hline 1445.76 & Si VIII & $2 s^{2} 2 p^{3}{ }^{4} S_{3 / 2}$ & $-2 \mathrm{~s}^{2} 2 \mathrm{p}^{3}{ }^{2} \mathrm{D}_{3 / 2}$ & 11.1 & 15.6 & 13.1 & & \\
\hline 1452.66 & & & & & & 0.77 & $\mathrm{x}$ & $1^{\text {st }}$ or $2^{\text {nd }} ?$ \\
\hline 1453.36 & (c) & & & & & 11.0 & & $1^{\text {st }}$ or $2^{\text {nd }} ?$ \\
\hline 1463.50 & $\mathrm{Fex}$ & $3 s^{2} 3 p^{4} 3 d^{4} F_{9}$ & ${ }^{2}-3 s^{2} 3 p^{4} 3 d^{2} F_{7 / 2}$ & 3.1 & 1.4 & 4.9 & & \\
\hline 1464.44 & Cl XII & $2 \mathrm{~s}^{2} 2 \mathrm{p}^{2}{ }^{3} \mathrm{P}_{1}$ & $-2 \mathrm{~s}^{2} 2 \mathrm{p}^{2}{ }^{1} \mathrm{D}_{2}$ & & & 0.21 & & \\
\hline 1467.07 & Fe XI & $3 s^{2} 3 p^{4}{ }^{3} P_{1}$ & $-3 s^{2} 3 p^{4}{ }^{1} S_{0}$ & 12.5 & 1.5 & 15.5 & & \\
\hline 1477.16 & K XIV & $2 \mathrm{~s}^{2} 2 \mathrm{p}^{2}{ }^{3} \mathrm{P}_{1}$ & $-2 \mathrm{~s}^{2} 2 \mathrm{p}^{2}{ }^{1} \mathrm{D}_{2}$ & & & 0.47 & & $1^{\text {st }}$ or $2^{\text {nd }} ?$ \\
\hline 1489.02 & $\operatorname{Cr} \mathrm{X}$ & $3 s^{2} 3 p^{3} S_{3 / 2}$ & $-3 \mathrm{~s}^{2} 3 \mathrm{p}^{3}{ }^{2} \mathrm{P}_{3 / 2}$ & 0.23 & & & & \\
\hline$[1504.27$ & Ca XIV & $2 s^{2} 2 p^{3} S_{3 / 2}$ & $-2 \mathrm{~s}^{2} 2 \mathrm{p}^{3}{ }^{2} \mathrm{P}_{1 / 2}$ & & & 1.4 & 23.0 & $F$ in QS \\
\hline 1515.19 & & & & & & & $\mathrm{x}$ & \\
\hline 1544.18 & & & & & 1.1 & & & $1^{\text {st }}$ or $2^{\text {nd }} ?$ \\
\hline 1586.36 & Fe Xx & $2 \mathrm{~s}^{2} 2 \mathrm{p}^{3}{ }^{2} \mathrm{P}_{1 / 2}$ & $-2 \mathrm{~s}^{2} 2 \mathrm{p}^{3}{ }^{2} \mathrm{P}_{3 / 2}$ & & & & 6.2 & \\
\hline
\end{tabular}

Explanations

o: $3^{\text {rd }}$ order lines for which no calibration is available.

*: taken with a different slit at a different height above the limb.

\#: lines measured from spectra recorded by detector " $\mathrm{B}$ " $1^{\text {st }}$ or $2^{\text {nd }}$ it was not possible to determine the order of diffraction.

$\mathrm{x}$ : flare line where calculated radiance was not available or unidentified line (flare intensities are from calculations - for details see text).

$[$ : blend.

F: cold line.

I: intermediate temperature line.

$1^{\text {st }}: 1^{\text {st }}$ order line. 
W. Curdt et al.: Coronal EUV atlas, Online Material $p 13$

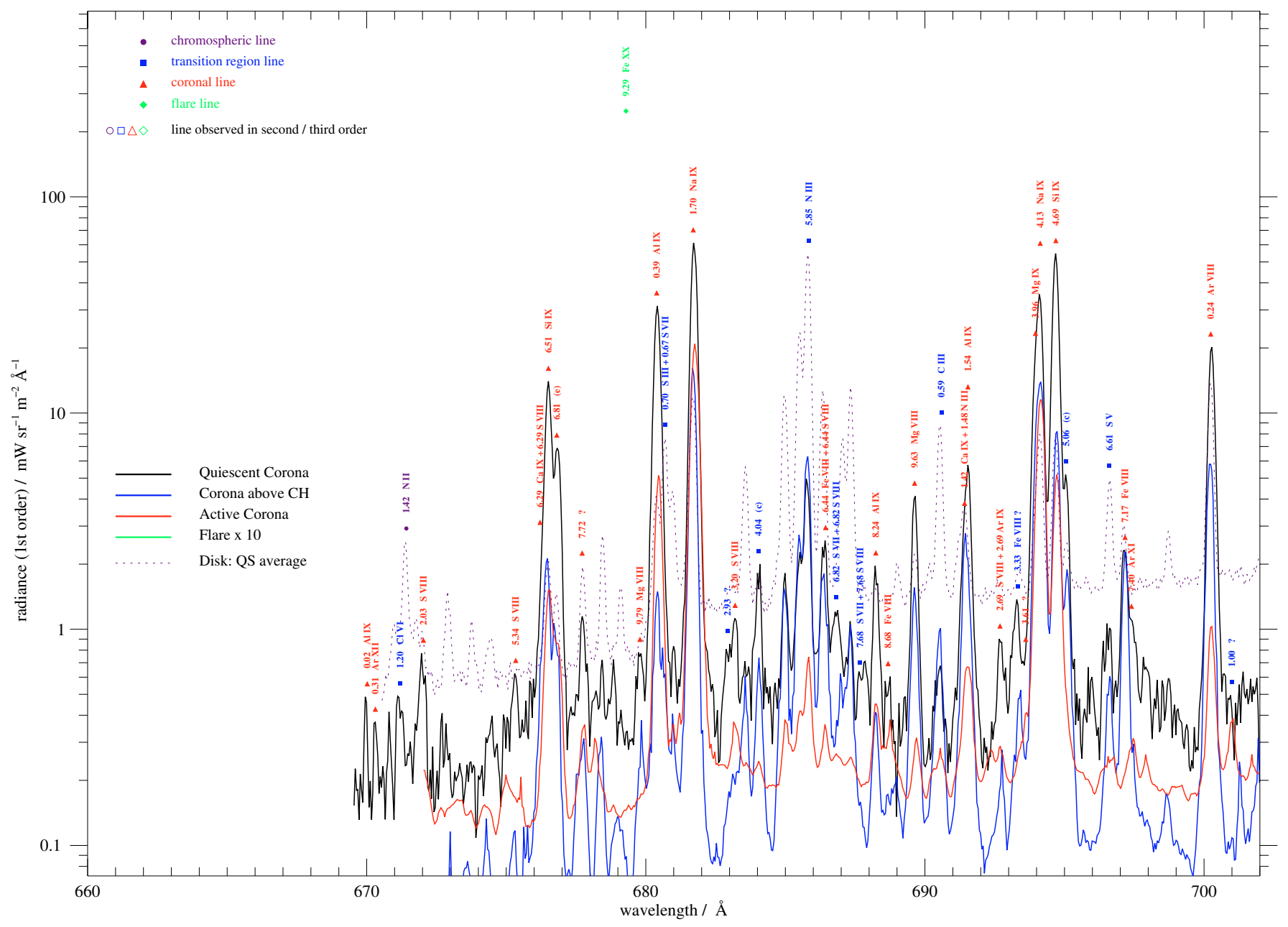

Fig. 3. The SUMER spectral atlas of solar coronal features includes profiles of the quiescent corona (black), the corona above a coronal hole (blue), the corona above an active region (red) and during a flare (green). For comparison we also present the average on-disk spectrum of the quiet Sun. Resolved emission lines are indicated by a mark, the measured wavelength in angstrom $(\AA)$, and the identification, if available. Marks and colours are coded and give a rough temperature estimate. Circles ( $\circ)$ indicate chromospheric emission seen as scattered light from the disk, blue squares $(\square)$ indicate transition region lines, red triangles $(\triangle)$ indicate true coronal emission. Green diamonds $(\diamond)$ denote flare lines which are normally not observed in the solar atmosphere. Filled symbols denote lines observed in first order of diffraction, open symbols are second-order or third-order lines. Only the three least-significant digits of the wavelength values are given. If available, unidentified lines are characterized by the temperature classification of Feldman et al. (1997) (a: $T_{\mathrm{e}}<3 \times 10^{5} ; \mathrm{b}: T_{\mathrm{e}} \approx 3 \times 10^{5} ; \mathrm{c}: T_{\mathrm{e}} \approx 4 \times 10^{5} ; \mathrm{d}: 6 \times 10^{5}<T_{\mathrm{e}}<9 \times 10^{5}$; e: $T_{\mathrm{e}} \approx 1.4 \times 10^{6} ; \mathrm{f}: T_{\mathrm{e}} \approx 1.8 \times 10^{6}$. The profiles have been radiometrically calibrated assuming first order of diffraction and the radiance axis is scaled to $\mathrm{mW} \mathrm{sr} \mathrm{m}^{-1} \mathrm{~m}^{-2} \AA^{-1}$. We have taken care of the type of photocathode (bare or $\mathrm{KBr}$ ) when applying the radiometric calibration to different sections of the spectrum. For lines observed in second order, the right vertical axis is applicable. Note, that the sensitivity ratio between both orders, which is wavelength dependent, has been chosen for (and is only correct for) the central wavelength. Also note, that second order lines are always superimposed on a first order background. 
W. Curdt et al.: Coronal EUV atlas, Online Material p 14

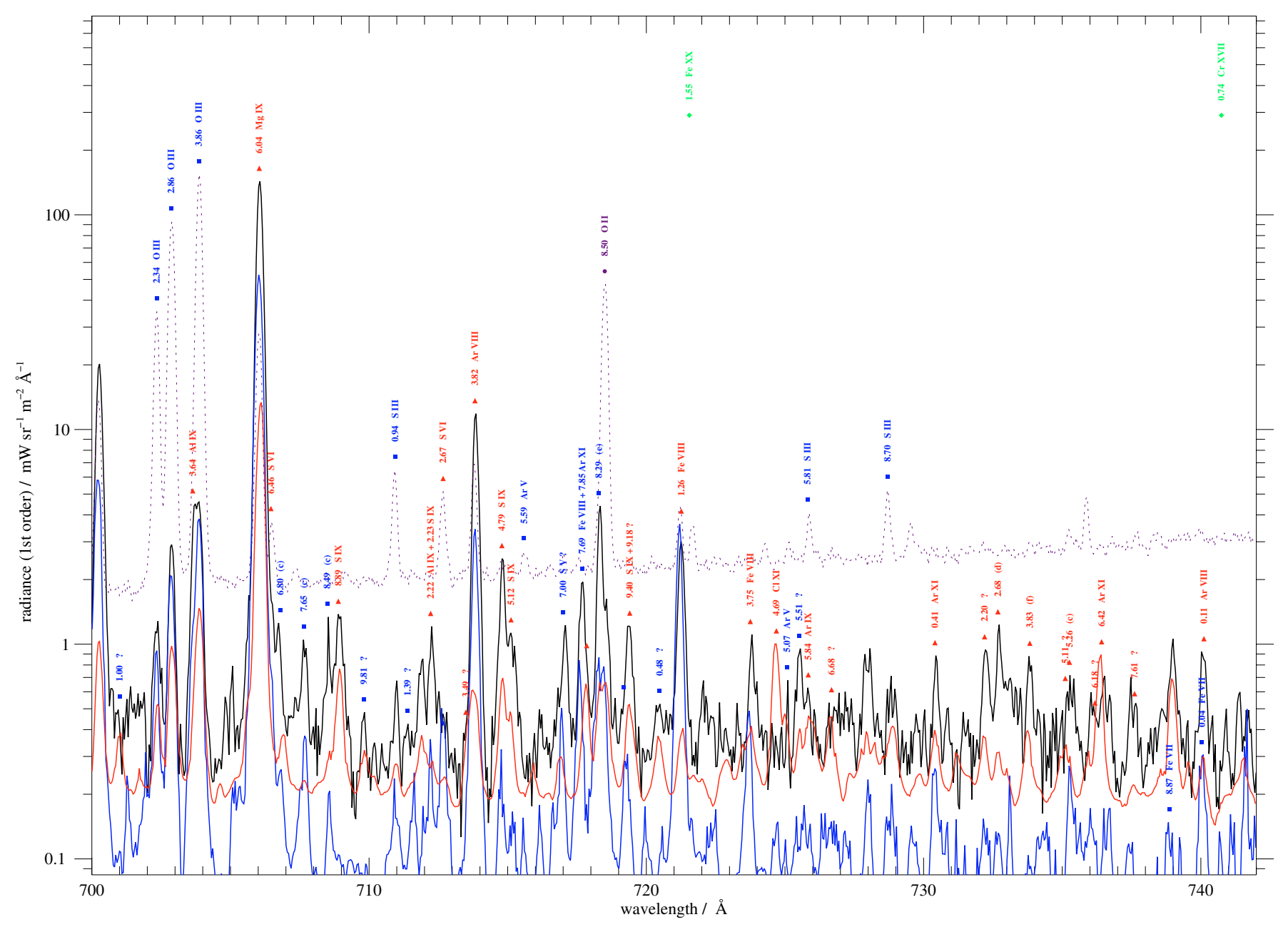

Fig. 3. continued. 
W. Curdt et al.: Coronal EUV atlas, Online Material p 15

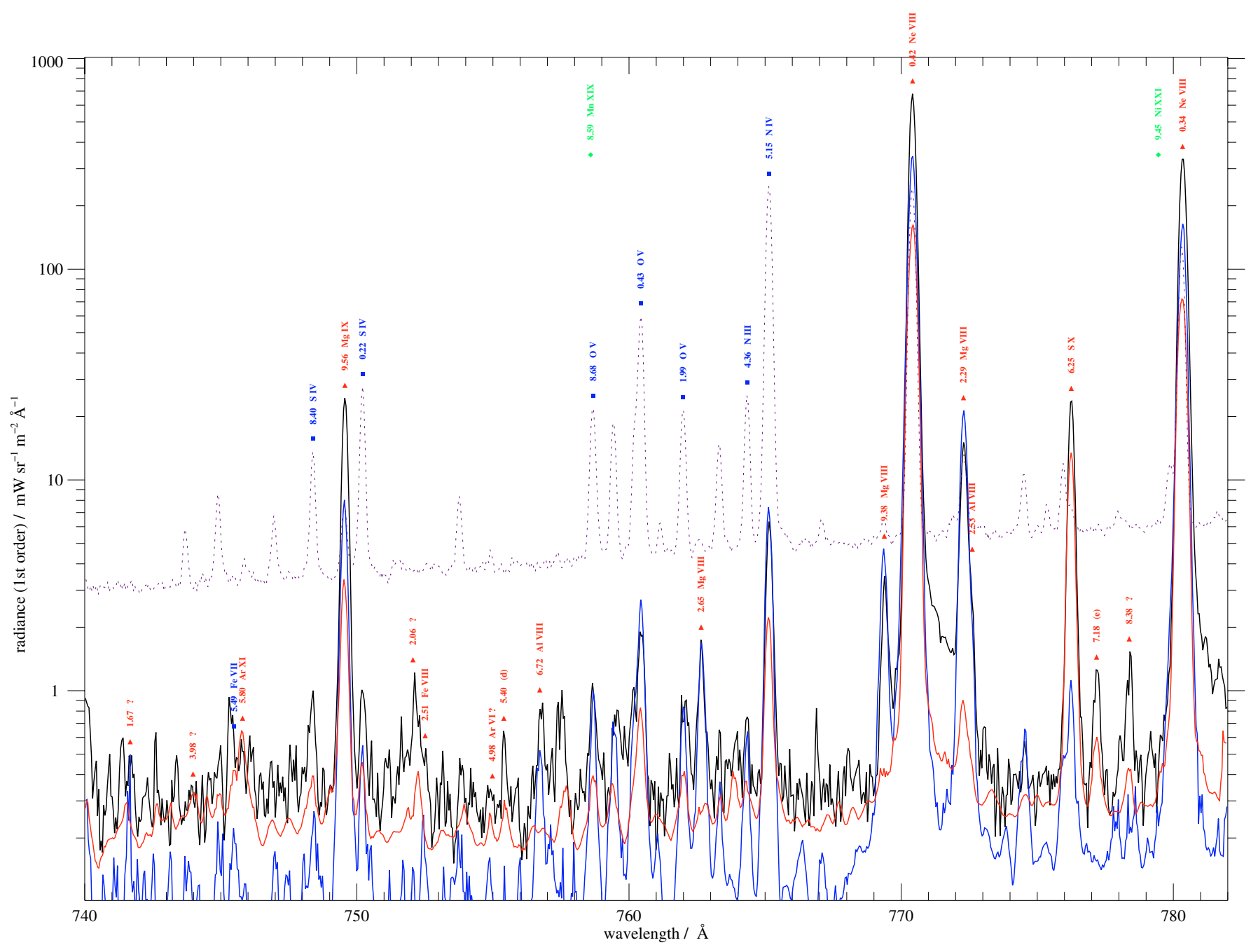

Fig. 3. continued. 
W. Curdt et al.: Coronal EUV atlas, Online Material p 16

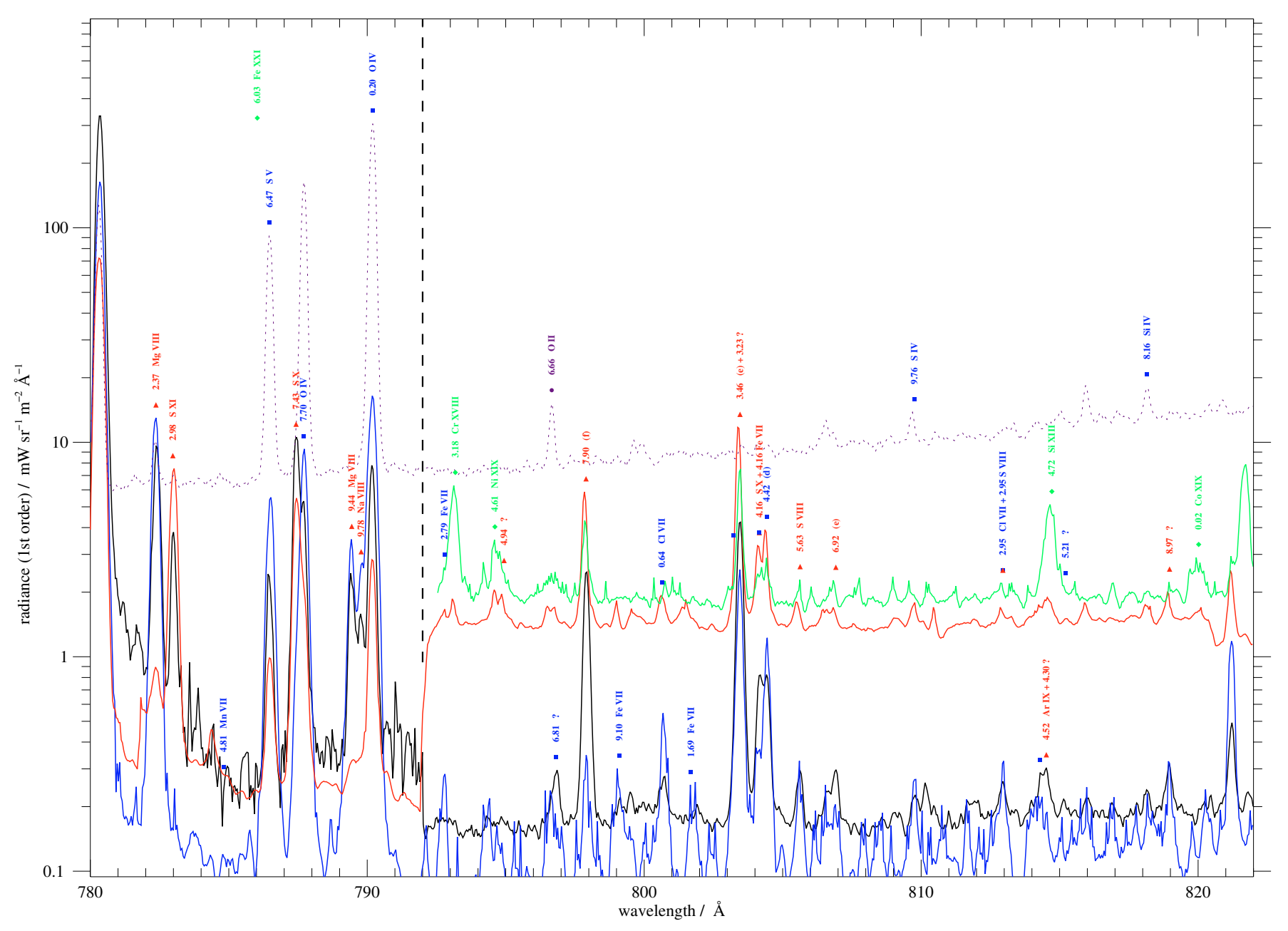

Fig. 3. continued. 
W. Curdt et al.: Coronal EUV atlas, Online Material p 17

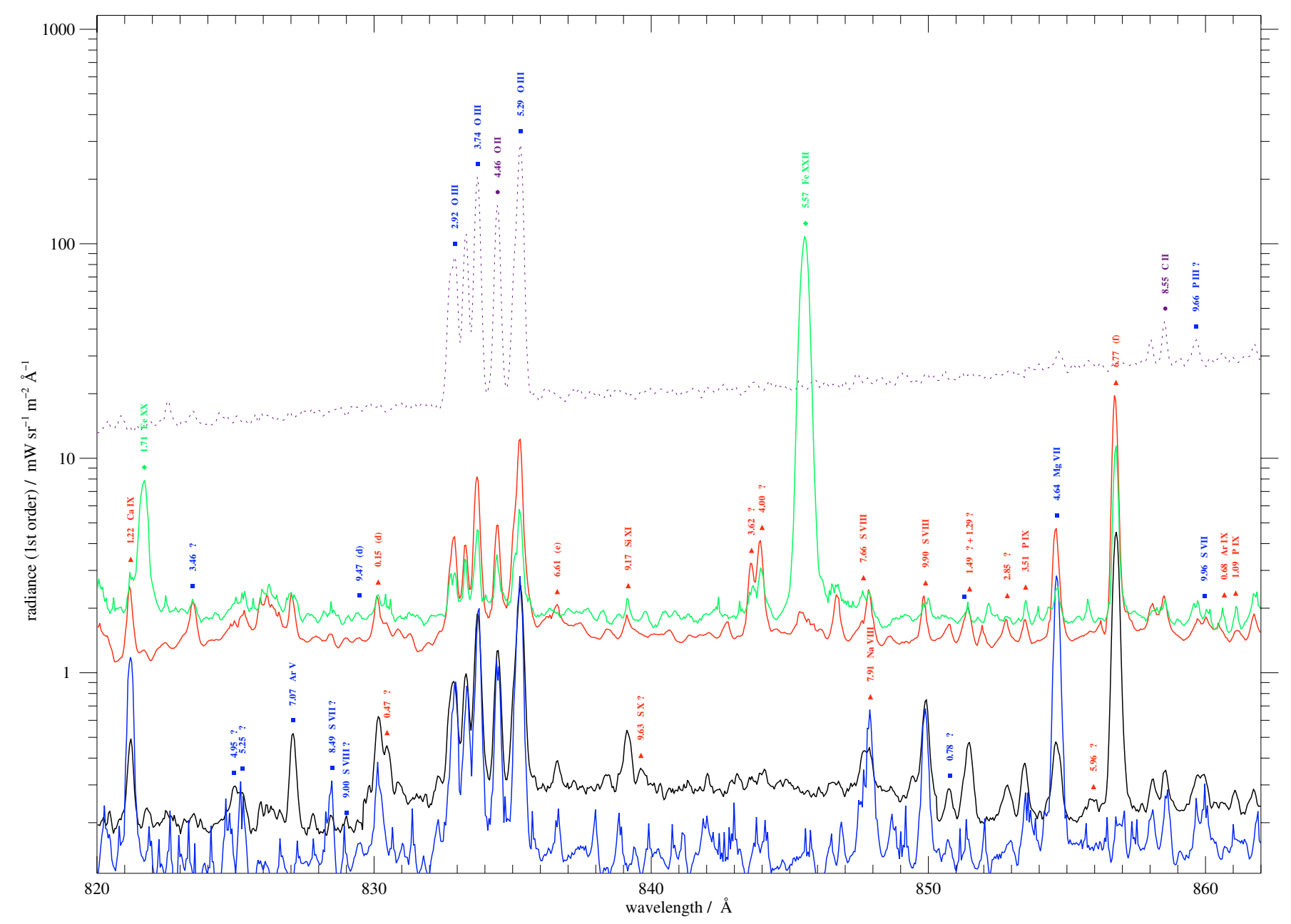

Fig. 3. continued. 
W. Curdt et al.: Coronal EUV atlas, Online Material p 18

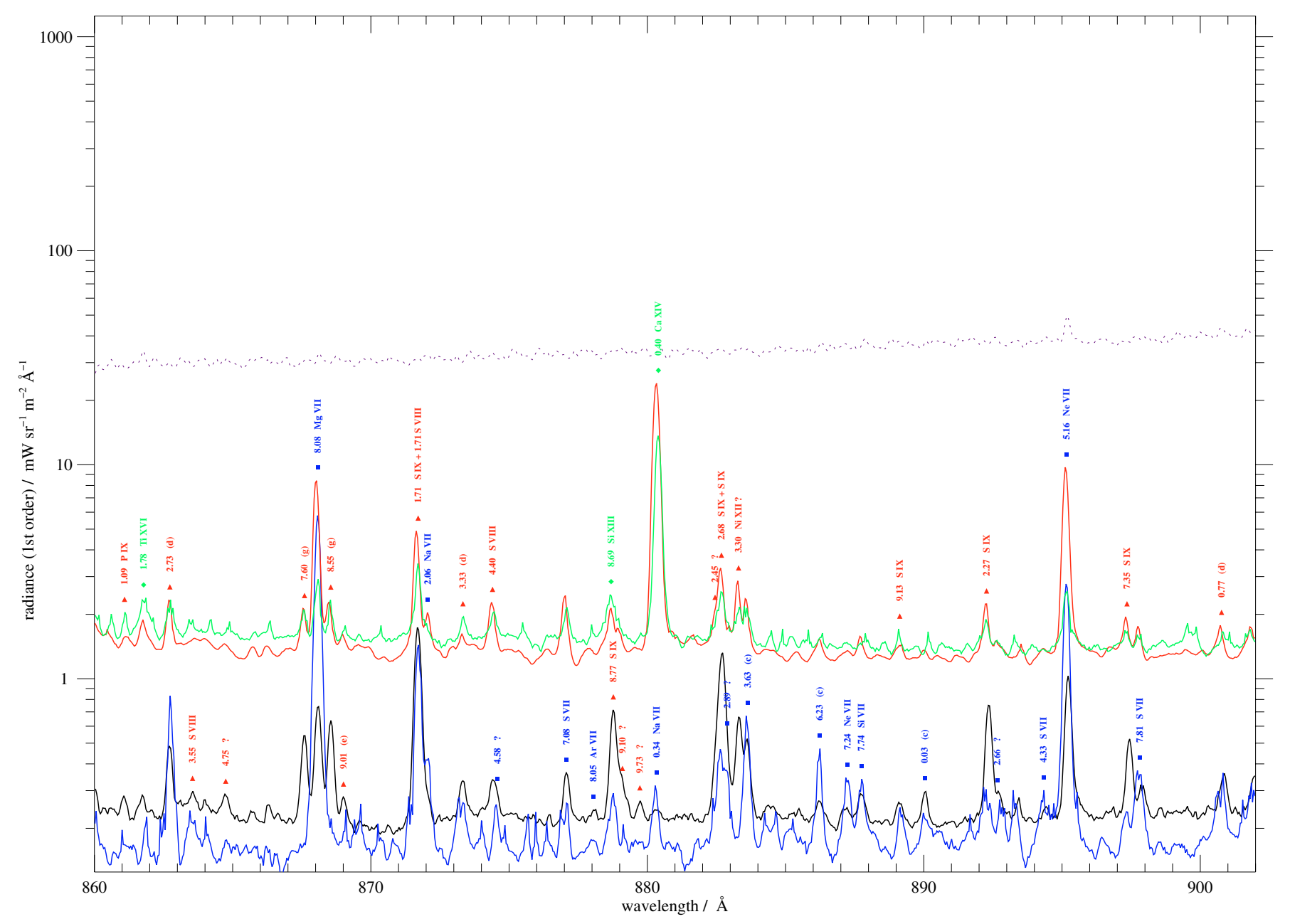

Fig. 3. continued. 
W. Curdt et al.: Coronal EUV atlas, Online Material p 19

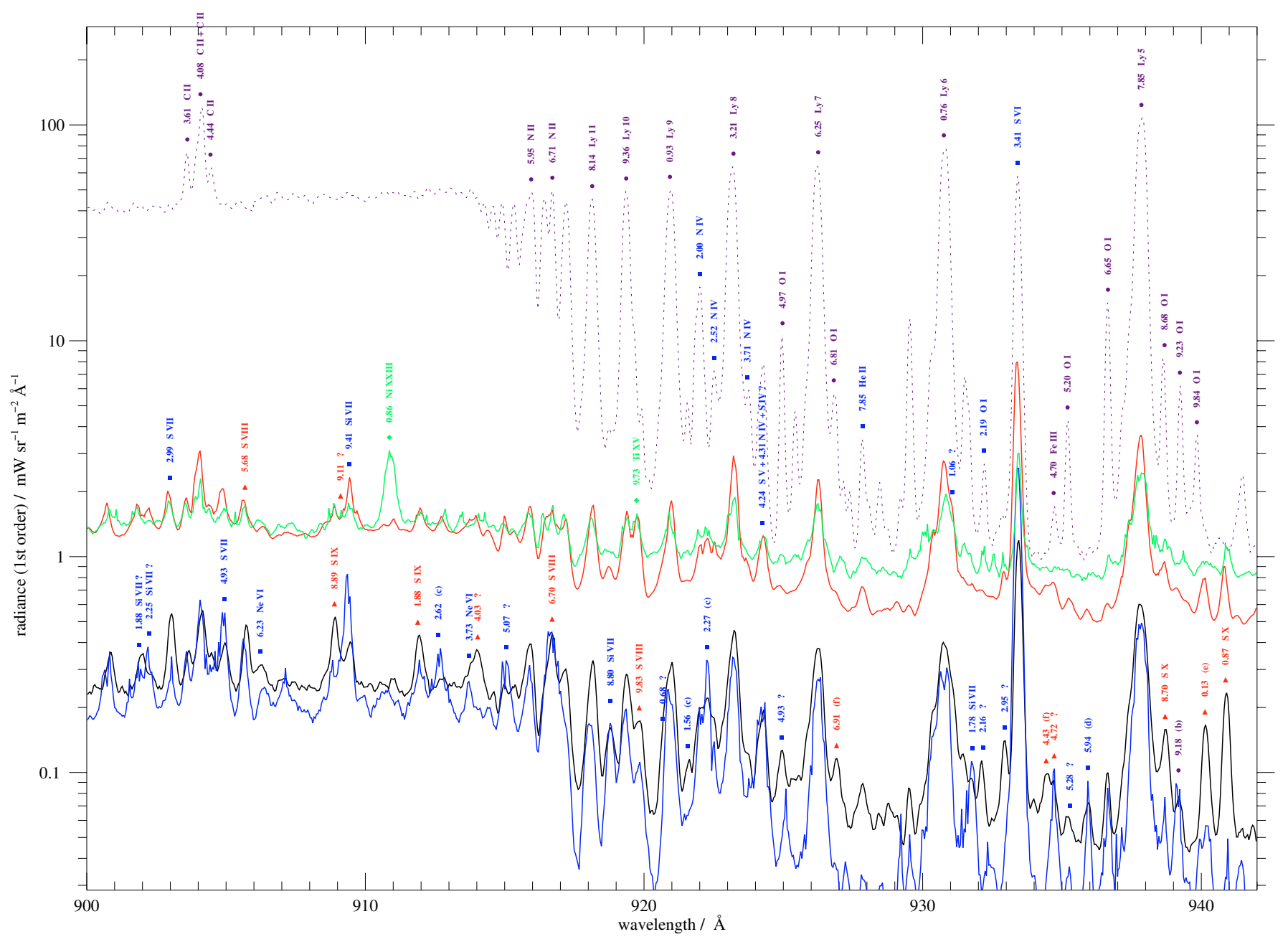

Fig. 3. continued. 
W. Curdt et al.: Coronal EUV atlas, Online Material p 20

wavelength (2nd order) / $\AA$

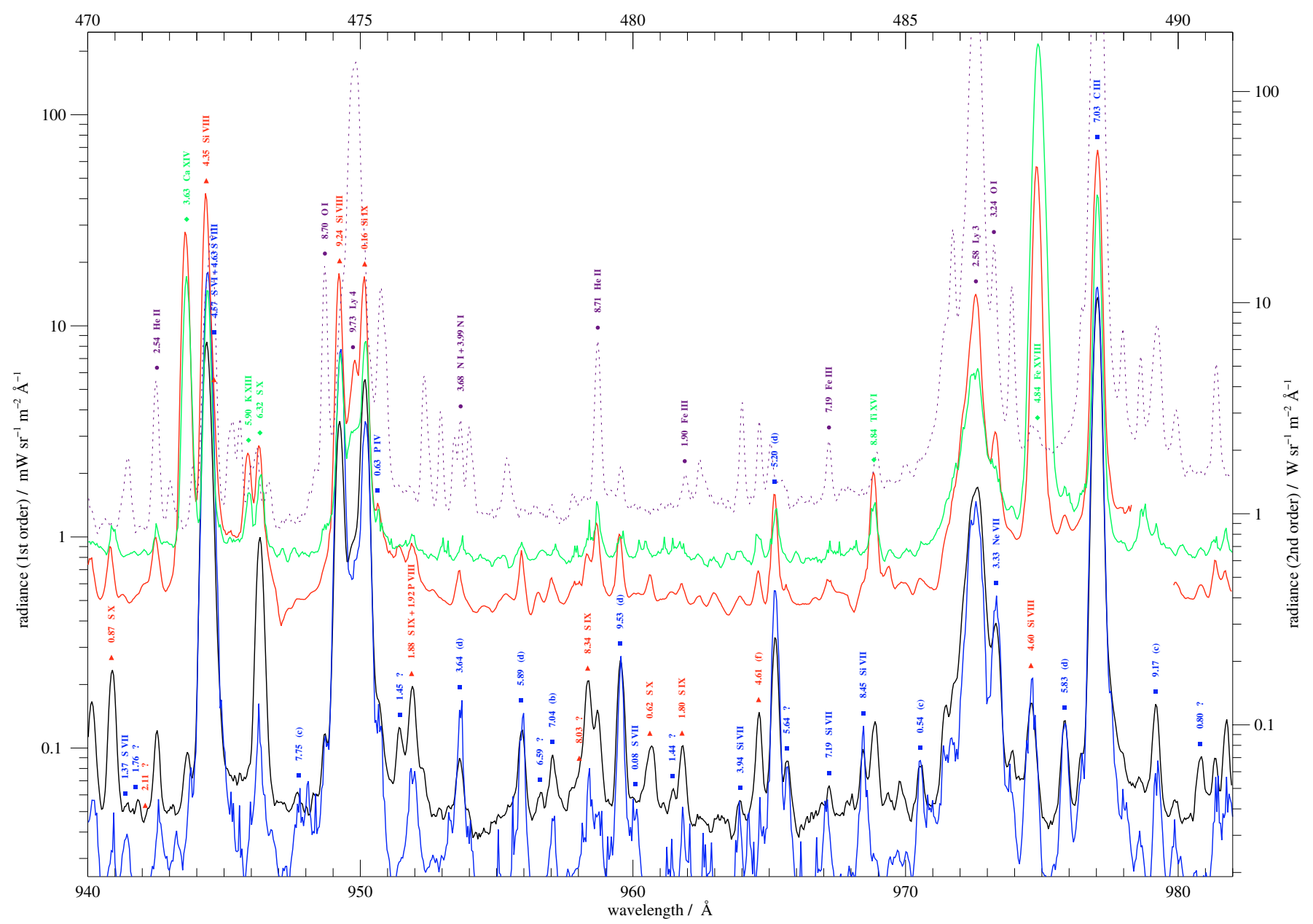

Fig. 3. continued. 
W. Curdt et al.: Coronal EUV atlas, Online Material p 21

wavelength (2nd order) / §

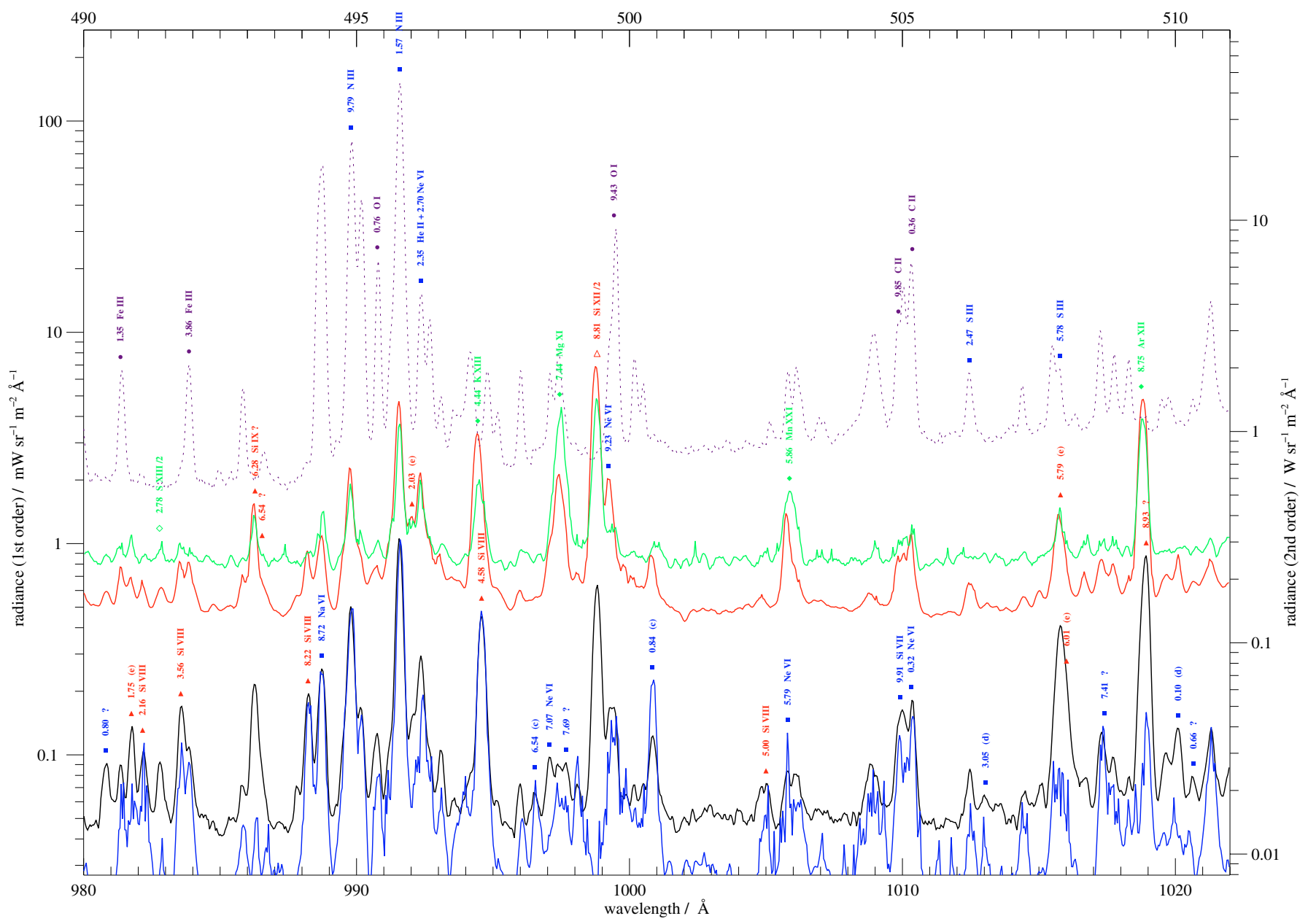

Fig. 3. continued. 
W. Curdt et al.: Coronal EUV atlas, Online Material p 22

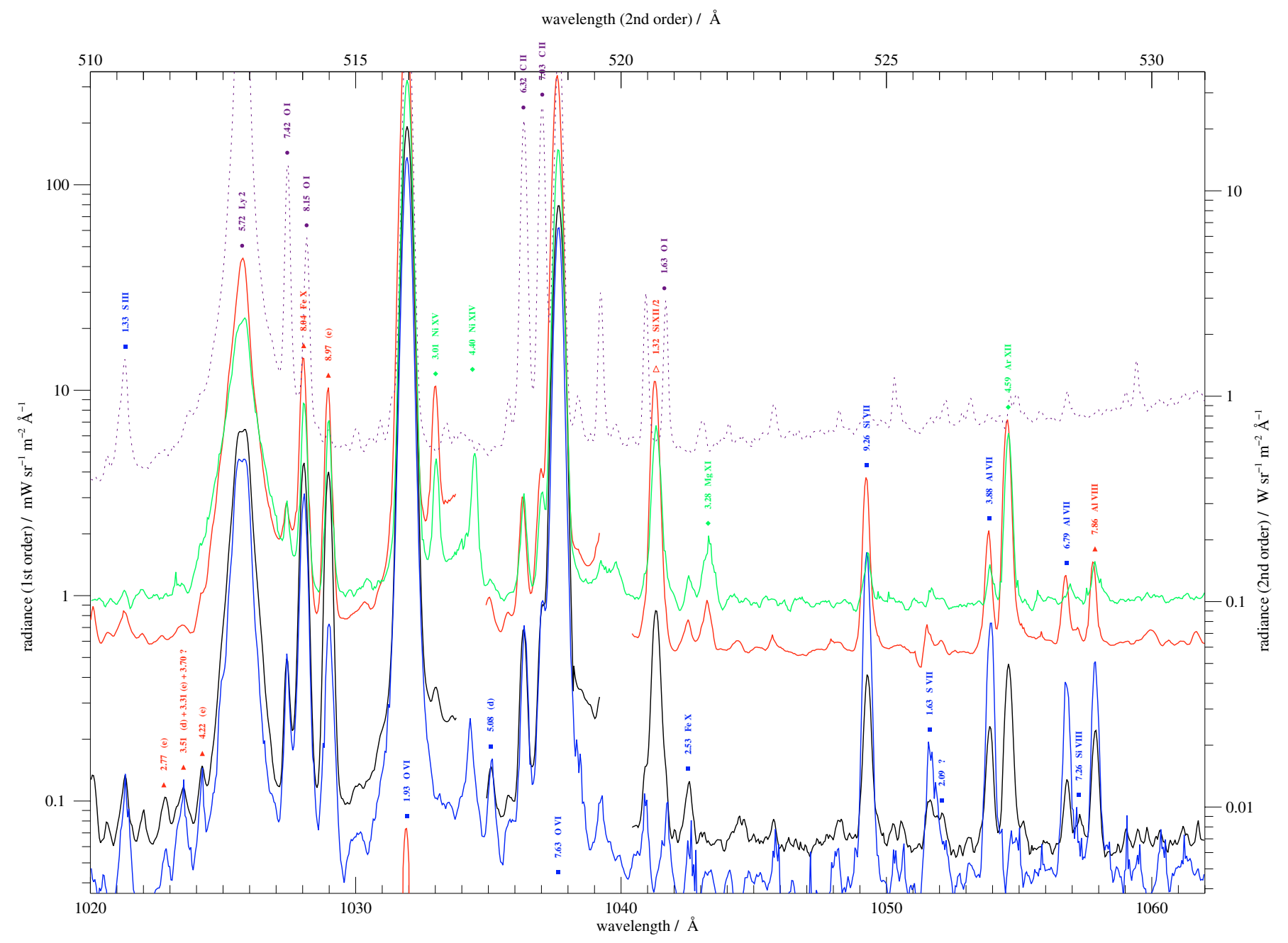

Fig. 3. continued. 
W. Curdt et al.: Coronal EUV atlas, Online Material p 23

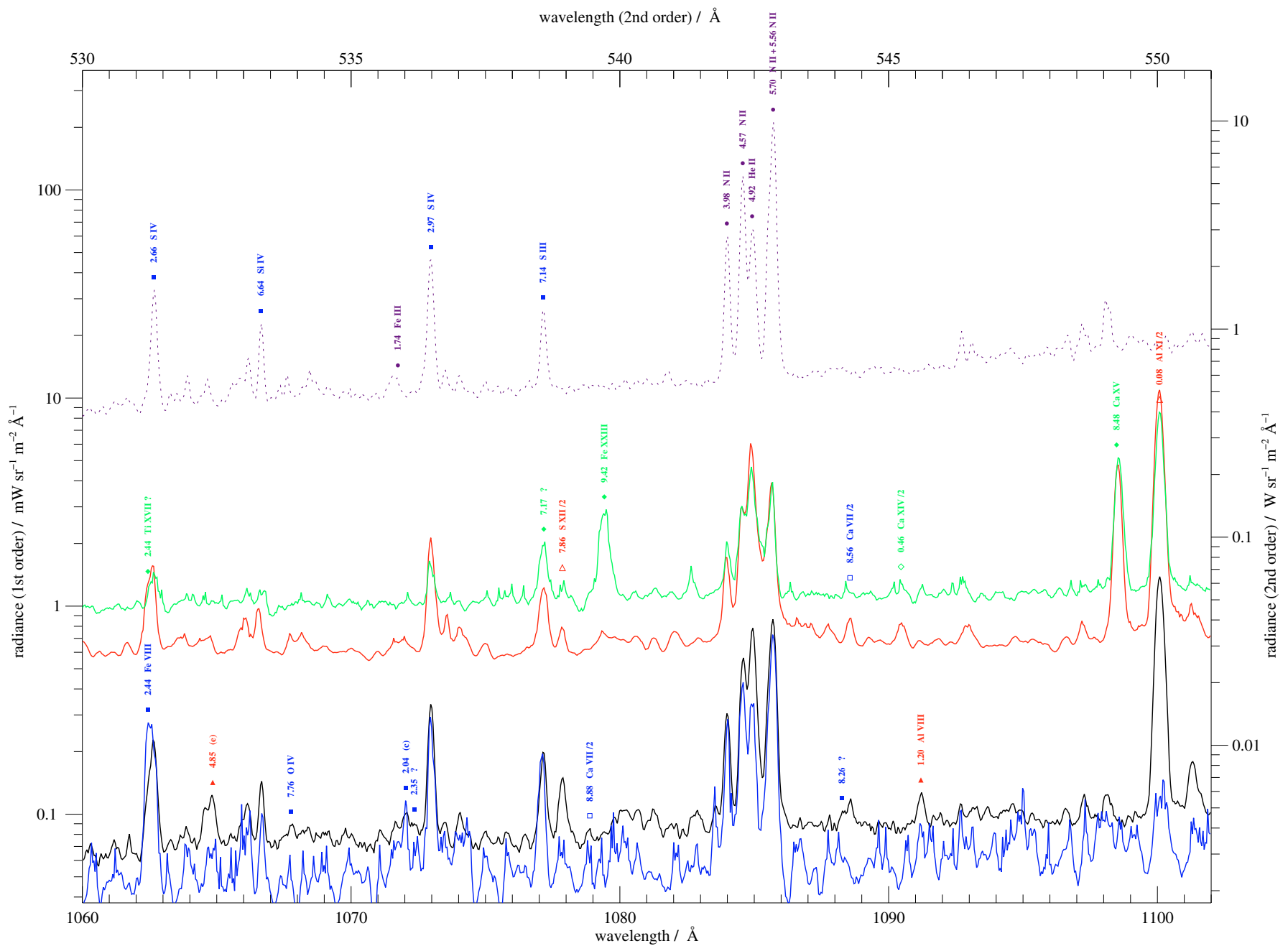

Fig. 3. continued. 
W. Curdt et al.: Coronal EUV atlas, Online Material p 24

wavelength (2nd order) / $\AA$

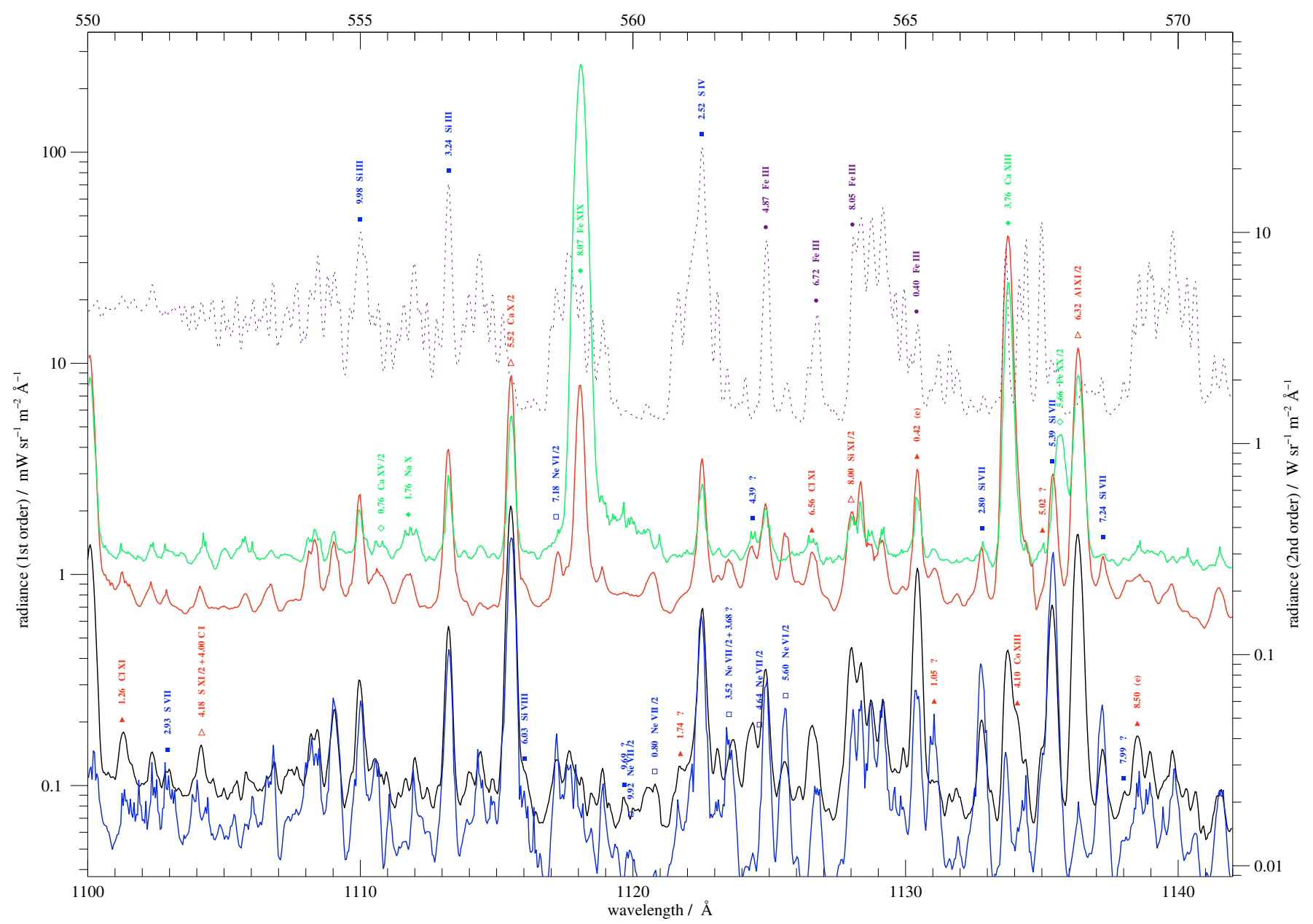

Fig. 3. continued. 
W. Curdt et al.: Coronal EUV atlas, Online Material p 25

wavelength (2nd order) / $\AA$

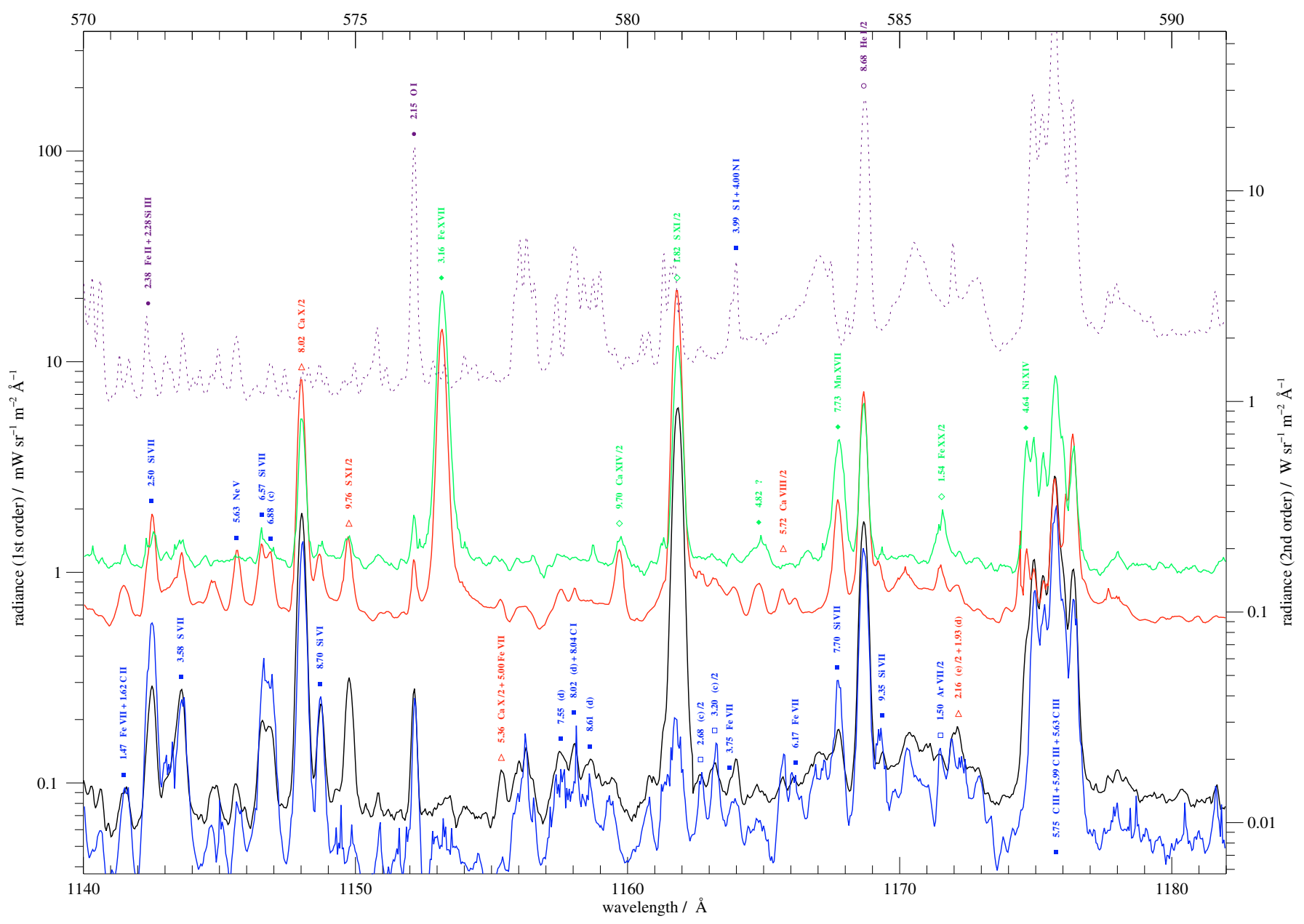

Fig. 3. continued. 
W. Curdt et al.: Coronal EUV atlas, Online Material p 26

wavelength (2nd order) / $\AA$

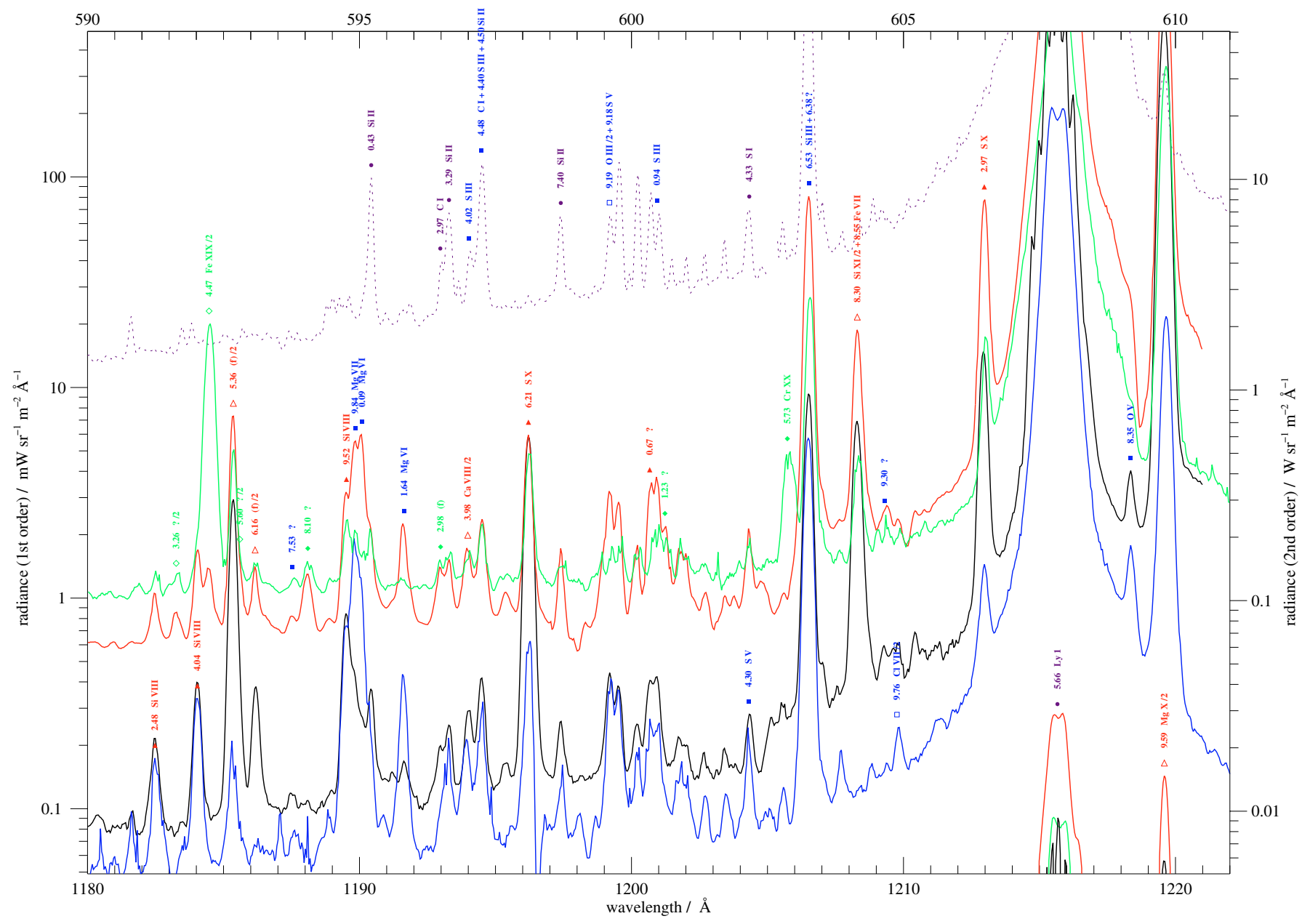

Fig. 3. continued. 
W. Curdt et al.: Coronal EUV atlas, Online Material p 27

wavelength (2nd order) / $\AA$

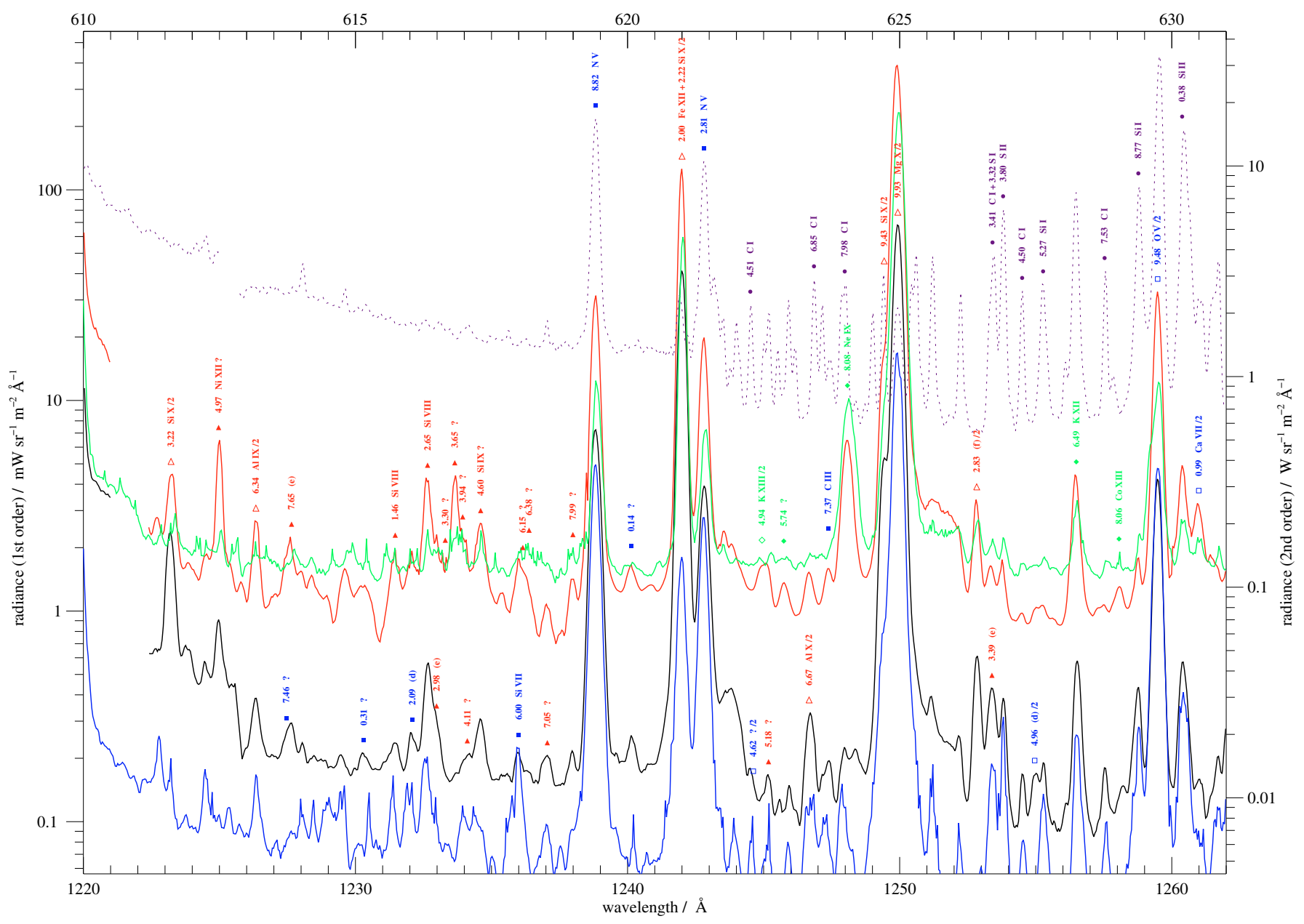

Fig. 3. continued. 
W. Curdt et al.: Coronal EUV atlas, Online Material p 28

wavelength (2nd order) / $\AA$

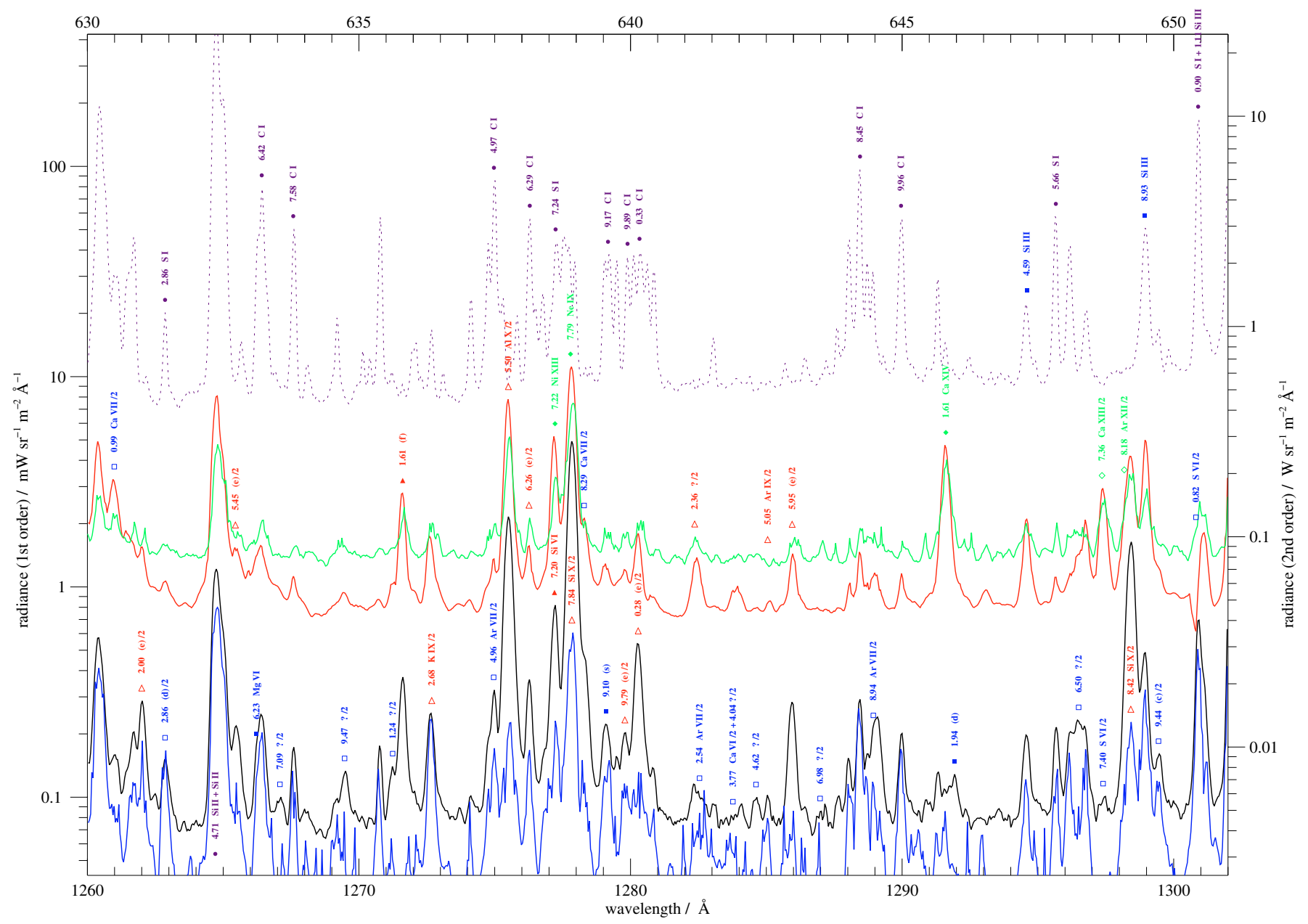

Fig. 3. continued. 
W. Curdt et al.: Coronal EUV atlas, Online Material p 29

wavelength (2nd order) / $\AA$

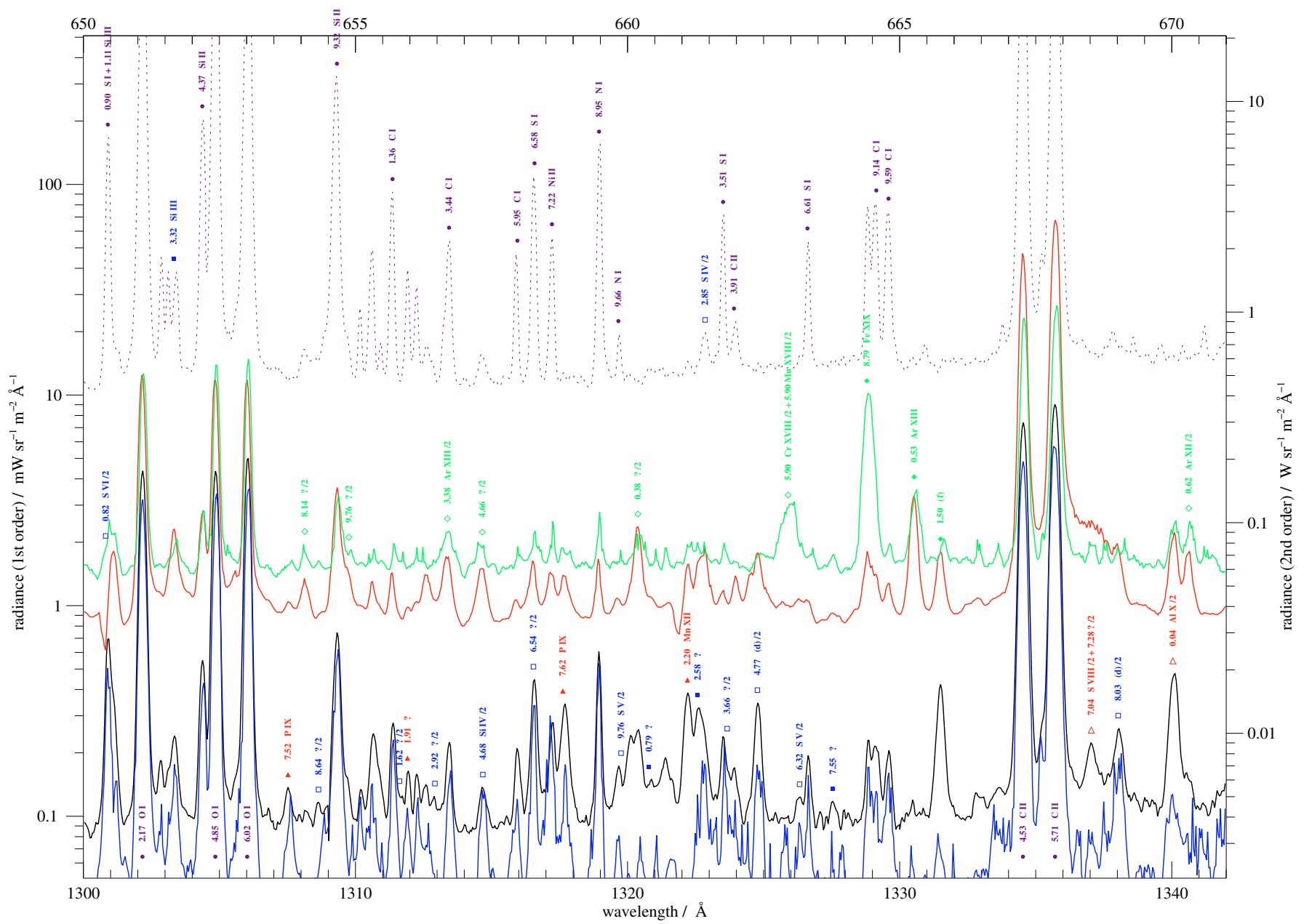

Fig. 3. continued. 
W. Curdt et al.: Coronal EUV atlas, Online Material p 30

wavelength (2nd order) / $\AA$

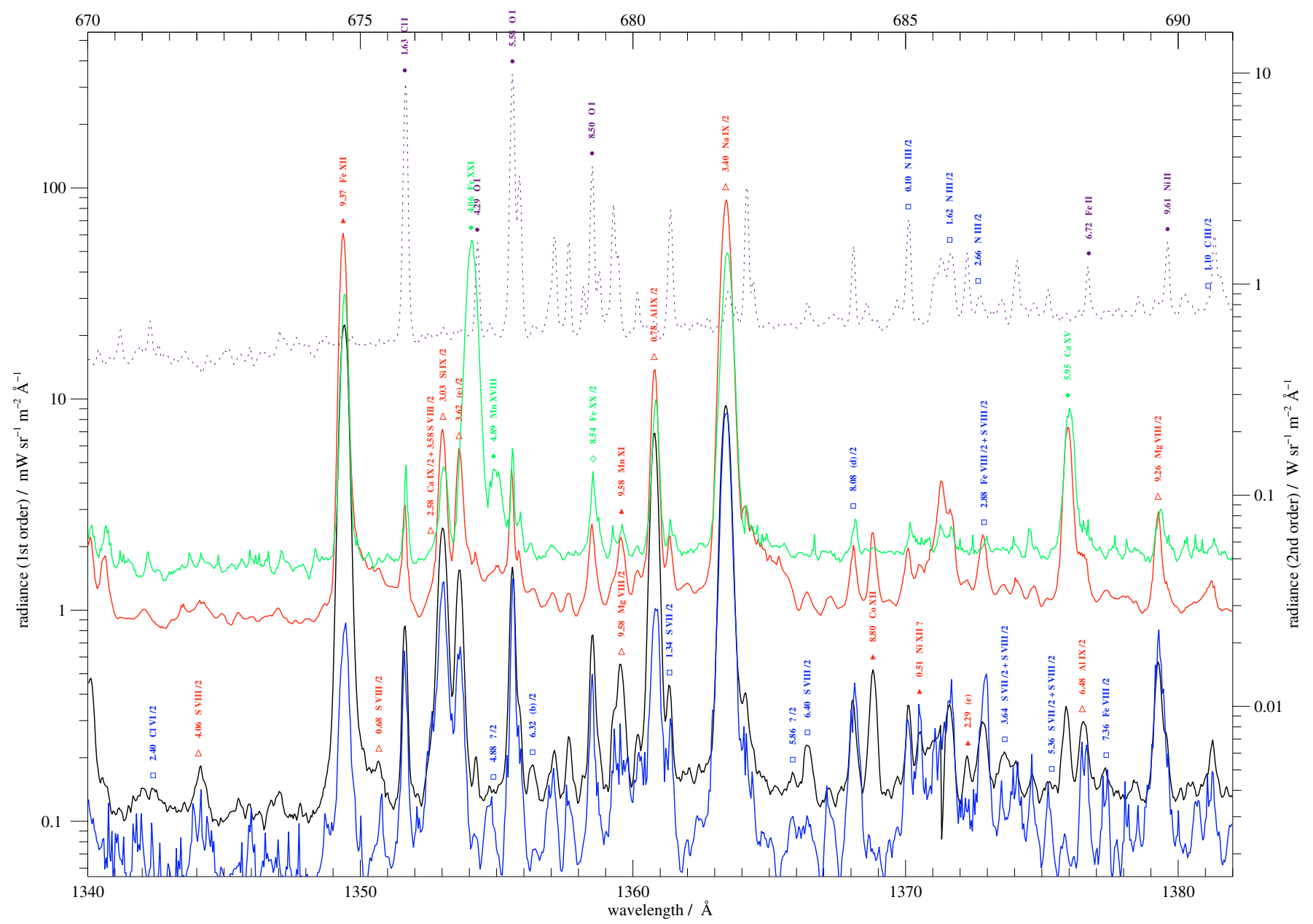

Fig. 3. continued. 
W. Curdt et al.: Coronal EUV atlas, Online Material p 31

wavelength (2nd order) / $\AA$

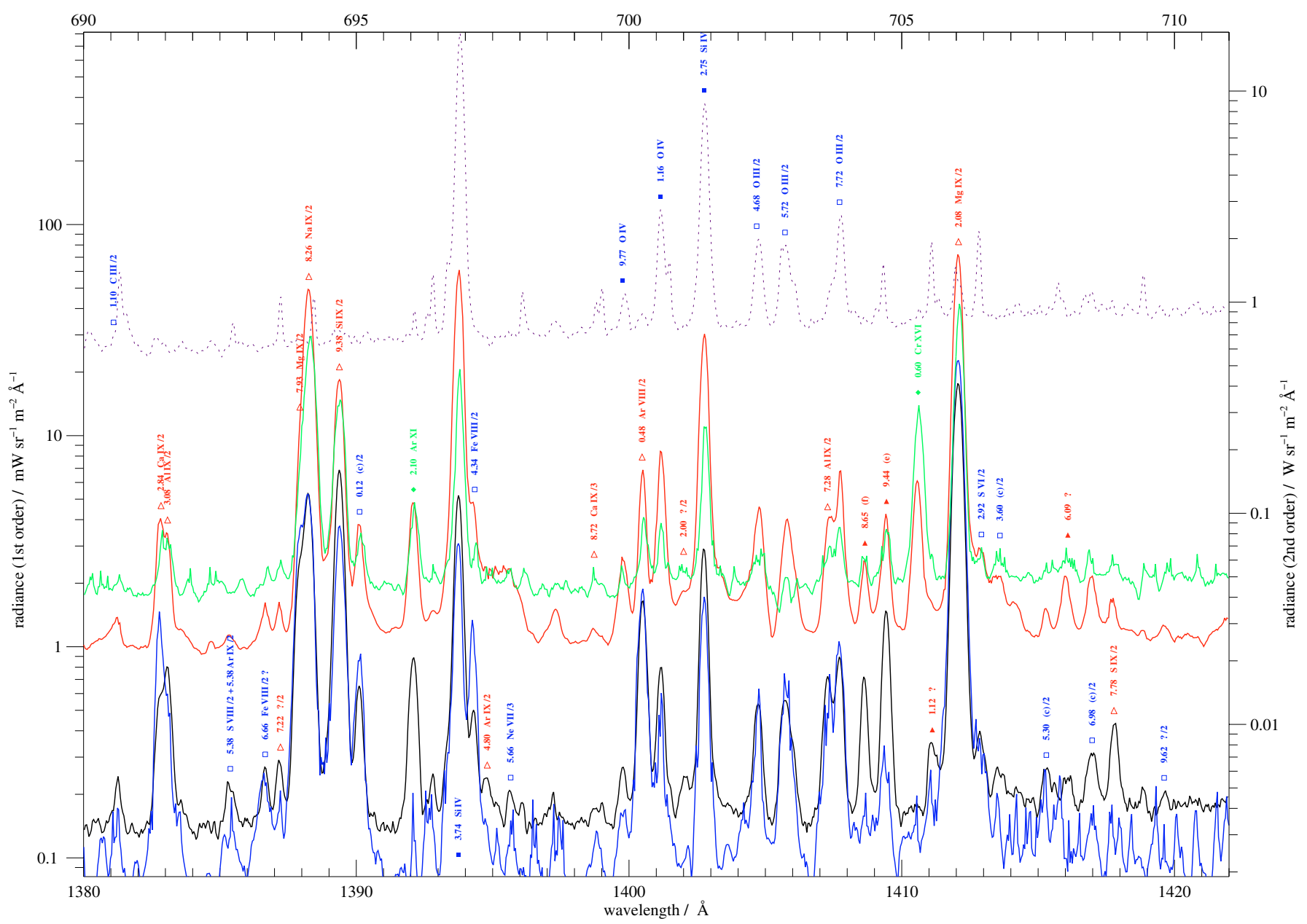

Fig. 3. continued. 
W. Curdt et al.: Coronal EUV atlas, Online Material p 32

wavelength (2nd order) / $₫$

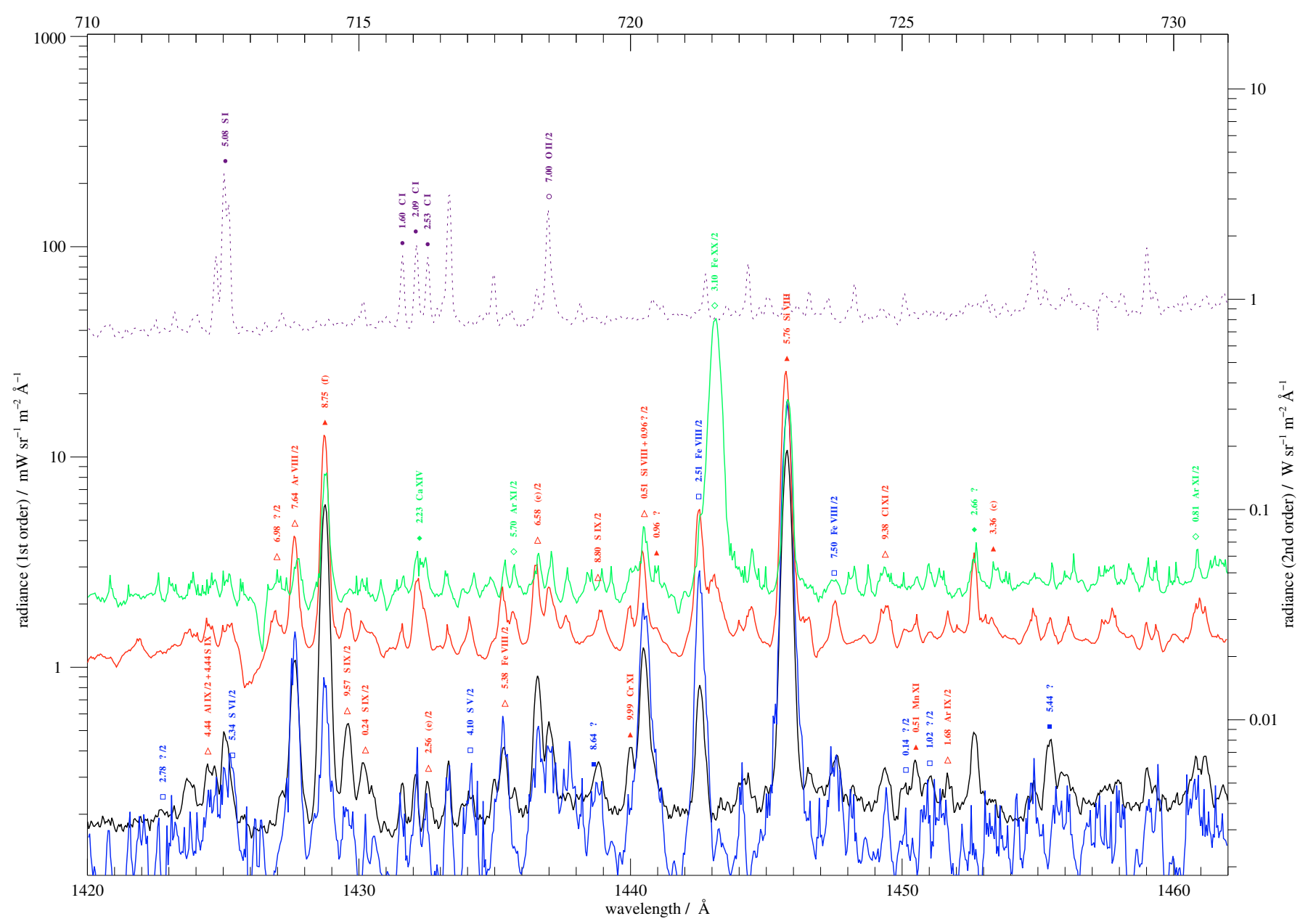

Fig. 3. continued. 
W. Curdt et al.: Coronal EUV atlas, Online Material p 33

wavelength (2nd order) / $\AA$

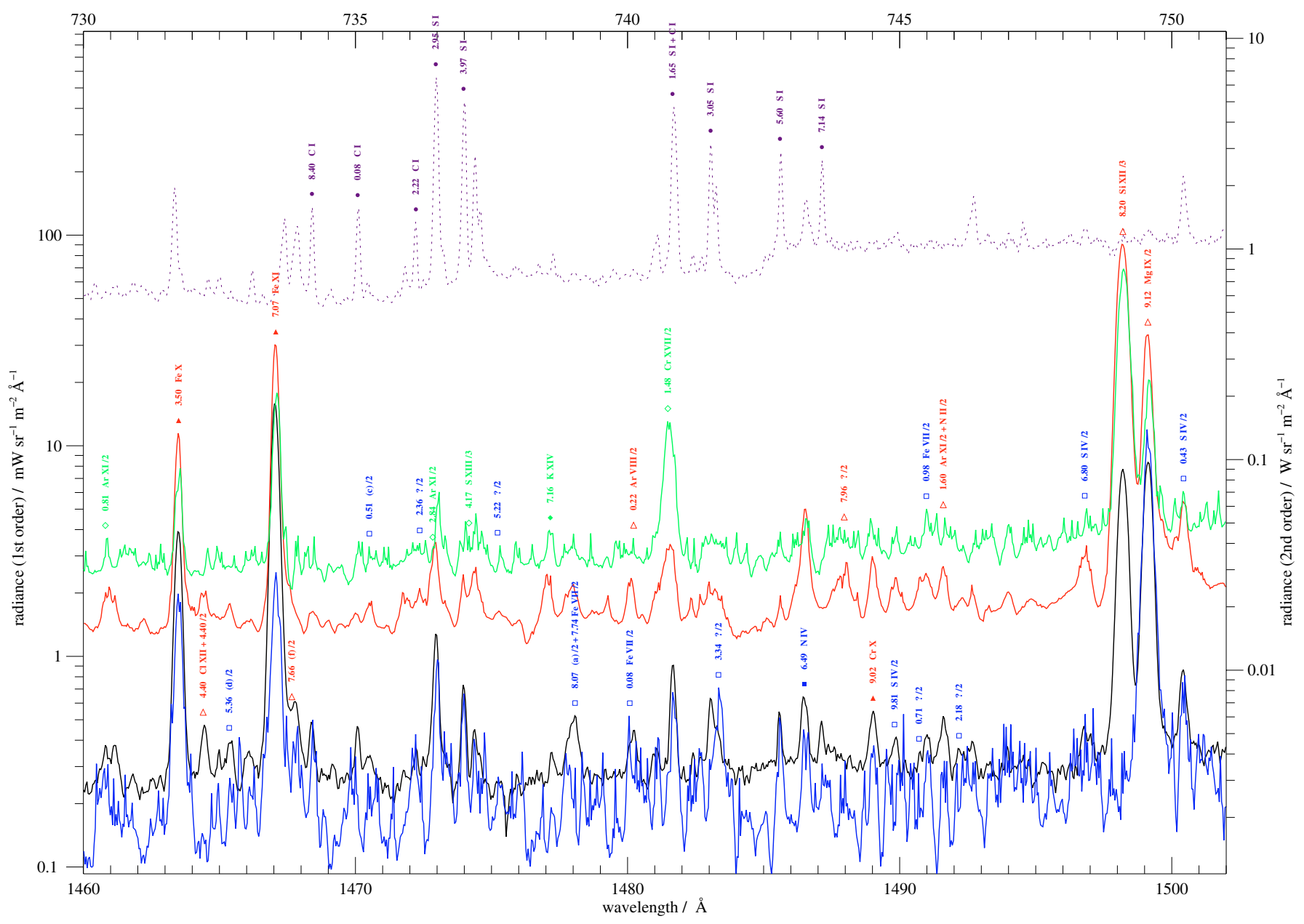

Fig. 3. continued. 
W. Curdt et al.: Coronal EUV atlas, Online Material p 34

wavelength (2nd order) / $\AA$

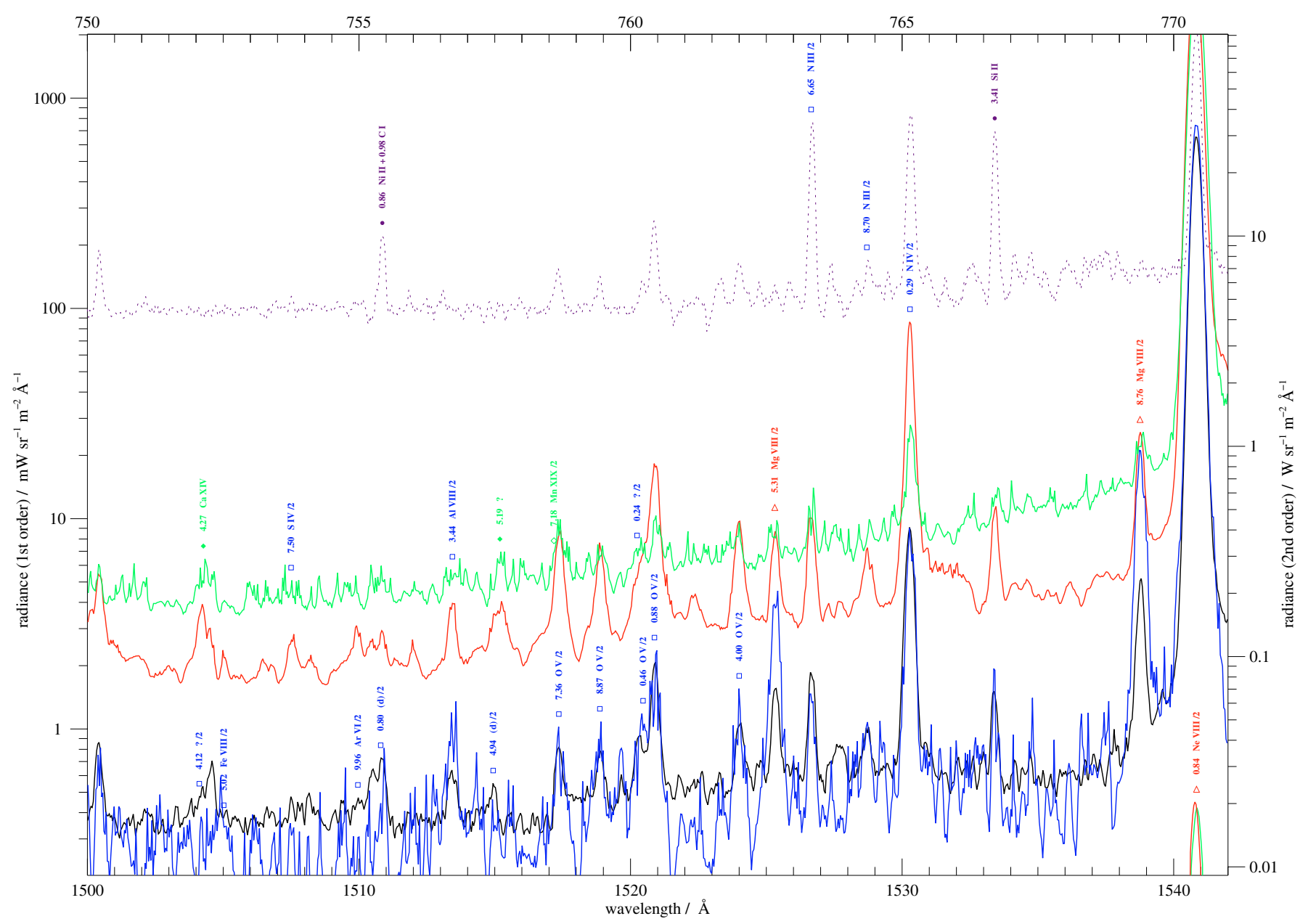

Fig. 3. continued. 
W. Curdt et al.: Coronal EUV atlas, Online Material p 35

wavelength (2nd order) / $\AA$

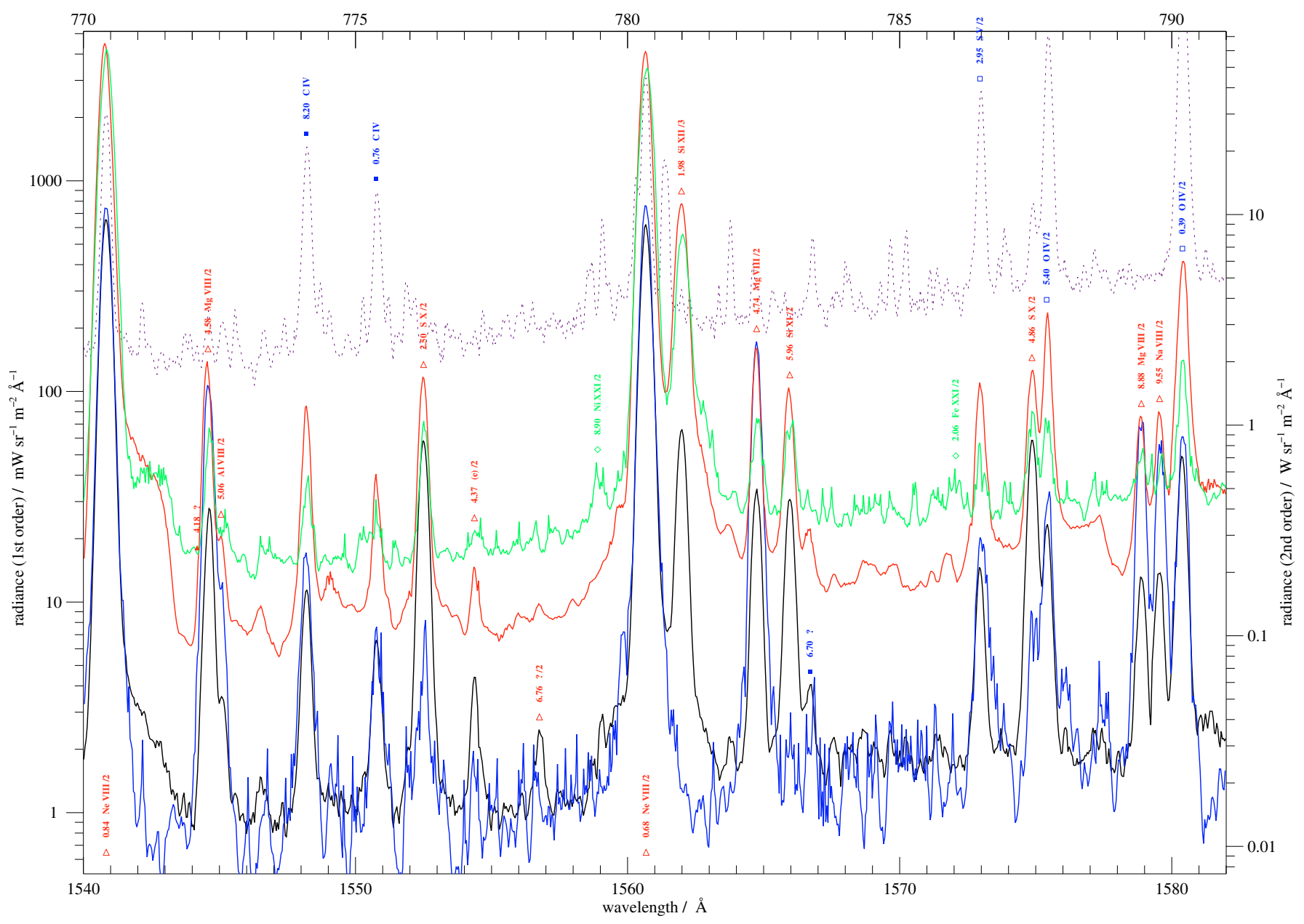

Fig. 3. continued. 
W. Curdt et al.: Coronal EUV atlas, Online Material p 36

wavelength (2nd order) / $\AA$

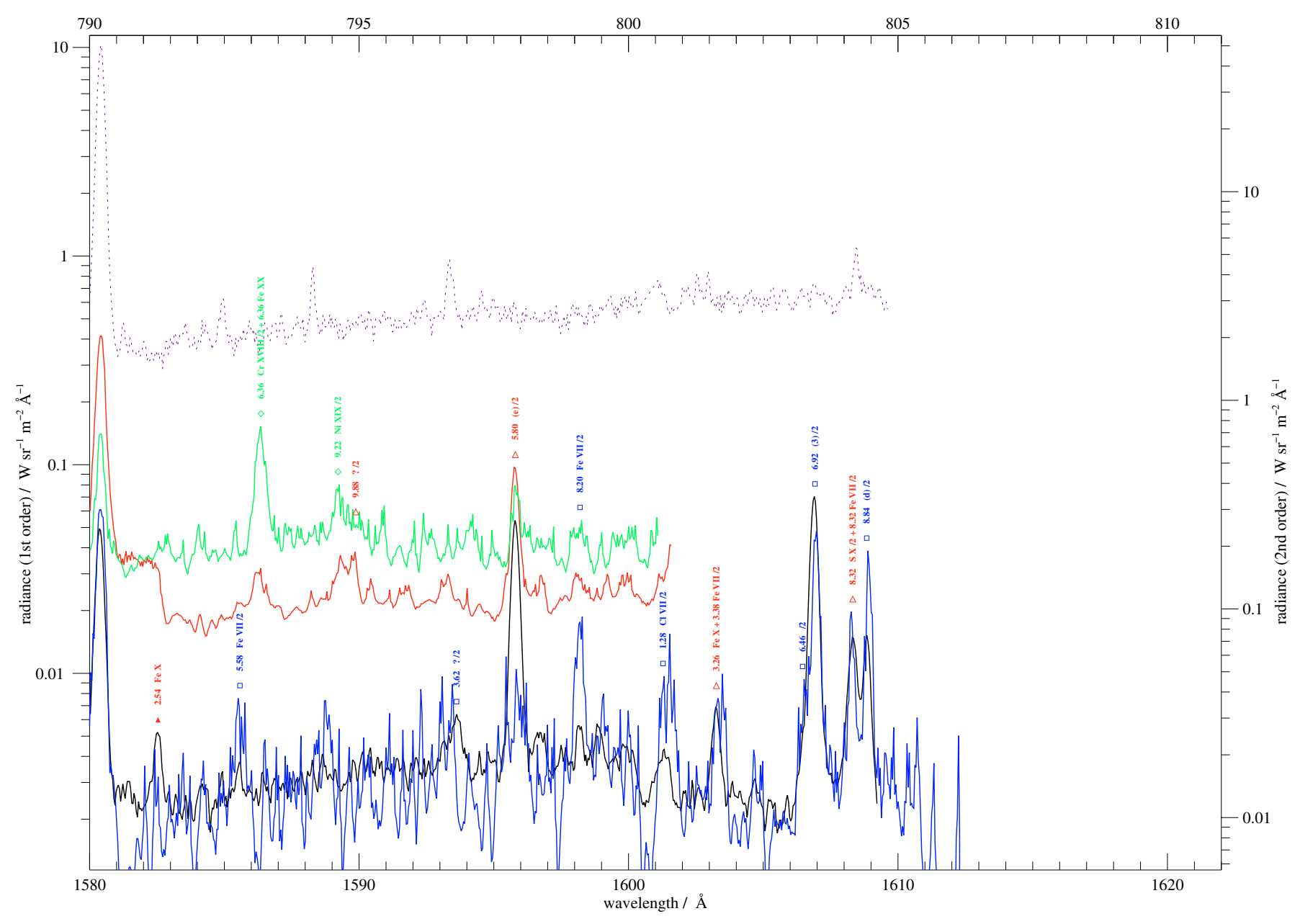

Fig. 3. continued. 